Gerión. Revista de Historia Antigua

ISSN: 0213-0181

http://dx.doi.org/10.5209/GERI.61885

\title{
Latinità non latina: lo ius Latii come strumento di integrazione delle comunità provinciali in età repubblicana
}

\author{
Simone Sisani ${ }^{1}$
}

Recibido: 14 de abril de 2018 / Aceptado: 12 de julio de 2018

Riassunto. Il contributo prende in esame alcuni aspetti particolarmente problematici della Latinitas di età tardo-repubblicana ed alto-imperiale: la diffusione in contesti provinciali della colonizzazione di diritto latino, la data di introduzione dello ius adipiscendae civitatis per magistratum, le ragioni giuridiche sottese alla creazione nei decenni finali del I sec. a.C. della nuova categoria del municipium Latinum.

Parole chiave: Carteia; conubium; ius adipiscendae civitatis per magistratum; lex Minicia; lex Pompeia; municipium Latinum; Saguntum; Valentia.

\section{[en] Non Latin Latinitas: Ius Latii as a Tool for the Integration of Provincial Communities during the Republic}

\begin{abstract}
This paper deals with some of the most problematic aspects of late Republican and early Imperial Latinitas: the diffusion in provincial contexts of the Latin colonization, the date of introduction of the ius adipiscendae civitatis per magistratum, the legal reasons underlying the creation in the last decades of the first century B.C. of the new category of the municipium Latinum.

Keywords: Carteia; conubium; ius adipiscendae civitatis per magistratum; lex Minicia; lex Pompeia; municipium Latinum; Saguntum; Valentia.
\end{abstract}

Sommario. 1. Carteia (171 a.C.) e Valentia (138 a.C.): le ultime deduzioni latine. 2. Lo ius Latii: una creazione dell'89 a.C. 3. Latinitas senza conubium: i municipia Latina e la lex Minicia. 4. Bibliografia.

Cómo citar: Sisani, S. (2018): Latinità non latina: lo ius Latii come strumento di integrazione delle comunità provinciali in età repubblicana, en Gerión 36/2, 331-378.

1 Università dell'Aquila.

E-mail: simone.sisani@univaq.it 
A meno di contrasti insuperabili o di prove chiarissime le parole delle fonti, per quanto dieno un senso meno sistematico o meno corrispondente alle idee subiettive dello scrittore, prevarranno sempre ad una teoria inventata da lui (...) la legge e l'antichità debbono interpretarsi come sono o furono e non foggiarsi quali ci sembra dovrebbero essere od essere state (L. Landucci).

A Giorgio Luraschi

Le colonie di Aquileia (183-181 a.C.) $)^{2}$ e di Luca (180 a.C.) $)^{3}$ costituiscono, come è noto, le ultime colonie di diritto latino fondate in Italia: con esse si chiude di fatto una pratica che -al di là del precedente rappresentato dalle priscae coloniae Latinae anteriori alla dissoluzione della lega latina nel 338 a.C.- aveva preso avvio nel 334 a.C. con la fondazione di Cales, seguita nel giro di circa centocinquanta anni da altre ventisette deduzioni di analoga natura giuridica. L'interruzione della pratica è in diretta relazione con il nuovo volto contestualmente assunto dalle colonie di diritto romano, che a partire dalla deduzione di Mutina, Parma e Saturnia nel 183 a.C. ${ }^{4}$ cessano di essere piccoli presidi costieri, assumendo proporzioni e funzioni analoghe a quelle originariamente caratteristiche delle colonie latine.

A distanza di neppure un secolo, la chiave coloniaria latina verrà tuttavia riesumata -e debitamente reinterpretata - in occasione del riassetto amministrativo che interessò tra il 90 e l'89 a.C. la provincia della Gallia Cisalpina, costituita da poco più di un decennio. ${ }^{5}$ In questo contesto, subordinatamente all'estensione nel 90 a.C. della civitas Romana alle colonie latine precedentemente dedotte entro i confini provinciali (Ariminum, Placentia, Cremona, Bononia, Aquileia), venne concesso il diritto latino alle restanti comunità locali. Quest'ultima misura -che possiamo ritenere formalizzata da una lex Pompeia (Strabonis) rogata verosimilmente sullo scorcio dell'89 a.C. ${ }^{6}$ - è richiamata dalla notissima testimonianza di Asconio, contenuta nel commento all'orazione ciceroniana Contra L. Pisonem (55 a.C.):

Neque illud dici potest, sic eam coloniam esse deductam quemadmodum post plures aetates Cn. Pompeius Strabo, pater Cn. Pompei Magni, Transpadanas colonias deduxerit. Pompeius enim non novis colonis eas constituit, sed veteribus incolis manentibus ius dedit Latii, ut possent habere ius quod ceterae Latinae coloniae, id est ut $\dagger$ petend $<0>$ magistratus $\dagger$ civitatem Romanam adipiscerentur. ${ }^{7}$

\footnotetext{
Liv. 39.55.5-6; 40.34.2-3.

Liv. 40.43.1; cf. Vell. 1.15.2. Sui problemi relativi a questa deduzione si veda Bandelli 2009, 198-199.

Liv. 39.55.7-9.

Sulla data di costituzione della provincia, circoscrivibile agli anni 104-103 a.C., si veda ora Sisani 2016 b.

Sulla paternità e la data della legge e sull'ambito geografico di applicazione si veda Luraschi 1979, 143-156.

Ascon. 12 S.: "Né si può sostenere che quella colonia [Placentia] sia stata dedotta nello stesso modo in cui molto tempo dopo Cn. Pompeo Strabone, padre di Cn. Pompeo Magno, dedusse le colonie transpadane. Pompeo infatti non le fondò con nuovi coloni, ma concesse ai vecchi abitanti, rimasti in loco, lo ius Latii, affinché potessero avere il diritto proprio delle altre colonie latine, vale a dire che essi attraverso la candidatura alle magistrature [scil. che tra essi coloro che avessero gerito una regolare magistratura] (?) conseguissero la cittadinanza romana" (trad. Barbati, con modifiche). Per un commento testuale e giuridico al passo si veda da ultimo Barbati 2013. Sulla problematica lezione "petendi [codd. PM, peti cod. S] magistratus" offerta dai codici e variamente emendata dagli editori si veda Luraschi 1983, 271-279 (cf. Luraschi 1986, 51, nota 43): tra le possibili alternative, l'emendamento “petendo magistratus" (proposto dal Clark) resta in termini filologici il più economico e restituisce a mio avviso piena comprensibilità allo stesso pensiero di Asconio, interessato non certo ad offrire una illustrazione tecnica della norma giuridica regolante l'ottenimento della civitas (riconosciuta ai magistrati solo al termine del mandato), quanto piuttosto a compendiare la trafila prevista in materia dallo ius Latii, attraverso un richiamo all'atto -la candidatura alle magistrature ordinarie: quelle cioè conferite annualmente dai comitia - che di fatto attivava l'intera procedura.
} 
Da questa testimonianza possono ricavarsi almeno due ordini di informazioni, relative da un lato alla qualità giuridica dei diritti riconosciuti nell' 89 a.C. alle civitates peregrinae della Cisalpina, dall'altro alla soluzione istituzionale adottata per formalizzare a livello locale tale riconoscimento. Lo ius Latii, a detta di Asconio, si identificherebbe con lo ius goduto dalle ceterae Latinae coloniae, locuzione senz'altro da intendere come una allusione alla colonizzazione latina "tradizionale", ${ }^{8}$ ormai di fatto cancellata dalla generalizzata promozione dell'intero nomen Latinum nel 90 a.C.: un diritto che certamente contemplava in primo luogo lo ius commercii e lo ius conubii $i^{9}$-nonché, con precise limitazioni, lo ius migrandi ${ }^{10}$ e lo ius suffragii ${ }^{11}$ - ma che per Asconio si identificava essenzialmente, come denuncia la specificazione da egli stesso introdotta, con lo ius adipiscendae civitatis per magistratum. Lo ius Latii venne esteso alla Cisalpina attraverso una vera e propria fictio giuridica, trasformando le comunità locali in colonie latine, che si distinguevano da quelle tradizionali solo per la mancata deduzione in loco di novi coloni: la concessione si tradusse cioè nella semplice promozione giuridica dei veteres incolae.

Entrambi gli aspetti sottolineati da Asconio sono confermati, per via indipendente, da ulteriori testimonianze letterarie. Lo ius adipiscendae civitatis per magistratum come elemento caratteristico del nuovo Latium è espressamente richiamato da Appiano in relazione a Novum Comum $;{ }^{12}$ la sua centralità -ribadita anche da Strabone (nel caso della transalpina Nemausus) ${ }^{13}$ e da Plinio il Giovane (che tuttavia non ne specifica il meccanismo) ${ }^{14}-$ ne giustifica il richiamo da parte dei giuristi dell'età imperiale, nel contesto specifico delle modifiche introdotte in materia nei decenni iniziali del II sec. d.C. ${ }^{15}$ La veste coloniale assunta dalle comunità cisalpine all'atto

8 Cf. Luraschi 1979, 218-220.

9 Kremer 2006, 9-30.

10 Kremer 2006, 30-40.

11 Kremer 2006, 43-45.

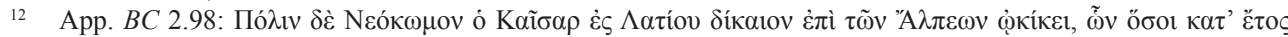

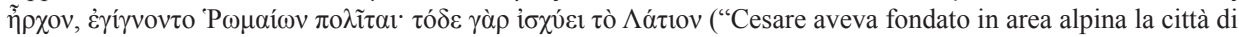
Novum Comum, di diritto latino, e tra i suoi abitanti coloro che annualmente rivestivano una magistratura diventavano cittadini romani: in questo infatti consiste lo ius Latii”').

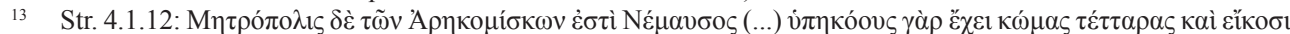

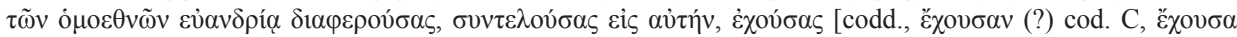

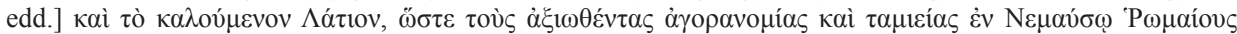

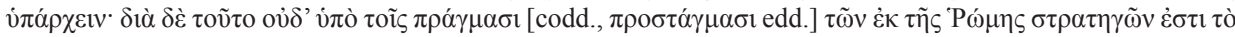

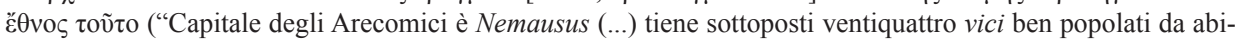
tanti della stessa etnia, a lei confederati, che godono del cosiddetto ius Latii, per cui coloro che rivestono l'edilità o la questura a Nemausus diventano cittadini romani: per tale ragione questa popolazione non è soggetta ai poteri dei governatori inviati da Roma"). Su questa testimonianza si veda Bats 2007; sul peculiare regime dello ius Latii vigente nel comparto arecomico rimando a Sisani 2018, 46-49.

14 Plin. Paneg. 37.3: Haec mansuetudo legis veteribus civibus servabatur: novi, seu per Latium in civitatem seu beneficio principis venissent, nisi simul cognationis iura impetrassent, alienissimi habebantur quibus coniunctissimi fuerant; 39.2: His quoque, quibus per Latium civitas Romana patuisset, idem indulsit omnibusque inter se cognationum iura commisit simul et pariter et more naturae, quae priores principes a singulis rogari gestiebant non tam praestandi animo quam negandi. Che l'ottenimento della cittadinanza, nella prospettiva pliniana, fosse vincolato all'esercizio delle magistrature lo si può ricavare da Plin. Paneg. 39.5: Laeti ergo adite honores, capessite civitatem (...).

15 Gai. Inst. 1.95-96: Alia causa est eorum, qui Latii iure cum liberis suis ad civitatem Romanam perveniunt; nam horum in potestate fiunt liberi. Quod ius quibusdam peregrinis civitatibus datum est vel a populo Romano vel a senatu vel a Cesare. *** aut maius est Latium aut minus. Maius est Latium, cum et hi, qui decuriones leguntur, et ei, qui honorem aliquem aut magistratum gerunt, civitatem Romanam consecuntur. Minus Latium est, cum hi tantum, qui magistratum vel honorem gerunt, ad civitatem Romanam perveniunt. Idque conpluribus epistulis principum significatur; cf. Fragm. Augustodun. 1.6-7: Peregrini aut specialiter petebant ab imperatore civitatem 
della concessione dello ius Latii è anch'essa confermata da altre testimonianze, sia in termini generali ${ }^{16}$ sia in relazione a singoli centri (Comum, Verona) ${ }^{17}$

Il quadro appena tratteggiato, ricostruibile sulla base delle esplicite indicazioni contenute nelle fonti antiche, non presenta almeno nelle linee generali particolari difficoltà interpretative. Esso, in ogni caso, non manca di sollevare alcuni cruciali interrogativi, sui quali vorrei concentrare la mia analisi: ${ }^{18}$

1) si registrano ricorsi alla colonizzazione di diritto latino tra il 180 a.C. (fondazione di Luca) e l'89 a.C. (lex Pompeia)?

2) quando viene introdotto lo ius adipiscendae civitatis per magistratum, elemento caratteristico del nuovo Latium?

3) per quali ragioni allo schema istituzionale delle colonie latine fittizie si sostituisce, a partire dall'età triumvirale-augustea, quello dei municipia Latina?

\section{Carteia (171 a.C.) e Valentia (138 a.C.): le ultime deduzioni latine}

Se Luca può essere a buon diritto considerata l'ultima colonia latina dedotta in Italia, la fondazione di Carteia nel 171 a.C. sembrerebbe prospettare una pressoché immediata replica della pratica, ora per la prima volta sperimentata in ambito provinciale. Le vicende legate a questa nuova e per più versi peculiare fondazione coloniaria sono dettagliatamente illustrate da Livio:

Et alia novi generis hominum ex Hispania legatio venit. Ex militibus Romanis et ex Hispanis mulieribus, cum quibus conubium non esset, natos se memorantes,

Romanam, aut generali beneficio perveniebant ad civitatem Romanam. Generale beneficium, quod postulabant peregrini, ius Latii dicebatur. Cum ex Latio origo civium Romanorum duceretur, ideo ius Latii dictum est ius civitatis Romanae. Interdum populus Romanus vel imperator deferebat civitati ius Latii. Hoc autem dicebatur ius Latii minoris, ius Latii maioris. Interdum dicebat populus: deferimus illi civitati ius Latii maioris. Si dicebat ius Latii maioris, statim qui in magistratu erant positi vel in honore aliquo, perveniebant ad civitatem Romanam, item decuriones. Si autem dicebat ius Latii minoris, hi soli perveniebant ad civitatem Romanam, qui erant in magistratu vel in aliquo honore positi. Sull'introduzione del Latium maius si veda Luraschi 1979, 320-323.

16 Suet. Iul. 8 (per il 68 a.C.): Decedens ergo ante tempus colonias Latinas de petenda civitate agitantes adiit, et ad audendum aliquid concitasset, nisi consules conscriptas in Ciliciam legiones paulisper ob id ipsum retinuissent; Caes. Civ. 3.87 .4 (per il 48 a.C.): Hae copiae quas videtis, ex dilectibus horum annorum in citeriore Gallia sunt refectae, et plerique sunt ex coloniis Transpadanis. Va forse riferita a questo stesso contesto istituzionale anche la più generica allusione, per il 50 a.C., ai municipia e alle coloniae della Cisalpina in Hirt. BG 8.50-51 (cf. Luraschi 1979, 198-199, nota 273).

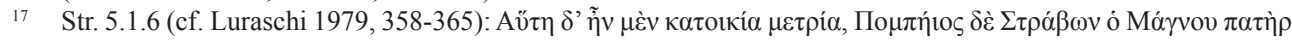

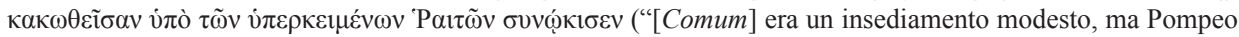
Strabone, padre del Magno, la costituì a centro urbano dopo che era stata devastata dai Reti sovrastanti"); Auct. Paneg. Constantin. Aug. 8: Sed enim aerumnosa illa et iam pridem perdita, aetate nostra civili sanguine maculata, Verona maximo hostium exercitu tenebatur, acerrimis ducibus pertinacissimoque praefecto, scilicet ut, quam coloniam Cn. Pompeius aliquando deduxerat, Pompeianus everteret. Resta incerta l'identificazione della colonia richiamata in forma anonima da Catullo nel carme 17, composto forse nel 59 a.C.: si pensa normalmente a Verona, città natale del poeta, ma non è escluso che si tratti piuttosto di Novum Comum (cf. in questo senso Luraschi 2007).

18 Sui temi che tratterò si è ormai venuta accumulando una bibliografia assai vasta: ne darò conto in forma estremamente selettiva, evitando programmaticamente di indulgere nel futile gioco dello smantellare ipotesi altrui al fine di rafforzare le proprie. È piuttosto mia intenzione concentrarmi direttamente sulle fonti documentarie, di cui vorrei proporre una rinnovata lettura, svincolata per quanto possibile dagli a priori che la moderna dottrina -a ragione o a torto- ha posto in essere. 
supra quattuor milia hominum, orabant ut sibi oppidum in quo habitarent daretur. Senatus decrevit, uti nomina sua apud L. Canuleium profiterentur eorumque, si quos †manumi $<$ si $>$ ssent: eos Carteiam ad Oceanum deduci placere; qui Carteiensium domi manere vellent, potestatem fieri, uti numero colonorum essent, agro adsignato; Latinam eam coloniam esse libertinorumque appellari. ${ }^{19}$

A prescindere dalle incertezze che gravano sulla corretta restituzione testuale del passo -limitatamente all'inciso "si quos manumisissent", ${ }^{20}$ cui si ricollega la questione relativa all'enigmatica definizione di colonia libertinorum assegnata alla deduzione $^{21}$ - è a mio avviso evidente dalle parole di Livio che Carteia venne dedotta secondo la prassi fino ad allora canonica per le colonie latine: un consistente contingente coloniario (oltre quattromila hybridae nati da cives romani e da peregrinae) venne insediato per iniziativa del senato in un oppidum già esistente (Carteia) e contestualmente inquadrato nel diritto latino, in associazione ai veteres incolae che avessero scelto di restare in loco, ciascuno dei quali avrebbe ricevuto -al pari, come è chiaro, dei nuovi coloni- un lotto di terra nell'ager attribuito alla colonia.

Per quanto concerne il vero e proprio nucleo coloniario, non vi è alcun motivo per ritenere che gli hybridae in questione fossero unicamente i figli nati da donne di Carteia: il loro numero, assai elevato, e la natura della richiesta da essi avanzata -"orabant ut sibi oppidum in quo habitarent daretur"-induce piuttosto a credere che essi provenissero da diversi luoghi della penisola iberica (non necessariamente dalla sola Ulteriore) e fossero il frutto delle verosimilmente numerose unioni illegittime contratte da legionari romani e da donne locali nel corso di quasi un cinquantennio di diffusa presenza militare sul territorio. ${ }^{22}$

La questione sollevava un problema di natura non tanto giuridica, quanto amministrativa. Nonostante le parole di Livio, che parla di novum genus hominum, è infatti certo che i figli di tali unioni dovessero, ai sensi dello ius gentium, essere considerati a tutti gli effetti peregrini, tant'è che non è su questo aspetto che si appuntò la richiesta da essi avanzata al senato. Il problema risiedeva piuttosto nell'apparente impossibilità, per questi soggetti, di essere accolti a pieno titolo nelle comunità di origine delle loro madri: ${ }^{23}$ una circostanza che faceva di essi dei veri e propri apolidi, il cui alto numero -nonché il loro essere pur sempre figli di cives Romani-rendeva opportuna una pronuncia da parte del senato..$^{24}$ La soluzione adottata in questo contesto appare pienamente logica, ed anzi in certa misura obbligata: la deduzione di questo gruppo di persone in una colonia latina appositamente creata allo scopo rappresentava un implicito riconoscimento della peculiare origine di tali soggetti, ora di fatto promossi ad una condizione giuridica senza dubbio privilegiata rispetto a quella di semplici peregrini, ed offriva nel contempo allo stato romano l'occasione per

19 Liv. 43.3.1-4.

20 L'unico testimone dei libri 41-45 di Livio reca la lezione "si quos manumissent", emendata nell'editio princeps frobeniana (1531) in "si quos manumisisset". Sulle varie soluzioni proposte dagli studiosi si veda Hernández Fernández 1994, 84-86: a prescindere dalle implicazioni giuridiche, l'emendamento "manumisissent" resta a mio avviso il più aderente alla lezione del codice e alla struttura sintattica dell'enunciato.

21 Si vedano Humbert 1976, 225-234, e Cels-Saint-Hilaire 1985 (in part. 352-354).

22 Si potrà in particolare pensare a soggetti nati negli anni iniziali del II sec. a.C., all'indomani del consolidamento della presenza militare romana nella penisola (Cadiou 2008a, 29-41).

23 Sul punto cf. Humbert 1976, 231-233.

24 Cadiou 2008a, 642-644. 
consolidare il controllo militare di una base navale importante come quella di Carte$i a$, ben collocata anche in rapporto alla viabilità terrestre.

La fondazione, come ho anticipato, dovette avvenire nel solco della tradizione appare decisivo, in questo senso, il ruolo autoritativo giocato dal senato- tant'è che Livio non sente il bisogno di sottolineare la novità della procedura, al di là della peculiarità insita nella composizione del contingente coloniario; né vale a smentire il racconto liviano il silenzio di Velleio, il quale tra l'altro, nel momento in cui considera Carthago Iunonia la prima colonia dedotta extra Italiam,$^{25}$ pensa senza dubbio alle fondazioni di diritto romano. L'idea che Carteia sia una colonia latina in senso proprio è del resto confermata dalla struttura amministrativa locale, ricostruibile essenzialmente sulla base della ricca documentazione numismatica.

Alla zecca di Carteia, attiva dal 130 a.C. circa all'età tiberiana, sono attribuibili ventinove emissioni bronzee, ${ }^{26}$ tutte a legenda latina e di norma identificate dalla sottoscrizione magistratuale; i magistrati noti, tutti con onomastica romana, ${ }^{27}$ operano singolarmente o a coppie e non sempre esplicitano la carica rivestita. La seriazione cronologica delle emissioni $\mathrm{i}^{28}$ consente di isolare una prima fase, compresa entro l'ultimo quarto del II sec. a.C., durante la quale la funzione di magistratura monetale è rivestita da singoli quaestores ${ }^{29}$ (Fig. 1): un tratto apparentemente caratteristico proprio delle colonie latine, come documentano le emissioni di Venusia, di Brundisium e di Copia ${ }^{30}$ che non vanta di fatto altri paralleli se non nel caso-significativo, come vedremo- della zecca di Valentia. ${ }^{31}$

Il parallelo risulta a maggior ragione significativo alla luce dei dati relativi alle fasi successive, che suggeriscono una linea di sviluppo in tutto analoga a quella seguita dalle colonie latine di più antica fondazione. Alle emissioni curate da quaestores seguono quelle sottoscritte da censores, da aediles e da quattuorviri. ${ }^{32}$ Queste ultime, in particolare, documentano già a partire dai decenni iniziali del I sec. a.C. (e fino ad età tiberiana) l'assunzione da parte della comunità di un assetto amministrativo di marca indubbiamente municipale, la cui precocità è confermata dalla più antica attestazione epigrafica relativa ad un magistrato di Carteia: quella -databile su base paleografica in età certamente pre-augustea- del quattuorvir C. Curvius Rusticus ${ }^{33}$ il cui gentilizio ricorre anche in due emissioni monetali locali di cronologia risalente. ${ }^{34}$

25 Vell. 1.15.4, 2.7.8

26 Seguo la classificazione di Chaves Tristán 1979 (cf. CNH Carteia 1-71), da correggere per quanto riguarda l'emissione XIX: P MION IIIIVIR, di fatto inesistente: si tratta nella realtà di una errata attribuzione di alcuni esemplari dell'emissione HNI 1248-1249: м ост IIIIVIR, prodotta dalla zecca di Paestum (cf. Stannard - Faria 2009). Sulla zecca di Carteia si veda, da ultimo, Amela Valverde 2014.

27 Per una analisi dei gentilizi, quasi tutti di origine romano-italica, si veda Hernández Fernández 1994; cf. da ultimo Padilla Monge 2011.

28 La cronologia assoluta delle singole emissioni è determinabile solo in via ipotetica: in termini generali, le emissioni I-X sono databili al 130-100 a.C., le emissioni XI-XIII al 100-85 a.C., le emissioni XIV-XXII all'85-40 a.C., le emissioni XXIII-XXV (=RPC I 111-115) al 40-30 a.C., le emissioni XXVI-XXX (=RPC I 116-123) ad età augusteo-tiberiana.

29 Emissioni II-VI (circa $125-105$ a.C.).

$30 \quad$ HNI 718 (Venusia), 749 (Brundisium), 1935-1939 (Copia). Cf. Barreda Pascual 2007.

31 Ai casi citati può essere affiancato solo quello, assai più tardo, della zecca di Emporiae (RPC I 234-258), le cui emissioni latine si datano a partire dall'età augustea e sono pertinenti alla fase municipale del centro: cf. da ultimo Amela Valverde 2016b. Non sono invece magistrati locali i quaestores che sottoscrivono le emissioni di Urso (CNH Ursone 1-7) e di Corduba (CNH Corduba 1-4), sulle quali cf. infra.

32 Censores: emissioni XI-XII; aediles: emissioni XIII e XVIII; quattuorviri: emissioni XX-XXVII e XXX.

33 IRPCa 92: C. Curvio C.f. / Ser(gia) Rustico / IIIIvir(o) iterum / Tertius l(ibertus).

34 Emissioni III (circa 120 a.C.) e XVb (circa 80 a.C.). 
emiss. ser. nominale legenda (recto)

legenda (verso)

\begin{tabular}{|r|l|l|l|l|}
\hline I & A & semisse & & CARTEIA \\
\cline { 2 - 5 } & B & quadrante & & CARTEIA \\
\hline & C & sestante & & CARTEIA \\
\hline \multirow{2}{*}{ II } & A & semisse & & Q I CART \\
\hline & B & quadrante & & Q I CART \\
\hline & C & sestante & & CARTEIA \\
\hline III & & semisse & CART & Q I Q CVRVI \\
\hline IV & A & semisse & CARTEIA & Q I P IVLI \\
\hline & B & semisse & CARTEIA & Q I P IVLI \\
\hline \multirow{2}{*}{ V } & & semisse & & Q I C NINI I CARTEI \\
\hline \multirow{2}{*}{ VI } & A & semisse & & Q I C CVRMAN I CARTEI \\
\hline & B & semisse & & C CVRMAN I CAR \\
\hline \multirow{2}{*}{ VII } & A & semisse & & L MARCI I CARTEIA \\
\hline & B & semisse & & L MARC I CARTEIA \\
\hline \multirow{2}{*}{ VIII } & A & semisse & & Q OPS I CARTEIA \\
\hline & B & semisse & & Q OPSIL I CARTEIA \\
\hline \multirow{2}{*}{ IX } & A & semisse & (CARTIA) & Q PEDEC(AI) \\
\hline & B & semisse & & Q PEDECAI I CARTEIA \\
\hline & C* & semisse & CARTE & PEDECA \\
\hline \multirow{2}{*}{ X } & A* & semisse & & M SEP I CAR \\
\hline & B* & semisse & & M SEP I KAR \\
\hline & C* & semisse & & M SEPT(V) I CAR \\
\hline & & & & \\
\hline
\end{tabular}

Figura 1. La zecca di Carteia: emissioni della fase coloniaria latina (circa 130-100 a.C.).

Sebbene Plinio non specifichi lo statuto di Carteia, l'avvenuta promozione municipale è assicurata da almeno un frammento epigrafico della piena età imperia1e. ${ }^{35}$ La struttura quattuorvirale e l'ascrizione alla tribù Sergia sono elementi che suggeriscono in se stessi l'origine pre-augustea del municipium, ${ }^{36}$ la cui costituzione ha anzi buone probabilità di risalire già ad età pre-cesariana: nonostante la suggestione offerta dall'ascrizione tribale dei suoi abitanti, è infatti a mio avviso improbabile che la promozione si debba allo stesso Cesare, in considerazione dell'orientamento pompeiano di Carteia durante il bellum Hispaniense. ${ }^{37}$ La documentazione numismatica permette del resto di collocare il passaggio istituzionale piuttosto nei decenni iniziali del I sec. a.C., e mi chiedo a questo punto se esso non debba considerarsi l'esito della stessa lex Iulia del 90 a.C., che sancì la municipalizzazione dell'intero nomen Latinum, ivi comprese le colonie presenti -come nel

IRPCa 96 (II sec. d.C.): [- - -]Q[- - -] / [- - - ]+ALIQVI+ [- - ] / [- - - in munic[ipio - - -].

Sul quattuorvirato delle comunità privilegiate delle province iberiche rimando a Sisani 2018, 50-60.

Auct. B. Alex. 32.6-8, 36.1, 37; App. BC 2.436; D.C. 43.31.3. 
caso della Cisalpina- su suolo provinciale: ${ }^{38}$ una circostanza che, come è chiaro, andrebbe a confermare il carattere propriamente coloniario della deduzione del 171 a.C.

Alla luce di questo esempio, non sono mancati i tentativi di rintracciare altri casi di colonie di diritto latino dedotte in ambito provinciale anteriormente all' 89 a.C. Sebbene non siano infrequenti le allusioni a centri creati in provincia per diretta iniziativa delle autorità romane, è metodologicamente opportuno isolare in via preliminare $\mathrm{i}$ casi in cui le fonti parlano esplicitamente di deduzioni coloniarie, in quanto tali potenzialmente assimilabili all'intervento attuato nel 171 a.C.

In questo senso, l'unico reale parallelo sembrerebbe rappresentato da Aquae Sextiae, centro qualificato come oppidum Latinum nell'elencazione pliniana delle comunità della Narbonense ${ }^{39}$ e che 1'autore delle periochae liviane dichiara fondato come colonia nel 122 a.C.:

C. Sextius procos. victa Salluviorum gente coloniam Aquas Sextias condidit, ob aquarum copiam e caldis figidisque fontibus atque a nomine suo ita appellatas. ${ }^{40}$

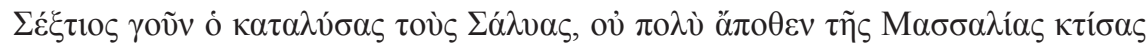

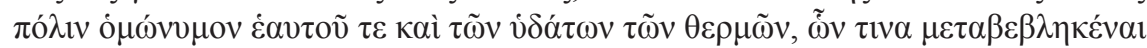

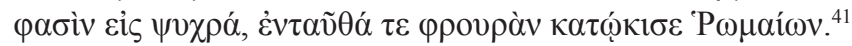

His conss. [Cn. Domitius, C. Fannius] C. Sextius oppidum aedificavit, in quo aquae Sextiae, in Galliis. ${ }^{42}$

Il parallelo tra la testimonianza liviana e quella straboniana è strettissimo, tanto da far sospettare l'utilizzo da parte di entrambi gli autori della stessa fonte. La circostanza, come è chiaro, spinge a postulare nella periocha un uso improprio del termine colonia, che traduce quello che per Strabone -come anche per Cassiodoro- parrebbe piuttosto essere un intervento di natura puramente urbanistica, ${ }^{43}$ accompagnato dalla "deduzione" in loco di un presidio romano nel quale andrà verosimilmente identificato, più che uno stanziamento a carattere propriamente militare, un conventus di negotiatores, strutturato grazie all'intervento di Sestio Calvino. ${ }^{44}$ Fino ancora agli anni Settanta del I sec. a.C. questa componente sociale parrebbe di fatto costituire, insieme ai coloni di Narbo Martius, l'unica presenza romana a carattere stabile nella Gallia Transalpina, come si ricava dal quadro tracciato da Cicerone nella Pro Fonteio, ${ }^{45}$ dove indicativamente non compare la minima allusione all' esistenza all'interno della provincia, a questa quota cronologica, di un nucleo coloniario latino. La promozione di

38 Gell. 4.4.3: civitas universo Latio lege Iulia data est. Cf. Luraschi 1978, 332, nota 42, e 1979, 312-313.

39 Plin. HN 3.36.

40 Liv. Per. 61.1.

41 Str. 4.1.5: "Sestio, il vincitore dei Salluvi, fondata non molto lontano da Massilia una città che prende nome da lui stesso e dalle sorgenti di acque calde (alcune delle quali dicono siano diventate fredde), vi stanziò un presidio di Romani".

42 Cassiod. Chron. 442.

43 Verso questa interpretazione orienta anche il ricorso, nella periocha, al verbo condere, rarissimamente utilizzato -mai da Livio- nel senso di (coloniam) deducere: su questo lessico si veda ora Tarpin 2018.

44 Su questo tipo di interventi cf. Sisani 2011, 678-690, e 2017.

45 Cf. Christol 1999, 2-9. 
Aquae Sextiae a colonia latina dovrà piuttosto risalire, come nel caso delle altre comunità della Narbonense, ad età cesariana ${ }^{46}$ cronologia verso cui orienta la stessa titolatura ufficiale - colonia Iulia (Augusta) $)^{47}$ - del centro.

Le vicende istituzionali di Aquae Sextiae spingono in se stesse alla massima cautela nell'interpretare in chiave coloniaria latina i casi in cui le fonti ricordano la strutturazione di oppida provinciali ad opera delle autorità romane. Il sospetto, infatti, è che di norma si tratti piuttosto di interventi di natura "giuridico-urbanistica" i cui esiti sono assimilabili a quelli prodotti dalla pratica della contributio ${ }^{48}$ motivati da esigenze di controllo territoriale e attuati per diretta iniziativa di singoli magistrati, indipendentemente cioè da una preliminare pronuncia senatoria, secondo quella che fino a tutto il II sec. a.C. risulta essere la prassi attesa -come conferma, appunto, l'esempio di Carteia - nel caso di fondazioni propriamente coloniarie: ${ }^{49}$ questo ricorso, non necessariamente legato a finalità di carattere strettamente militare, è ben illustrato da Strabone in relazione alla strategia applicata da Roma nei territori iberici situati a nord del fiume Tagus. ${ }^{50}$

Nell'ambito delle stesse province iberiche,$^{51}$ andranno a mio avviso intesi in questa chiave i casi di Tarraco (206 a.C.?), ${ }^{52}$ della Turris Lascutana (190-189 a.C.), ${ }^{53}$ di Complega (178 a.C.), ${ }^{54}$ di Gracchuris (178 a.C. $)^{55}$ e di Iliturgi (178 a.C.?). ${ }^{56}$ tutte comunità peregrine nei riguardi delle quali l'intervento romano, almeno inizialmente, non sembrerebbe aver comportato alcuna particolare forma di promozione ${ }^{57} \mathrm{Mi}$

46 Cf. infra.

47 CIL XII 982, 4414, 4528.

48 Su questo vincolo giuridico cf. Laffi 1966, 99-158.

49 Su questa prassi si veda Laffi 2001 [1988].

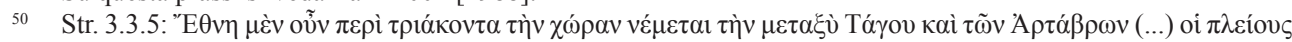

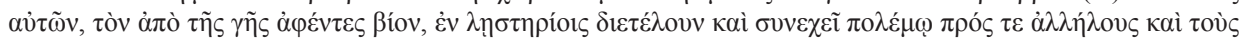

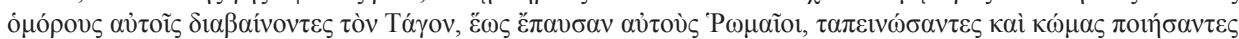

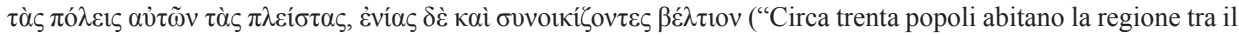
Tagus e gli Artabri (...) per la maggior parte, disdegnando di vivere di agricoltura, si diedero al brigantaggio e cominciarono a muover guerra gli uni contro gli altri e contro i propri vicini, attraversando il Tagus, finché non li fermarono i Romani, i quali ridussero a villaggi la maggior parte delle loro città, mentre alcune ne accrebbero concentrandovi la popolazione"). Il contesto storico al quale allude il geografo è verosimilmente quello delle campagne militari di Bruto Callaico (138-136 a.C.): cf. Str. 3.3.1, 3.4.

51 Si veda il quadro tracciato da Bandelli 2002, di cui condivido tanto l'impostazione metodologica quanto -eccezion fatta per Valentia- le conclusioni. Per una opposta prospettiva cf. ora García Fernández 2009a e 2009b; Espinosa Espinosa 2014 e 2016.

52 Plin. HN 3.21: colonia Tarracon, Scipionum opus, sicut Carthago Poenorum; cf. Isid. Etym. 15.1.65: Terraconam in Hispania Scipiones construxerunt.

53 CIL I $\mathrm{I}^{2} 614$ (=ELRH u1): L. Aimilius L. f. inpeirator decreivit / utei quei Hastensium servei / in Turri Lascutana habitarent / leiberei essent, agrum oppidumqu(e) / quod ea tempestate posedisent / item possidere habereque / iousit dum poplus senatusque / Romanus vellet. Act(um) in castreis / a(nte) d(iem) XII K(alendas) Februarias.

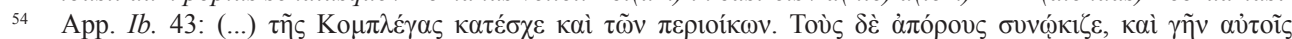
$\delta ı \mu \varepsilon ́ \tau \rho \varepsilon ı$ (Sempronio Gracco "sottomise la città di Complega e quanti erano stanziati nella zona. Vi concentrò i poveri ed assegnò loro le terre").

55 Liv. Per. 41.2: Tib. Sempronius Gracchus procos. Celtiberos victos in deditionem accepit, monimentumque operum suorum Gracchurim oppidum in Hispania constituit; cf. Fest. 86 L.: Gracchuris urbs Hiberae regionis, dicta a Graccho Sempronio, quae antea Ilurcis nominabatur.

56 CIL I 2927 (=CIL II²/7, 32): Ti. Sempronio Graccho / deductori / populus Iliturgitanus.

57 Ai casi citati può essere affiancato quello, più tardo e senza dubbio peculiare, documentato da App. Ib. 100: Пó $\lambda ı v$

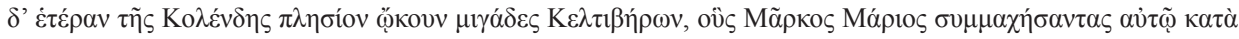

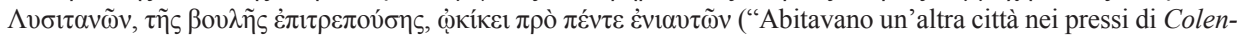
$d a$ delle tribù miste di Celtiberi le quali, alleate di Marco Mario durante una guerra contro i Lusitani, erano state lì insediate da lui, con il consenso del senato, cinque anni prima"). L'intervento si distingue dagli altri per le sue 
sembrano decisive, in questo senso, le vicende di Gracchuris, ricordato da Plinio tra gli oppida Latinorum veterum del conventus Caesaraugustanus, ${ }^{58}$ la cui elevazione al rango di municipium Latinum risale senz'altro ad età augusteo-tiberiana. ${ }^{59}$ Dinamiche analoghe sono prospettabili anche per Iliturgi, la cui "deduzione" ad opera di Sempronio Gracco, se intesa in senso propriamente coloniario, mal si concilia con il poleonimo Forum Iulium associato al centro, ${ }^{60}$ che permette di postulare una sua iniziale costituzione come forum -verosimilmente contestuale all'attribuzione dello ius Latii, e preliminare alla definitiva promozione municipale- in epoca non anteriore all'età cesariana.

Nel caso poi dei centri di Corduba (169-168/152-151 a.C. ${ }^{61}$ e di Palma e Pollentia (122 a.C.), ${ }^{62}$ se è pur vero che le fonti attestano esplicitamente la deduzione in loco di "coloni", si dovrà piuttosto pensare -analogamente a quanto ipotizzato per Aquae Sextiae - all'insediamento all'interno delle comunità indigene di consistenti nuclei di cittadini romani, contestualmente organizzati in conventus. Per quanto concerne in particolare Corduba, ${ }^{63}$ il centro ancora negli anni centrali del I sec. a.C. risulta essere un semplice oppidum sede di un conventus civium Romanorum, ${ }^{64}$ che sembrerebbe detenere il pieno ed esclusivo controllo politico della città e quasi identificarsi con il suo intero corpo civico. ${ }^{65}$

Proprio a realtà di questo tipo sono a mio avviso da riferire le allusioni, nel corpus Caesarianum, a milizie reclutate nelle coloniae (o tra i coloni) della Ulteriore, ${ }^{66}$ dove

finalità -ricompensare gli auxilia che avevano affiancato le truppe romane durante la campagna militare del 102101 a.C. (cf. MRR I, 568, 572)- e non è forse casuale che in questa specifica occasione sia espressamente ricordato il ruolo giocato dal senato, il quale in ogni caso parrebbe essersi limitato ad avallare l'iniziativa personale del magistrato. Sul contesto storico di questo episodio si veda da ultimo Sánchez Moreno 2017.

58 Plin. HN 3.24.

59 Come confermano le emissioni monetali locali RPC I 429-430: MVNICIP GRACCVRRIS, coniate durante il regno di Tiberio.

60 Plin. $H N 3.10$.

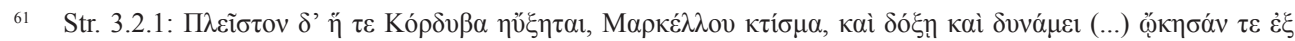

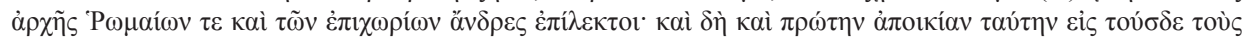

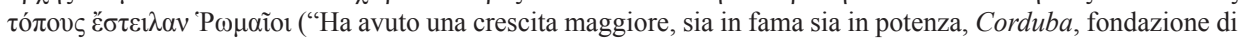
Marcello (...) fu abitata in principio da uomini scelti, Romani e indigeni; inoltre, i Romani fecero di essa la prima colonia fondata in questi luoghi”). Su questa testimonianza si veda da ultima García Fernández 2014, per la quale la notizia relativa alla fondazione di Claudio Marcello andrebbe scissa dalla notazione sul primato temporale della colonia, da riferire alla successiva deduzione del 44-43 a.C.

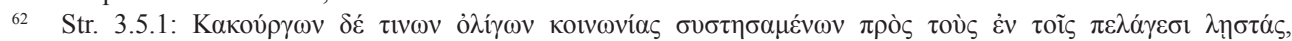

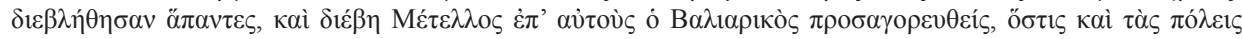

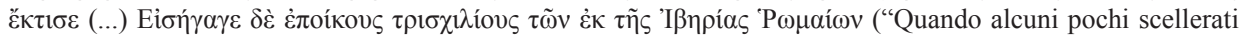
strinsero alleanza con i pirati del mare, tutti risultarono screditati, e contro di loro [gli abitanti delle isole Gimnesie] si mosse Metello detto Balearico, che tra l'altro fondò le città [di Palma e Pollentia] (...) Condusse così dall'Iberia tremila coloni romani”); cf. Mela 2.124: Palma et Pollentia coloniae. Su questo intervento si vedano Pena 2004 e -con altra prospettiva- Olesti 2010, 1014-1017.

63 Sisani 2011, 688-690.

64 Caes. Civ. 2.19.3, 21.1-2 (49 a.C.); Auct. B. Alex. 57.4-59.2 (48 a.C.).

65 Particolarmente esplicita in questo senso la testimonianza di Caes. Civ. 2.21.1: Caesar contione habita Cordubae omnibus generatim gratias agit: civibus Romanis, quod oppidum in sua potestate studuissent habere, Hispanis, quod praesidia expulissent, che oppone ai cives Romani di Corduba gli Hispani delle altre comunità.

${ }_{66}$ Caes. Civ. 2.19.3: Simul ipse Cordubae conventus per se portas Varroni clausit, custodias vigiliasque in turribus muroque disposuit, cohortis duas, quae colonicae appellabantur, cum eo casu venissent, tuendi oppidi causa apud se retinuit; Auct. B. Alex. 56.4: Equitum autem Romanorum dilectum instituit; quos ex omnibus conventibus coloniisque [codd. $\beta$, colonisque codd. $\sigma$ ] conscriptos transmarina militia perterritos ad sacramenti redemptionem vocabat; Auct. B. Hisp. 7.4: Aquilas et signa habuit XIII legionum. Sed ex quibus aliquid firmamenti se existimabat habere, duae fuerunt vernaculae [codd., vernacula $e<t$ II $>$ Mommsen] quae a Trebonio 
il termine, piuttosto che testimoniare un diffuso ricorso in quest'area alla colonizzazione di diritto latino, parrebbe nuovamente alludere ad una presenza istituzionalmente strutturata di cives Romani all'interno delle civitates peregrinae della provincia. Mi pare in questo senso decisiva la testimonianza relativa al dilectus tenuto da Cassio Longino nella tarda estate del 48 a.C. ${ }^{67}$ limitato ai soli equites Romani, coscritti "ex omnibus conventibus coloni(i)sque": dove il nesso sembra esprimere, in endiadi, la reale consistenza giuridica di tali "colonie". ${ }^{68}$

Nel caso infine di Italica (206 a.C.), ${ }^{69}$ nulla prova che l'intervento promosso da Scipione -la concentrazione in questo centro dei soldati dell'esercito romano feriti durante la battaglia di Ilipa- abbia avuto carattere permanente, tanto meno che esso si configuri come una vera e propria deduzione coloniaria. ${ }^{70} \mathrm{~A}$ sostegno di una precoce condizione privilegiata del centro si potrebbe invocare l'attestazione locale di un praetor - M. Trahius, verosimilmente un avo paterno dell'imperatore Traiano ${ }^{71}$ - noto da una iscrizione musiva databile negli anni a cavallo tra il II e il I sec. a.C.:.$^{72}$ e tuttavia non è affatto certo che si tratti di un magistrato locale, a fronte in particolare dell' assenza di reali paralleli in area iberica ${ }^{73}$ circostanza quest'ultima che spinge ad identificare nel personaggio piuttosto un governatore della provincia Ulterior, ossia un magistrato di Roma. L'esistenza di una verosimilmente significativa componente romano-italica all'interno della comunità ${ }^{74}$ non contrasta con la sua eventuale condizione di civitas peregrina, la cui promozione parrebbe realizzarsi al più presto in età cesariana, all'atto della trasformazione del centro in municipium civium Romanorum. ${ }^{75}$

I centri fin qui richiamati sono gli unici per i quali il sospetto di una possibile condizione coloniaria latina vanta se non altro qualche minimo appiglio nelle testimonianze letterarie. In altri casi l'ipotesi appare fondata su argomenti ancora più deboli: in particolare, le attestazioni relative a magistrati con titolature e/o onomasti-

transfugerant, una facta ex coloniis quae [codd. $\beta$, ex colonis qui codd. $\sigma$ ] fuerunt in his regionibus, quarta fuit Afraniana, ex Africa quam secum adduxerat. Su queste testimonianze si veda Gabba 1973 [1970]; relativamente alle varianti offerte dai codici del corpus Caesarianum, si tenga conto che le famiglie $\beta$ (codd. TVURW) e $\sigma$ (codd. SL) costituiscono rami indipendenti della tradizione (Klotz 1927, vi-xvi) e pertanto le loro lezioni, da un punto di vista strettamente filologico, vanno giudicate di pari valore.

67 Auct. B. Alex. 56.4.

68 All'interno dello stesso corpus Caesarianum, un analogo uso improprio del termine colonia è riscontrabile in Hirt. $B G$ 8.24.3, su cui si veda Sisani 2017.

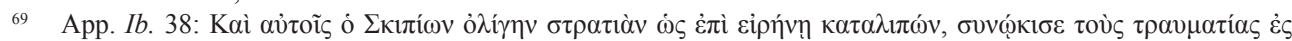

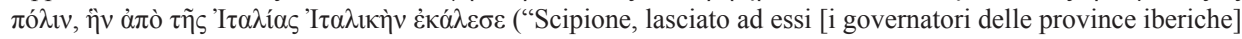
un piccolo esercito per mantenere la pace, concentrò i soldati feriti in una città, che chiamò Italica da Italia").

70 Cadiou 2008a, 636-640.

71 Canto 2010. Il gentilizio - decisamente raro, ma ben attestato nell' ambito delle province iberiche $\left(C I L \mathrm{II}^{2} / 7,547\right.$; CILA 2, 225; CILA 3, 383; CILCC III 1139)- è senza dubbio di origine centro-italica: cf. CIL IX 1484 (ager Ligurum Baebianorum), CIL IX 1529 (ager Beneventanus); CIL XI 4686 (Tuder).

72 CILA 3, 578 (=ELRH u23): M. Trahius C.f.pr(aetor) AP[- - -] / de stipe idemq(ue) caul[as - - -]. Cf. Caballos Rufino 1987-1988.

73 Le uniche comunità a risultare rette da praetores sono la civitas foederata di Bocchorum (CIL II 3695, del 6 d.C.) e la colonia civium Romanorum di Lepida Celsa (RPC I 261-264, del 44-36 a.C.). Il titolo di praetor attestato dalla tabula Contrebiensis $\left(C I L \mathrm{I}^{2} 2951 \mathrm{a}=\right.$ ELRH C9) sarà invece semplicemente da intendere come interpretatio latina della suprema magistratura locale; così anche il praetor saguntino di Liv. 21.12.7.

74 Una testimonianza precoce di tale presenza è offerta dal caso dell'italicense C. Marcius, menzionato da Appiano (Ib. 66) in relazione ai fatti del 143 a.C.: cf. García Fernández 2009a, 385-386.

75 Il centro, di cui Plinio (HN 3.11) non esplicita lo status, va senza dubbio contato nel novero dei dieci municipia civium Romanorum della Baetica (Plin. HN 3.7), solo due dei quali - Regina e Gades-identificabili con certezza: cf. ora Sisani 2018, 50-60. 
ca romane, documentati con funzione monetale da emissioni locali di cronologia apparentemente risalente (ante 44 a.C.). ${ }^{76}$

L'ambiguità di questa documentazione risiede in primo luogo nella difficoltà di dare ad essa un inquadramento cronologico sicuro: alle proposte di datazione "alta", che vorrebbero far risalire la gran parte di tali emissioni già al II sec. a.C., si oppone infatti il sospetto che in molti casi esse siano piuttosto da collocare ben dentro il I sec. a.C., con tutto ciò che ne consegue sul piano della corretta ricostruzione dei tempi e dei modi degli sviluppi istituzionali delle comunità emittenti. A ciò si aggiunga che, se è pur vero che una formula onomastica di tipo romano denuncia la condizione giuridica privilegiata -romana o latina- del possessore, ${ }^{77}$ un magistrato monetale non va necessariamente identificato con un magistrato municipale. Nel caso ad esempio delle isolate emissioni di Corduba ${ }^{78}$ e di Urso ${ }^{79}$ sottoscritte da quaestores, è forte il sospetto che esse -qualunque sia la loro cronologia- siano il prodotto di zecche militari: ${ }^{80}$ una chiave interpretativa che può essere estesa anche ad altri casi, ed in particolare alle emissioni locali eventualmente collocabili nei concitati anni del bellum Sertorianum (82-72 a.C.) o del bellum Hispaniense (47-45 a.C.). ${ }^{81}$

Questa lettura permetterebbe del resto di spiegare il carattere effimero che caratterizza, a livello numerico e temporale, la gran parte di queste emissioni "latine" di cronologia risalente. L'unica eccezione- tolti i casi di Valentia e di Saguntum, su cui avremo modo di tornare- è di fatto costituita dalla zecca di Castulo, già attiva dalla fine del III sec. a.C., le cui emissioni più recenti (VI-X), senza dubbio distribuite nell'arco di vari decenni, risultano sottoscritte da magistrati con onomastica romana ${ }^{82}$ (Fig. 2).

76 Quaestores: Corduba $\left(L M R S^{2}\right.$, nr. 77), Urso $\left(L M R S^{2}\right.$, nrr. 288, 1054), Valentia (LMRS 2 , nrr. 950-955, 1216). Aediles: Acinippo $\left(L M R S^{2}\right.$, nr. 5), Baelo $\left(L M R S^{2}\right.$, nr. 28), Obulco $\left(L M R S^{2}\right.$, nrr. 211-212). Magistrati privi di titolatura ma con onomastica romana: Baelo $\left(L M R S^{2}\right.$, nrr. 25-26), Brutobriga $\left(L M R S^{2}\right.$, nr. 321), Castulo $\left(L M R S^{2}\right.$, nrr. 304-305=11401141, 585-598, 1137-1138), Corduba (LMRS $S^{2}$, nr. 1006), Lascuta (LMRS $S^{2}$, nrr. 302-303, 1031), Myrtilis (LMRS ${ }^{2}$, nrr. 358-359), Onuba (LMRS $S^{2}$, nrr. 224-226), Osset (LMRS', nrr. 230-231), Saguntum (LMRS $S^{2}$ nrr. 843, 847-848, 11741184), Salacia $\left(L M R S^{2}\right.$, nr. 388), Toletum $\left(L M R S^{2}\right.$, nr. 927), Vesci (LMRS ${ }^{2}$, nr. 297). Tra questi centri, Castulo, Myrtilis e Salacia sono qualificati da Plinio come oppida Latina, Lascuta e Toletum come oppida stipendiaria.

77 García Fernández 2011.

78 CNH Corduba 1-4: CN IVLI L F Q.

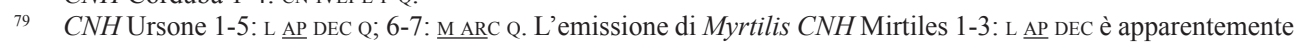
sottoscritta dallo stesso magistrato operante a Urso.

80 Cf. da ultimo Amela Valverde 2012.

81 Possono essere lette in questa chiave anche alcune testimonianze epigrafiche di cronologia risalente relative a magistrati con onomastica romana. È il caso, in particolare, di tre iscrizioni concernenti la realizzazione di interventi edilizi legati ad apprestamenti difensivi: Saquete - Guerra Millán 2015, da Metellinum: [- - - d]uo (?) mur(um) et a++[- - - / [Q.?] Caecilius Sex.f. Teirus / Q. Caecilius Q.f. Segoss(us) / aedil(es) f(aciunda) c(uraverunt); CIL I² 2275 (=IRILAD 2 65), da Lucentum: [-] Tadius M. f. / Ruf(us) praef(ectus) tur(rim) / faciun(dam) coer(avit); CIL II²/5, 521 (=ELRH u38), da Sabetum: L. Lentulo C. Marcello co(n)s(ulibus) / Q. Cassio C. f. Long(ino) tr(ibuno) pl(ebis) pro pr(aetore) / Binsnes Vercellonis $f$. Xvir maxs(umus) / M. Coranus Acrin(i) $f$. Alpis / aedilis portam faciund(am) / coer(averunt) [d] e sua pecun(ia). L'iscrizione di Metellinum risale quasi certamente agli anni del bellum Sertorianum e può essere ragionevolmente posta in relazione con la creazione stessa della piazzaforte ad opera di Q. Cecilio Metello Pio (Cadiou 2008a, 352-353): i due aediles -appartenenti a famiglie verosimilmente locali, i cui membri dovettero ottenere la cittadinanza romana singillatim dallo stesso proconsole (cf. Cic. Arch. 26; Balb. 5051)- sono senza dubbio espressione di una embrionale struttura amministrativa interna al presidio, da leggere in ogni caso in contesto strettamente militare. Nel caso di Lucentum -oppidum Latinum (Plin. HN3.20) costituito a municipium (IRILAD ${ }^{2}$ 62) solo nel corso dell'età augustea- nulla obbliga ad identificare nel personaggio menzionato un magistrato municipale: si tratterà piuttosto di un funzionario straordinario (praefectus operi faciendo) nominato in seno al presidio romano di stanza nella città, verosimilmente nel contesto degli scontri tra cesariani e pompeiani. L'iscrizione di Sabetum, datata al 49 a.C. e da riferire allo stesso contesto storico, documenta una coppia magistratuale "ibrida" composta da un peregrinus e da un civis Romanus di origine verosimilmente locale, la cui promozione (virtutis causa?) non dice nulla, tuttavia, sullo statuto giuridico della comunità in quest'epoca.

82 DCPH Kaśtilo 32-46. L'emissione VI è databile al 90-70 a.C., le emissioni VII-X all'80-45 a.C. 
emiss. nr. nominale legenda (recto)

legenda (verso)

\begin{tabular}{|c|l|l|l|l|}
\hline VI & 32 & semisse & CN VOC ST F & CN FVL CN F | kaśtilo \\
\cline { 2 - 5 } & 33 & semisse & CN VOC ST F & CN FVL CN I kaśtilo \\
\cline { 2 - 5 } & 34 & semisse & CN VOC ST & \\
\cline { 2 - 5 } & 35 & semisse & & CN \\
\cline { 2 - 5 } & 36 & quadrante & CN VOC ST F & CN FVL CN F | kaśtilo \\
\hline \hline \multirow{2}{*}{ VII } & 37 & asse & SACAL I ISCER & SOCED I CAST \\
\cline { 2 - 5 } & 38 & semisse & M VAL & C COR \\
\hline \hline \multirow{2}{*}{ VIII } & 39 & asse & C AEL I M ISC & M FVL \\
\cline { 2 - 5 } & 40 & semisse & M POIPILLI M F & P COEISTAIRE F \\
\cline { 2 - 5 } & 41 & quadrante & AP CLO & C AVF I A POS \\
\hline \hline \multirow{2}{*}{ IX } & 42 & asse & L QV L F I Q IS C F & M C F \\
\cline { 2 - 5 } & $42 *$ & asse & L C L L F I Q IS C F & M C F \\
\cline { 2 - 5 } & 43 & semisse & M BA L F & M Q F \\
\cline { 2 - 5 } & 44 & semisse & M BA L F & \\
\cline { 2 - 5 } & 45 & semisse & M BA P F & \\
\hline \hline X & 46 & semisse & M VIRIL I M BA & \\
\hline
\end{tabular}

Figura 2. La zecca di Castulo: serie emesse tra il 90 e il 45 a.C. circa.

È difficile fare ipotesi sul contesto istituzionale che può aver prodotto questo tipo di emissioni, la più antica delle quali tra l'altro reca ancora in legenda il poleonimo in lingua iberica e che in ogni caso sembrerebbero tutte da datare nella prima metà del I sec. a.C. Il centro è ricordato da Plinio tra gli oppida Latii veteris del conventus Carthaginiensis, ${ }^{83}$ ma si tratta di una promozione giuridica apparentemente non anteriore all'età cesariana: almeno a giudicare dalla denominazione -Castulonenses qui Caesarii Iuvenales appellantur- dei suoi abitanti. Con tutte le cautele del caso, non escluderei che la marca latina che caratterizza le emissioni di Castulo già a partire dal principio del I sec. a.C. sia in qualche rapporto da un lato con la feroce repressione attuata nei confronti della comunità dall'esercito romano nel 97 a.C. ${ }^{84}$ dall'altro con la verosimilmente precoce e consistente presenza romano-italica nell'area, impegnata nello sfruttamento delle ricche risorse minerarie locali: ${ }^{85}$ pur restando incerti gli esiti inizialmente prodotti da questi fattori sull'assetto giuridico-amministrativo del centro.

Con altra prospettiva, l'argomento onomastico è stato utilizzato anche per postulare la condizione latina, da epoca anteriore all'89 a.C., del centro di Ilerda. La suggestione nasce in questo caso dalle formule onomastiche dei tre cavalieri ilerdensi -(?) Otacilius Suisetarten f., Cn. Cornelius Nesille f., P. Fabius Enasagin f.- menzionati nel decreto di Pompeo Strabone del novembre dell'89 a.C. relativo alla con-

83 Plin. HN 3.25.

${ }^{84}$ Plu. Sert. 3.5-10. La città, colpevole di aver congiurato contro le truppe romane lì accampate, venne prontamente occupata da Sertorio - all'epoca tribuno militare del proconsole Didio- che a detta di Plutarco avrebbe ordinato il massacro dell'intera popolazione maschile adulta.

85 Str. 3.2.10-11. 
cessione virtutis causa della cittadinanza romana ai membri della turma Salluitana. ${ }^{86}$ I tre cavalieri sono gli unici, nel lungo elenco dei beneficiari, a fregiarsi di una onomastica di tipo romano: una circostanza che ha indotto a vedervi non già dei semplici peregrini ma dei cives Latini, con ciò che ne consegue in relazione allo statuto di Ilerda, senz'altro identificata come una ulteriore colonia latina della penisola iberica, poi promossa -entro l'età augustea- a municipium civium Romanorum. ${ }^{87}$

La spiegazione, a mio avviso, è un'altra, ed è suggerita dalla coincidenza tra l'onomastica di due dei tre ilerdensi e quella di alcuni membri del consilium di Pompeo Strabone (11. 4-13), che annovera ben due esponenti della poco diffusa gens Otacilia (M’. Otacilius della tribù Pollia, L. Otacilius della tribù Pupinia) e un esponente della gens Cornelia ( $\mathrm{Cn}$. Cornelius della tribù Palatina), il cui prenome, tra 1'altro, è lo stesso utilizzato dall'omonimo cavaliere iberico. Tenendo nel dovuto conto la lacuna che interessa questa sezione dell'iscrizione -al cui interno non farebbe difficoltà restituire la menzione di un $P$. Fabius ${ }^{88}$ - e la relativa rarità del gentilizio Otacilius, mi sembra che la soluzione si imponga da sola: i tre cavalieri ilerdensi figurano, nel testo del decreto, già con l'onomastica assunta all'atto stesso della concessione della cittadinanza romana, evidentemente calcata su quella di quei membri del consilium che dovettero agire, nei loro riguardi, in funzione di patroni.

Sgombrato il campo da quelle che rischiano di risultare autentiche forzature nella lettura delle fonti antiche, restano da analizzare gli interventi promossi dalle autorità romane nella penisola iberica durante gli anni 139-138 a.C., ed in particolare le vicende istituzionali del centro di Valentia:

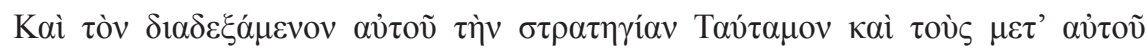

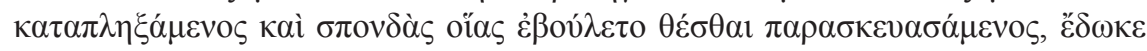

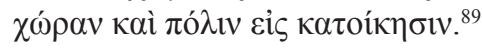

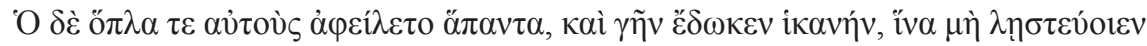
$\dot{\varepsilon} \xi \dot{\alpha} \pi \mathrm{o} \rho \dot{\alpha} \alpha \varsigma^{90}{ }^{90}$

Iunius Brutus cos. in Hispania iis qui sub Viriatho militaverant agros et oppidum dedit, quod vocatum est Valentia. ${ }^{91}$

86 CIL I ${ }^{2}$ 709, cf. p. 714 (=CIL VI 37045). I nomi del primo e del terzo personaggio figurano sul bronzo nelle forme OOTACILIVS $\cdot$ SVISETARTEN $^{*} \mathrm{~F}$ e P $\cdot$ EABIVS $\cdot$ ENASAGIN $\cdot$ F. In entrambi i casi siamo di fronte a evidenti errori di incisione, il secondo dei quali certamente originato dalla meccanica anticipazione, quale prima lettera del gentilizio, della prima lettera (E) del prenome paterno; nel caso di OOTACILIVs, si ha a mio avviso un errore analogo, che di fatto impedisce di conoscere il prenome del personaggio, all'atto di scrivere il quale l'incisore ha semplicemente anticipato, raddoppiandola, la prima lettera (o) del gentilizio: gli emendamenti di norma proposti $-<_{\mathrm{C}}>$ vel $<\mathrm{Q}>$ OTACILIVS- non hanno dunque ragion d'essere.

87 Il centro è elencato da Plinio (HN 3.24) tra gli oppida civium Romanorum del conventus Caesaraugustanus; l'assetto duovirale e l'ascrizione alla tribù Galeria orientano per una promozione a municipium in età post-cesariana.

88 Nell'elenco dei cinquantonove membri del consilium (cf. Cichorius 1922, 130-185), risultano totalmente o parzialmente perduti in lacuna (11. 4-7) i nomi dei nrr. 3: [M. Caecilius (?) - f. - - -], 4: [Ser. Sulpi]cius (?) C. f. Ani(ensis), 9: [- - ], 15: L. [- - ], 16: [- - ]f. Suc(cusana), 22: [- - -]+++[- - ] M.f. [..]r(- - -).

89 D.S. 33.1.4: "E dopo che [Servilio Cepione] ebbe terrorizzato Tautamo - che era succeduto [a Viriato] come comandante supremo- e il suo esercito e aver firmato una pace secondo i termini che egli stesso aveva voluto, diede [ai Lusitani] un territorio e una città dove abitare".

90 App. Ib. 75: "[Servilio Cepione] tolse [ai Lusitani] tutte le armi e diede loro terra sufficiente, affinché non fossero costretti per necessità al brigantaggio".

91 Liv. Per. 55.4. 


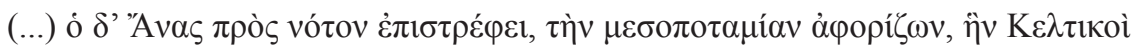

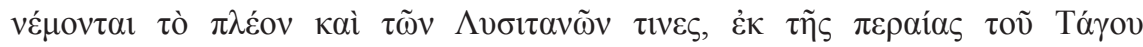

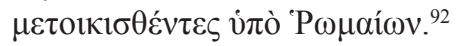

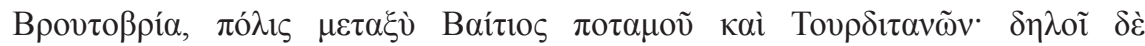

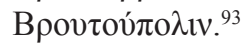

La fonte liviana -complice, senza dubbio, l'intervento di sintesi operato dall'autore della periocha- risulta per più versi problematica. Ad intendere alla lettera questa testimonianza, Valentia sarebbe stata fondata nel 138 a.C. da Bruto Callaico per insediarvi i Lusitani che avevano combattuto al comando di Viriato, ma non si vedono francamente le finalità di un simile intervento, tanto più che secondo Diodoro gli stessi soggetti già nel 139 a.C. avevano ricevuto terre -così anche per Appiano-e un oppidum da Servilio Cepione: terre e oppidum verosimilmente da localizzare non già nella lontana Edetania ma, sulla scorta della testimonianza di Strabone, nell'assai più prossima regione compresa tra i bassi corsi dell'Anas e del Tagus. ${ }^{94}$

L'intervento di Bruto Callaico si inquadra certo meglio se pensato piuttosto in funzione dei veterani italici della campagna del 140-139 a.C. ${ }^{95}$ smobilitati subito prima di dare avvio alle nuove operazioni militari contro Lusitani e Callaeci. L'ipotesi resta valida indipendentemente dalle possibili interpretazioni della locuzione "qui sub Viriatho militaverant" utilizzata dalla periocha, dove il costrutto "sub Viriatho" è forse da intendere in senso banalmente temporale ("al tempo di Viriato"). Viceversa, si dovrà postulare che l'epitomatore abbia fuso la notizia della deduzione di Valentia con l'azione svolta da Bruto Callaico a completamento del progetto di Servilio Cepione concernente i Lusitani, ed in questo caso l'oppidum assegnato a questi ultimi potrebbe eventualmente identificarsi con Brutobriga -da localizzare, in base alla testimonianza di Stefano di Bisanzio, nella stessa regione indicata da Strabonela cui fondazione tuttavia può anche risalire agli anni 137-136 a.C. ed essere piuttosto in relazione con la nuova campagna di pacificazione avviata nel 138 a.C.

Al di là di questi aspetti, resta da determinare la natura giuridica della fondazione di Valentia, oscurata anch'essa dalla fisiologica reticenza della periocha liviana. In questo senso, il carattere apparentemente personale dell'iniziativa -Iunius Brutus (...) agros et oppidum dedit- è in marcato contrasto con la scelta di un poleonimo il quale, a differenza del caso di Brutobriga, richiama piuttosto il criterio di marca augurale spesso adottato in relazione alle deduzioni di natura propriamente coloniaria. L'ipotesi di identificare in Valentia una vera e propria colonia, giocoforza di diritto latino, è del resto sostenuta dalla documentazione numismatica, che permette di istituire uno stretto parallelo tra la struttura istituzionale di questo centro e quella della colonia di Carteia.

La zecca locale di Valentia (Fig. 3) emette tre serie monetali databili tra i decenni finali del II sec. a.C. ed il principio del secolo successivo, ${ }^{96}$ tutte a legenda latina e

92 Str. 3.1.6: “(...) mentre l'Anas scorre deviando verso sud, delimitando una regione intermedia abitata per la maggior parte dai Celti e da alcuni Lusitani, trapiantati qui dalla riva opposta del Tagus ad opera dei Romani”.

93 St. Byz. 187 M: "Brutobriga, città tra il fiume Baetis e i Turdetani: significa "città di Bruto"”.

94 Pina Polo 2009, 282-283.

95 L'origine romano-italica dei coloni insediati a Valentia è del resto suggerita dall'epigrafia del centro: in particolare dai numerosi graffiti ceramici in lingua latina restituiti dall'area urbana (De Hoz García Bellido et alii 2013), databili nei decenni immediatamente successivi alla fondazione.

96 Ripollès 1988. La prima serie è databile intorno al 130 a.C., le altre a cavallo tra II e I sec. a.C. 
serie nrr. nominale legenda (recto)

legenda (verso)

\begin{tabular}{|r|r|l|l|l|}
\hline I & $1-20$ & asse & C LVCIEN I C MVNI Q & VALENTIA \\
\hline & 21 & semisse & & VAL \\
\hline & 22 & quadrante & & \\
\hline \hline II & $23-58$ & asse & T AH(I) T F I L TRINI L F Q & $\underline{\text { VALENTIA }}$ \\
\hline & $59-62$ & semisse & & $\underline{\text { VAL }}$ \\
\hline & $63-66$ & semisse & T AT L TR & VAL \\
\hline & $67-68$ & quadrante & & \\
\hline \hline III & $69-86$ & asse & L CORANI I C NVMI Q & VALENTIA \\
\hline
\end{tabular}

Figura 3. La zecca di Valentia.

sottoscritte da coppie di quaestores con onomastica romana: ${ }^{97}$ un tratto caratteristico -come si è già avuto modo di rilevare- appunto delle colonie latine e della stessa Carteia. Rispetto a quest'ultimo centro, la breve vita della zecca di Valentia non consente purtroppo di ricostruire gli sviluppi istituzionali del centro, in particolare per quanto concerne una sua eventualmente precoce promozione municipale in virtù della lex Iulia del 90 a.C.: circostanza da spiegare alla luce delle particolari vicende storiche della città, base operativa di Sertorio ${ }^{98}$ occupata e distrutta da Pompeo nel 75 a.C., ${ }^{99}$ ed apparentemente ricostituita come comunità dotata di una propria individualità amministrativa solo al momento della deduzione in loco, in età triumvirale-augustea, di una colonia di veterani. ${ }^{100}$

In merito a tali sviluppi, ${ }^{101}$ è in ogni caso metodologicamente inopportuno, a mio avviso, continuare ad evocare la nota testimonianza epigrafica rappresentata dalla dedica cuprense al console del 60 a.C. L. Afranius, ${ }^{102}$ sottoscritta dai conscripti et coloni coloniae Valentinorum, a fronte dell'eventualità che il centro in questione sia piuttosto da identificare con l'omonima colonia civium Romanorum della Gallia Narbonense. Rivestono semmai maggior significato le vicende familiari del tribuno della plebe del 90 a.C. Q. Varius Severus Hispanus/Sucronensis-propter obscurum ius civitatis Hybrida cognominatus ${ }^{103}$ - che in virtù del suo status giuridico e della sua formula onomastica possiamo ritenere figlio di un cittadino romano residente a Sucro e di una donna locale dotata di conubium. Il luogo di nascita del personaggio è un forte indizio per identificare nella madre una cittadina della vicina Valentia, comunità che in questa prospettiva risulterebbe dunque godere già nei decenni finali

97 Sull'onomastica di questi magistrati -tutti di origine italica-cf. Pena 1986.

98 Cf. Flor. 2.10.9.

99 Sall. Hist. 2.98.6 M. (=2.82.6 McG.); Plu. Pomp. 18.5.

100 Il centro, ascritto alla tribù Galeria, è qualificato come colonia (civium Romanorum) in Plin. HN 3.20. La deduzione, che dovette incorporare quanto rimaneva degli originari abitanti del centro, portò apparentemente alla nascita di una comunità "doppia", composta da Valentini veterani (CIL II ${ }^{2} / 14,24-26$, dell'inizio del II sec. d.C.) e Valentini veteres (menzionati congiuntamente ai primi in iscrizioni del III sec. d.C.: CIL II $2 / 14,14-19,21-22$ ) e dotata di due ordines decurionum (CIL II $2 / 14,26-27)$.

101 Pena 1989. Per una recente messa a punto della questione si veda Cadiou 2008b.

102 CIL I ${ }^{2}$ 752: L. Afr[a]nio A. f. / co(n)s(uli) / consc[r]ip(ti) et c[ol(oni)] / col(oniae) Vale[nt(inorum)].

103 Val. Max. 8.6.4. Cf. Wiseman 1971, 270, nr. 465. 
del II sec. a.C. di un diritto come lo ius conubii caratteristico, seppure in via non esclusiva, proprio delle colonie latine.

L'ipotizzato statuto coloniario di Valentia consentirebbe del resto di spiegare alcune peculiarità della sua deduzione, che distinguono il caso da tutti gli altri interventi promossi dalle autorità romane nelle province iberiche. L'oppidum -caso unico nell'ambito delle fondazioni romane della penisola-sorge apparentemente in vacuo, in una località sub-costiera strategicamente collocata in rapporto alla viabilità sia terrestre che fluviale e marittima: ${ }^{104}$ caratteri, questi ultimi, che fanno del centro l'ideale controparte settentrionale di Carteia. Questi aspetti permettono di attribuire alla deduzione specifiche finalità di controllo territoriale, pienamente in linea con quelle che informano la colonizzazione latina di tipo tradizionale: finalità cui ben si adatta la stessa marca militare del contingente coloniario, che fa di Valentia una vera e propria colonia di veterani, del tutto priva di precedenti su suolo provinciale -il caso di Italica, si è detto, ha altra natura- ma che può richiamare in certo modo l'origine "castrense" degli hybridae dedotti a Carteia.

\section{Lo ius Latii: una creazione dell'89 a.C.}

A fronte di quanto sono venuto argomentando, mi sembra ragionevole affermare che, al di fuori dei casi di Carteia e di Valentia, non si registrano altri esempi sicuri del ricorso alla colonizzazione di diritto latino tra il 180 e l'89 a.C. Entrambi i casi, come si è visto, si inquadrano perfettamente nel solco della tradizione, per quanto riguarda non solo la forma e la prassi della deduzione, ma anche le sue finalità: la dislocazione in località strategiche di contingenti coloniari -i figli di legionari e di donne iberiche a Carteia, i veterani italici della campagna contro Viriato a Valentia- legati direttamente o indirettamente alla presenza militare romana nella penisola e composti in via esclusiva da soggetti che vantavano de iure o de facto origine romano-italica.

Il fatto che Carteia e Valentia siano colonie in senso proprio induce a formulare una cruciale puntualizzazione: fino al principio del I sec. a.C., evidentemente, la chiave coloniaria latina non aveva ancora assunto il carattere di strumento funzionale alla promozione giuridica delle comunità locali. In assenza di altri precedenti, si dovrà dunque concludere che tale nuova funzione sia stata sperimentata per la prima volta proprio in relazione alla provincia della Gallia Cisalpina, nel contesto del riassetto giuridico e amministrativo dell'intera penisola attuato negli anni 90-89 a.C. Proprio questo contesto fornisce del resto la migliore giustificazione per l'elaborazione di un strumento giuridico come lo ius Latii, la cui funzione era appunto quella di favorire -grazie agli effetti combinati dello ius adipiscendae civitatis per magistratum e dello ius conubii- la graduale e controllata naturalizzazione delle élites locali.

Nel 90 a.C. il territorio della provincia risultava non solo profondamente romanizzato, ma diffusamente occupato da consistenti nuclei di cives romani: all'interno del solo settore a nord del Rubicone, erano presenti -tra coloniae (Dertona, Eporedia, Mutina, Parma) e municipia (Aquileia, Bononia, Cremona, Placentia)- ben otto comunità di diritto romano, oltre ai comparti (come quello dell'ager Ligustinus et Gallicus) popolati da coloni viritani. In questo specifico contesto territoriale, che fino ad appena un decennio prima costituiva ancora parte integrante dell'Italia, le

104 Per una sintesi del quadro archeologico e topografico si veda Ribera Lacomba - Jiménez Salvador 2012. 
previsioni della lex Iulia -che aveva escluso dalla cittadinanza i socii provinciali, ad eccezione delle sole comunità di diritto latino-avevano di fatto ingenerato una infelice disparità di trattamento che rendeva impellente l'elaborazione di una soluzione giuridica adeguata: la lex Pompeia dell'89 a.C. si configura, in questo senso, come un efficace compromesso, orientato a sanare almeno in via transitoria la questione.

La legge dovette in primo luogo prevedere la promozione a colonie latine fittizie di tutte le civitates foederatae cisalpine già strutturate in forma urbana. La concessione dello ius Latii parrebbe invece aver avuto una applicazione ancora più ampia, arrivando a coinvolgere anche quelle comunità "minori" le quali -in quanto prive di un assetto istituzionale sufficientemente definito e nel rispetto, forse, di antichi legami di dipendenza- ${ }^{105}$ vennero adtributae a centri dotati di compiuta autonomia amministrativa. ${ }^{106} \grave{E}$ quanto deve ricavarsi dalla lettura congiunta di due passi di Plinio:

Verso deinde in Italiam pectore Alpium Latini iuris Euganeae gentes, quarum oppida XXXIIII enumerat Cato. Ex iis Trumplini, venalis cum agris suis populus, dein Camunni conpluresque similes finitimis adtributi municipiis. ${ }^{107}$

Non alienum videtur hoc loco subicere inscriptionem e tropaeo Alpium, quae talis est: IMP. CAESARI DIVI FILIO AVG. PONT. MAX., IMP. XIIII, TR. POT. XVII, S.P.Q.R. QVOD EIVS DVCTV AVSPICIISQVE GENTES ALPINAE OMNES QVAE A MARI SVPERO AD INFERVM PERTINEBANT SVB IMPERIVM P.R. SVNT REDACTAE. GENTES ALPINAE DEVICTAE: TRVMPILINI, CAMVNNI, VENOSTES, VENNONETES, ISARCI, BREVNI, GENAVNES, FOCVNATES, VINDELICORVM GENTES QVATTVOR, COSVANETES, RVCINATES, LICATES, CATENATES, AMBISONTES, RVGVSCI, SVANETES, CALVCONES, BRIXENETES, LEPONTI, VBERI, NANTVATES, SEDVNI, VARAGRI, SALASSI, ACITAVONES, MEDVLLI, VCENNI, CATVRIGES, BRIGIANI, SOGIONTI, BRODIONTI, NEMALONI, EDENATES, VESVBIANI, VEAMINI, GALLITAE, TRIVLLATI, ECDINI, VERGVNNI, EGVI, TVRI, NEMATVRI, ORATELLI, NERVSI, VELAVNI, SVETRI. Non sunt adiectae Cottianae civitates $X V$, quae non fuerant hostiles, item adtributae municipiis lege Pompeia. ${ }^{108}$

Nel novero delle Euganeae gentes che godevano dello ius Latii, l'espressa menzione dei soli Trumplini e Camunni induce a distinguere sul piano degli sviluppi storico-amministrativi le vicende di queste due comunità -entrambe presenti nell'elencazione del tropaeum Alpium - da quelle dei populi "finitimis adtributi municipiis": questi ultimi dovranno nello specifico identificarsi, come assicura lo strettissimo parallelo testuale tra i due passi, con le civitates alpine "adtributae municipiis lege Pompeia" le quali, al pari delle Cottianae civitates, non figuravano tra le gentes devictae del tropaeum Alpium, evidentemente perché esterne alle aree soggiogate tra il 25 e il 14 a.C. ${ }^{109} \mathrm{Si}$ potrà pensare a comunità della fascia prealpina -in particolare quella centro-orientale- comprese entro i confini della Gallia Cisalpina fin dall'epoca di istituzione della provincia, la cui promozione giuridica e successiva adtributio

105 Analoghi a quelli ad esempio documentati, per la fine del II sec. a.C., dalla sententia Minuciorum (CIL I² 584).

106 Sulla questione si veda ora Faoro 2015, 173-182.

107 Plin. HN 3.133-134.

108 Plin. HN 3.138. Che la lex Pompeia menzionata da Plinio sia da attribuire a Pompeo Strabone e debba quindi identificarsi con la stessa legge che nell'89 a.C. portò all'istituzione delle colonie latine fittizie della Cisalpina resta a mio avviso la soluzione più semplice (pace Luraschi 1979, 189-209, che fa risalire il provvedimento pliniano ad età triumvirale-augustea).

109 Sulla conquista e la strutturazione dei distretti alpini si veda Laffi 2001 [1976]. 
ai centri vicini poterono realizzarsi, in forma contestuale, già nell' 89 a.C.: ${ }^{110}$ una soluzione estesa -in connessione o meno al riconoscimento dello ius Latii- ad ulteriori e più eccentrici settori solo ad opera di Augusto, nel quadro della ristrutturazione amministrativa del confine settentrionale dell'Italia. ${ }^{111}$

Il cardine giuridico delle promozioni ex lege Pompeia, come risulta ben chiaro già dalla stessa testimonianza di Asconio, era costituito dalla previsione concernente la concessione della cittadinanza romana a quanti avessero gerito una regolare magistratura, ${ }^{112}$ nonché -verosimilmente- ai loro figli e nipoti: ${ }^{113}$ una disposizione che in regime di conubium avrebbe portato negli anni alla progressiva naturalizzazione di fette sempre più ampie della società locale. L'evidente centralità di questa previsione induce a credere che lo ius adipiscendae civitatis per magistratum sia una autentica creazione della lex Pompeia, in quanto elemento costitutivo e caratterizzante del nuovo 'Gemeinderecht' da essa elaborato, che andava a reinterpretare, aggiornandone tanto le finalità pratiche quanto gli aspetti giuridici, il concetto stesso di Latinitas, la cui forma originaria era stata ormai cancellata dalla generalizzata promozione municipale dell'antico nomen Latinum nel 90 a.C.

Non sarà senza significato che le altre menzioni esplicite, per l'età repubblicana, di questo peculiare regime giuridico siano tutte relative a contesti storico-istituziona-

110 Nel loro novero possono ad esempio rientrare alcune comunità della regio $X-\mathrm{i}$ Farraticani nel bresciano, gli Arusnates e i Verates nel veronese, i Misquilenses nell'asolano, i Laebactes nel bellunese, gli Scaredrani nel trentino- che in età imperiale risultano costituire altrettanti pagi ormai pienamente integrati nei territoria dei centri maggiori, la cui marcata connotazione "etnica" va verosimilmente intesa come il retaggio di una originaria individualità istituzionale: su queste realtà rimando a Sisani 2011, 632-636. Un caso analogo nella regio XI-recentemente segnalatomi da Giovanni Mennella- è quello del pagus Agaminorum (CIL V 6587), nel novarese.

111 Faoro 2015, 182-197. I casi certi -oltre a quello dei Camunni e dei Trumplini, adtributi a Brixia-riguardano gli Anauni, i Sinduni e i Tulliasses, adtributi a Tridentum (cf. CIL V 5050), e i Carni e i Catali, adtributi a Tergeste (cf. CIL V 532); per contro, nel caso dei Benacenses e dei Sabini-comunità stanziate tra la riva occidentale del lago di Garda e la Val Sabbia ed entrambe assenti, a differenza dei Camunni e dei Trumplini, dall'elenco del tropaeum Alpium - nulla esclude che l'adtributio a Brixia risalga già all' 89 a.C. Relativamente alla condizione giuridica delle comunità adtributae in età augustea, non è affatto certo che il regime cui esse vennero sottoposte implicasse automaticamente la concessione dello ius Latii: i Carni e i Catali, ad esempio, furono ammessi al godimento dello ius adipiscendae civitatis per magistratum solo al tempo di Antonino Pio, attraverso un meccanismo -la cittadinanza romana è concessa in virtù dell'ingresso nella curia tergestina, previo rivestimento dell'edilità- che tra l'altro non coincide con nessuno dei modelli noti del Latium (sul punto si veda Mancini 1990, 373-374).

112 La fonte non fornisce indicazioni sull'esatto funzionamento del meccanismo (cf. Luraschi 1979, 316-325), ma possiamo ritenere che esso non differisse dalla prassi seguita in età imperiale (sulla quale si veda Mancini 1990). Nel caso dei municipia Latina di età flavia (cf. lex Irnitana, capp. 21 e 25), la cittadinanza era attributa al termine del madato unicamente a quanti, tra i membri del locale ordo decurionum, avessero gerito una magistratura ordinaria, compresa cioè tra quelle (duovirato, edilità, questura: lex Irnitana, capp. 18-20, 26-27) che da statuto dovevano essere conferite annualmente tramite elezione popolare (lex Irnitana, capp. 52-60); erano dunque esclusi dal beneficio sia i magistrati ordinari che non fossero anche decurioni, sia i praefecti nominati in sostituzione dei duoviri (lex Irnitana, capp. 24-25), nonché quanti avessero svolto eventuali munera di natura straordinaria.

113 È quanto porta a credere il confronto con il regime dello ius Latii vigente in età imperiale, secondo le informazioni ricavabili da un sintetico accenno di Gaio (Inst. 1.95: Alia causa est eorum, qui Latii iure cum liberis suis ad civitatem Romanam perveniunt: nam horum in potestate fiunt liberi), dove la menzione dei soli figli va spiegata alla luce dello specifico contesto giuridico -la normativa sullo status liberorum - in cui il richiamo è inserito, e dalle leggi municipali flavie (cf. lex Irnitana, cap. 21), che tuttavia estendono il privilegio anche a parentes e coniuges. Per l'età repubblicana, l'unica suggestione in merito è offerta dalle previsioni della lex repetundarum del 123/122 a.C. (cf. infra), dove il riconoscimento della cittadinanza romana a chi avesse sostenuto con successo una accusa in un processo de repetundis (11. 76-78) è esteso unicamente a figli e nipoti: ed è verosimilmente questo il regime recepito dalla lex Pompeia (cf. Luraschi 1979, 325-328). 
li successivi all'89 a.C. ${ }^{114}$ A fronte dell'ambigua affermazione di Asconio, che parrebbe ricomprendere lo ius adipiscendae civitatis per magistratum all'interno della somma dei diritti goduti dalle ceterae Latinae coloniae, si è invece preteso di collocarne l'introduzione già nel corso del II sec. a.C.: un postulato a favore del quale è stata invocata la presunta vigenza dell'istituto nel 123/122 a.C., secondo quanto dovrebbe ricavarsi dalle previsioni della lex Acilia repetundarum. ${ }^{115}$

La legge ${ }^{116}(11.76-79=82-85)$ dedica due capita ai premia riconosciuti ai soggetti non in possesso della cittadinanza romana che avessero sostenuto con successo una accusa in un processo de repetundis: il primo caput $(11.76-78=82-84)$ concerne il riconoscimento della civitas, il secondo caput (11. 78-79 = 84-85) il riconoscimento dello ius provocationis e della vacatio militiae, previsione quest'ultima espressamente rivolta a quanti non avessero gerito determinate magistrature in ambito locale (la dittatura, la pretura, 1'edilità). Il secondo caput è dai più inteso come l'alternativa offerta dalla legge a quanti avessero rifiutato la mutatio civitatis, in riferimento specifico al caso in cui l'accusa fosse stata sostenuta da un Latinus: in quest'ottica, l'esclusione degli ex magistrati dai suddetti riconoscimenti originerebbe unicamente dal fatto che tali soggetti già godevano della pienezza dei diritti implicati dalla civitas Romana, ottenuta in virtù dello ius adipiscendae civitatis per magistratum. ${ }^{117}$

A me pare che il dettato della legge, senza dubbio oscurato dalla grave frammentarietà del documento, si presti a tutt'altra interpretazione. Converrà partire dalla struttura testuale dei due capita, che risultano chiaramente costruiti in forma speculare: ${ }^{118}$

De ceivitate danda. ${ }^{\text {vac. }}$ Sei quis eor $[u] \underline{m}$
quei ceivis Romanus non erit ex
hace lege alteri nomen $\left[-{ }^{c} .50\right.$-adprae-
tor]em quoius ex hace lege quaestio
erit detolerit et is eo $\{$ eo $\}$ iudicio hace
lege condemnatus erit, tu $[$ m eis quei
eius nomen detolerit, quoius eorum
opera maxume is condemnatus erit,
ceivis Romanus iustus esto--- ]

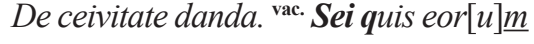
quei ceivis Romanus non erit ex tor]em quoius ex hace lege quaestio erit detolerit et is eo $\{e o\}$ iudicio hace lege condemnatus erit, tu[m eis quei eius nomen detolerit, quoius eorum ceivis Romanus iustus esto -- -]
De provocation [e vocation] eque danda. vac. Sei quis eorum quei $[-$ c. 60 - dicta]tor [[vac.]] praetor aedilisve non fuerint ad praetorem quoius ex hace lege quaestio erit [detolerit et is eo iudicio hace lege condemnatus erit, tum quei eius nomen detolerit, quoius eorum opera maxume is condemnatus erit, ei provocatio esto - - -]

A fronte di questa struttura, si può avanzare l'ipotesi che entrambi i capita concernano genericamente i non cittadini responsabili della nominis delatio, ai quali in caso di condanna dell'imputato erano riconosciuti praemia distinti sulla base del loro "rango": la civitas (e la vacatio militiae) agli accusatori -nonché ai loro figli e nipoti- che avessero gerito una magistratura in ambito locale, ${ }^{119}$ lo ius provocationis

114 Str. 4.1.12; App. BC 2.98.

115 Luraschi 1979, 301-315. Da ultimo in questo senso Kremer 2006, 113-118.

$116 \quad C I L \mathrm{I}^{2} 583$ (=RS 1).

117 Contro questa lettura si veda, giustamente, già Bradeen 1958-1959, 223-224: anche a seguire l'interpretazione tradizionale, la clausola può al più suggerire che gli ex magistrati delle colonie latine godessero dello ius provocationis, non che essi avessero ottenuto la cittadinanza romana.

118 Qui e oltre, trascrivo i due capita secondo la redazione incisa alle 11. 76-79, evidenziando in neretto le stringhe di testo leggibili nella reduplicazione di cui alle 11. 82-85.

119 La legge allude nello specifico al dictator, al praetor e all'aedilis: magistrature che la dottrina tradizionale (cf. Luraschi 1979, 305-306, nota 19) giudica caratteristiche, appunto, delle colonie latine. In realtà, il dettato del documento ha valore generico ed è volto semplicemente a richiamare, in forma cumulativa e con terminologia romana, l'insieme dei magistrati locali -superiori (il dictator nel caso di magistratura unica, il praetor nel caso di magistratura collegiale) ed inferiori (l'aedilis)-delle comunità peregrine, latine e non latine. 
e la vacatio militiae (munerisque publici in sua cuiusque civitate) ai non magistrati. ${ }^{120}$ A livello di dettato, proporrei dunque la seguente restituzione del testo, le cui integrazioni si adattano perfettamente all'ampiezza effettiva delle lacune: ${ }^{121}$

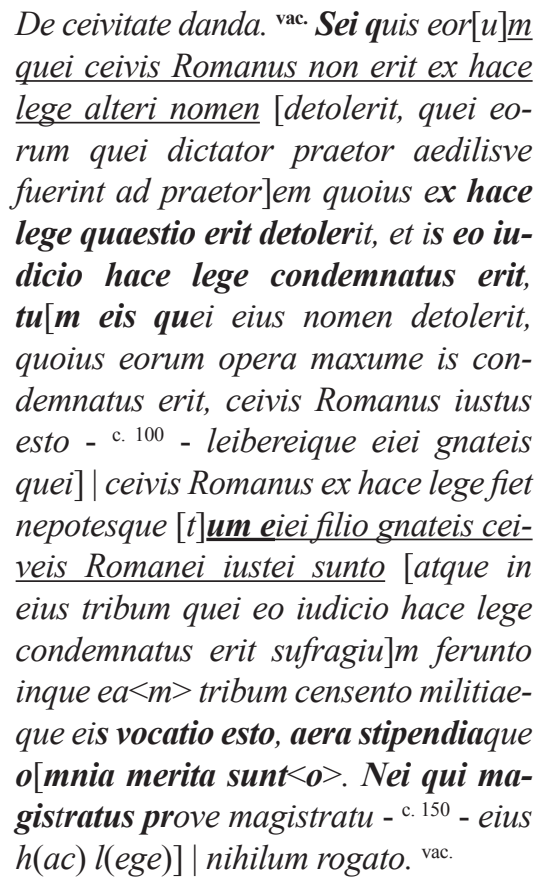

De provocation $[e$ vocation] $\underline{\text { eque }}$

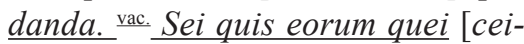
vis Romanus non erit ex hace lege alteri nomen detolerit, quei eorum quei dicta]tor praetor aedilisve non fuerint ad praetorem quoius ex hace lege quaestio erit [detolerit, et is eo iudicio hace lege condemnatus erit, tum quei eius nomen detolerit, quoius eorum opera maxume is condemnatus erit, ei provocatio esto - c. 20 - vocatioque militiae munerisve esto atque aera stipendiaque omnia merita sunto] | eius militiae munerisque poplici in su[a quoiusque cei] vitate.

Così intese, le previsioni della lex repetundarum risulterebbero in linea con quelle contenute nella rogatio de sociis del 125 a.C., che doveva essa stessa prevedere -secondo quanto si ricava dalla testimonianza di Valerio Massimo ${ }^{122}$ - un "doppio binario" per la

120 Coerentemente con questo impianto espositivo, sotto la rubrica De provocatione vocationeque danda sono inserite tre ulteriori clausole, concernenti il diritto dei beneficiari di scegliere il tribunale di Roma in caso di controversia (11. 85-87), la concessione della vacatio militiae nel caso in cui l'accusatore fosse un cittadino romano (11. 87-88), la salvaguardia dei privilegi riconosciuti ex hac lege (11. 88-89): [- - s]ei petetur, de ea re eius [optio est]o, utrum velit vel in sua ceivitat[e vel Romae - - sed fraude sua inperio inhi]bere liceto. vac. [vac. Quei cei]vis Romanus ex hace lege alte[ri nomen detolerit - - -] vac. Quoi ex h[ace lege militiae vo] catio erit esseve oporte[bit - - -]. La stessa sequenza testuale si riscontra nel fragmentum Tarentinum (CIL I $2924=R S$ 8), 11. 2-12: [- - quoiu]s eorum opera maxume is [condemnatus erit - - - in sua quoiusque ceivita] te omnium rerum [- - - vocatioque militiae mu]nerisve esto atque aera militaria stipendiaque [ei omnia merita sunto - - - in] ioudicium, Romae certet, sei Romae velet, ad quem [mag(istratum) - - - isque ma]g(istratus) ad quem de ea re aditum erit facito nei in eius [- - s]ed fraude sua inperio inhiber $<e>$ liceto. Quei ceivis [Romanus ex hace lege alteri nomen detolerit - - - ei libe]risque eius nepotibusque eo filio gnatis, quei eorum [- - - vocatio militiae munerisve esto atque aera] militaria stipendiaque eis omnia merita sunto. [Quoi ex hace lege militiae vocatio erit esseve oportebit - - -] munus faciat neive inperato neive advorsum provocationem [- - d] ucito neive facito quo invitus eat nisei tumultus Galici [Italicive causa]. Sulla natura di questa legge -senza dubbio una lex repetundarum, forse da identificare con la stessa lex Acilia del 123/122 a.C.- si veda in particolare Ferrary 1979, 108-111.

121 Sulla ricomposizione dei frammenti della tabula Bembina si veda ora Sisani 2015, 14-44.

122 Cf. Val. Max. 9.5.1: Atque ut superbia quoque et inpotentia in conspicuo ponatur, M. Fulvius Flaccus consul M. Plautii Hypsaei collega, cum perniciosissimas rei publicae leges introduceret de civitate danda et de provocatione ad populum eorum qui civitatem mutare †noluissent [codd. ALG, voluissent codd. dett.], aegre conpulsus est ut in curiam veniret: deinde partim monenti, partim oranti senatui ut incepto desisteret, responsum non dedit. Tyrannici spiritus consul haberetur, si adversus unum senatorem hoc modo se gessisset, quo Flaccus in to- 
promozione giuridica dei non cittadini, basato anche in questo caso sulla contrapposizione tra civitas e provocatio. La concessione dello ius provocationis, solitamente intesa come l'alternativa offerta a quanti avessero rifiutato la mutatio civitatis, ${ }^{123}$ doveva piuttosto configurarsi in termini di compensazione, nel quadro di un progetto che forse non contemplava -al pari della rogatio de sociis del 122 a.C. ${ }^{124}$ - una estensione generalizzata e indiscriminata della cittadinanza romana, eventualmente riservata alle sole élites alleate.

Lo ius Latii, elaborato nell'89 a.C. come strumento giuridico per la promozione delle comunità provinciali attraverso la loro trasformazione in colonie latine fittizie, conosce dunque una prima sperimentazione in relazione alla Gallia Cisalpina. Nei decenni successivi, tale soluzione giuridico-amministrativa verrà nuovamente sfruttata su larga scala da Cesare, al quale si deve -oltre alla (ri)fondazione della colonia cisal-

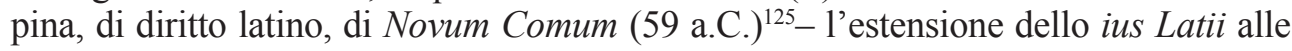
civitates peregrinae della Gallia Transalpina (49-46 a.C.) e della Sicilia (46-45 a.C.).

La presenza diffusa di comunità di diritto latino nella Narbonense è fotografata dagli elenchi pliniani, che attestano l'esistenza -a fianco delle sette coloniae (civium Romanorum) della provincia e della civitas foederata di Massilia- di trentacinque oppida Latina ${ }^{126}$ nel loro novero andranno ascritti anche i centri di Forum Iulii e Vien$n a$, fino alla deduzione in loco (rispettivamente, nel 30 a.C. circa e sotto Caligola) di due colonie di diritto romano, ${ }^{127}$ nonché le civitates Auscorum e Convenarum, ${ }^{128}$ comunità entrambe ricadenti nel territorio della provincia fino alla ridefinizione au-

tius amplissimi ordinis contemnenda maiestate versatus est. Appiano $(B C 1.86,152)$, in termini più generici, parla di concessione della civitas a tutti gli alleati (oi $\sigma u ́ \mu \mu \alpha \chi o \mathrm{\alpha} \pi \alpha v \tau \varepsilon \varsigma$ ).

123 Gabba 1973 [1954], 196-199. Questa ipotesi è chiaramente orientata dalla lezione "de civitate danda et de provocatione ad populum eorum qui civitatem mutare noluissent", che vanta il consenso dei codici primari: ma in questa forma la frase, mancante di ogni indicazione relativa ai beneficiari della datio civitatis, risulta assai male articolata, tanto da spingere alcuni editori ad emendare il testo tràdito in "de civitate $<$ Italiae $>$ danda". Sarei piuttosto dell'avviso di rivalutare la lezione "voluissent" offerta dai codici recenziori, intendendo la chiosa di Valerio Massimo come una allusione polemica alla eccessiva e perniciosa liberalità del console, che nella prospettiva dei suoi oppositori avrebbe voluto concedere la civitas (e lo ius provocationis) a chiunque lo avesse desiderato. La proposta, in ogni caso, doveva essere indirizzata a singoli individui, non a intere comunità (cf. Badian 1970-1971, 391-393).

124 App. $B C 1.99$ (cf. Plu. $C G$ 5.2, 8.3, 9.5; Vell. 2.6.2). La proposta riservava l'estensione della cittadinanza romana ai soli Latini, mentre ai restanti socii era concesso unicamente lo ius suffragii: cf. Meister 1976.

125 Luraschi 1979, 401-506.

126 Plin. HN3.32-35 (in ora): Illiberis (?), Ruscino, Agatha (?), Maritima Avaticorum (?), Antipolis; 3.36-37 (in mediterraneo): Aquae Sextiae Salluviorum, Avennio Cavarum, Apta Iulia Vulgentium, Alebaece Reiorum Apollinarium, Alba Helvorum, Augusta Tricastinorum, Anatilia, Aerea, Bormani, Comani, Cabellio, Carcasum Volcarum Tectosagum, Cessero, Carbantorate Meminorum, Caenicenses, Cambolectri Atlantici, Forum Voconi, Glanum, Libii, Lutevani Foroneronienses, Nemausus Arecomicorum, Piscinae, Ruteni, Samnagenses, Tolosani Tectosagum, Tasgoduni, Tarusconienses, Umbranici, Vocontii, Dinia. I centri di Agatha e di Maritima sono in verità qualificati da Plinio semplicemente come oppida, senza alcuna specificazione giuridica; relativamente a Illiberis, la notizia pliniana (3.32: oppida Illiberis, magnae quondam urbis tenue vestigium, Ruscino Latinorum) è ugualmente ambigua, anche a fronte della testimonianza di Pomponio Mela (2.84: colonia Ruscino, vicus Eliberrae, magnae quondam urbis et magnarum opum tenue vestigium), che qualifica il centro come semplice vicus. Nel caso di Dinia, citata da Plinio non all'interno ma a chiusura dell'elenco alfabetico degli oppida Latina dell'entroterra (3.37: Adiecit formulae Galba Imperator ex Inalpinis Avanticos atque Bodionticos, quorum oppidum Dinia), non vi è ragione di credere che il centro non rientrasse in origine entro i confini della Narbonense: la notizia pliniana dà solo conto del trasferimento sotto la sua giurisdizione, nel 68 d.C., dei cantoni alpini degli Avantici e dei Bodiontici (cf. Morabito 2010, 111-112).

127 Come tali sono menzionate da Plinio (HN 3.35-36). Forum Iulii risulta in ogni caso già esistente nel 43 a.C. (Cic. Fam. 10.15.3, 17.1), pur restando incerta la sua condizione giuridica, latina o romana. Nel caso di Vienna, l'originario status di comunità latina è denunciato dal suo assetto magistratuale, inizialmente di marca quattuorvirale (cf. Gascou 1997, 120-122).

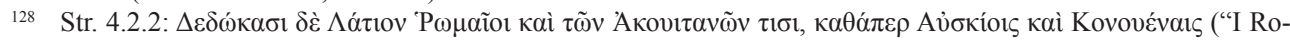
mani hanno concesso lo ius Latii anche ad alcuni degli Aquitani, come agli Ausci e ai Conveni”). 
gustea del confine con l'Aquitania. ${ }^{129}$ La promozione, come per la Cisalpina, comportò la trasformazione delle comunità beneficiarie in colonie latine fittizie, ${ }^{130} \mathrm{come}$ traspare dall'attribuzione ufficiale del titolo di colonia, direttamente documentato per almeno quattordici di questi centri. ${ }^{131}$

La cronologia pre-augustea della promozione, indiziata dalla stessa ricorrenza dell'epiteto Iulia nelle titolature coloniarie di questi centri, ${ }^{132}$ è in alcuni casi confermata dalla documentazione epigrafica e numismatica. ${ }^{133}$ La circostanza consente di collegare l'avvio della strutturazione istituzionale delle neo-promosse comunità latine alle deduzioni coloniarie curate nella Narbonense, tra il 46 e il 45 a.C., da Tiberio Claudio Nerone, di cui ci informa Suetonio. ${ }^{134}$ L'intervento potrebbe non essere stato limitato alle sole colonie di diritto romano (Narbo e Arelate), come suggerisce una ulteriore notizia trasmessa dal biografo, ${ }^{135}$ allusiva ai peculiari legami tra Nemausus e l'imperatore Tiberio forse derivanti dai rapporti clientelari allacciati dal padre du-

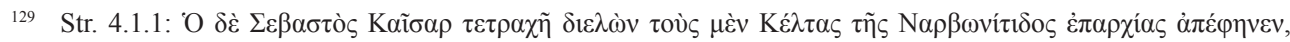

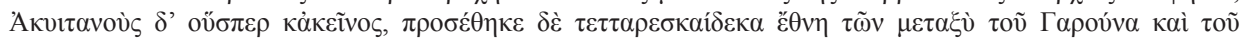

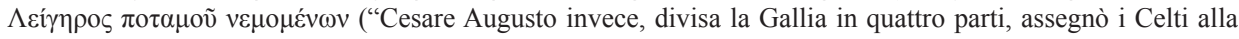
provincia Narbonsense, mentre rispettò la divisione già stabilita [da Cesare] per gli Aquitani, ai quali tuttavia ha

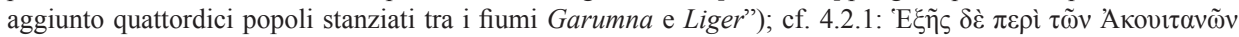

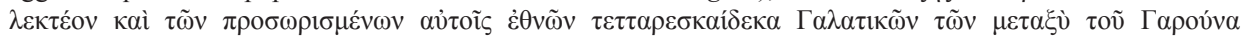

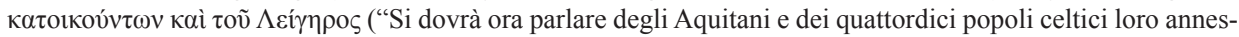
si che vivono tra Garumna e Liger"). Nella sezione dedicata al popolamento di questa regione -Str. 4.2.2: Tà $\delta \grave{\varepsilon}$

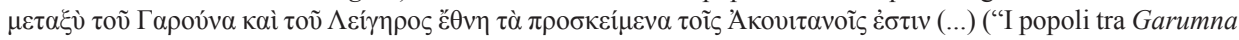
e Liger annessi agli Aquitani sono (gli Elvi, i Vellavi, gli Arverni, i Lemovici, i Petrocori, i Nitiobrigi, i Cadurci, i Biturigi Cubi, i Santoni, i Pictoni, i Ruteni, i Gabali)")- il geografo ricorda i nomi di dodici ethne di stirpe celtica, a fronte del totale dichiarato di quattordici popoli annessi all'Aquitania da Augusto: i restanti due popoli dovranno giocoforza coincidere con gli Ausci e i Conveni, menzionati in chiusura della stessa sezione quali comunità aquitane insignite dello ius Latii.

130 La definizione pliniana di oppida Latina non identifica una specifica categoria di centri, non qualificabili come coloniae o municipia, ma è solo volta ad abbracciare l'insieme delle comunità provinciali beneficiare dello ius Latii, indipendentemente dall'assetto statutario - di marca coloniale o municipale- da esse rivestito: cf. García Fernández 2001, 104-124.

131 Gascou 1991; Kremer 2006, 237-244. Le attestazioni epigrafiche e numismatiche documentano il titolo di colonia per Alebaece/Reii Apollinares, Aquae Sextiae (cf. Ptol. 2.10.8 M.), Apta Iulia, Avennio (cf. Ptol. 2.10.8 M.), Cabellio (cf. Ptol. 2.10.8 M.), Carbantorate, Carcasum, Dinia, Glanum, Lugdunum Convenarum (cf. Ptol. 2.7.13 M.), Nemausus (cf. Ptol. 2.10.6 M.), Ruscino (cf. Mela 2.84), Tolosa (cf. Ptol. 2.10.6 M.) e Vienna; a questi casi vanno forse aggiunti quelli di Maritima (colonia per Ptol. 2.10.5 M.: ma cf. Gascou 2002) e di Forum Neronis/Luteva (nell'ipotesi che la titolatura di colonia Claudia Luteva trasmessa da CIL XII 4247 discenda dalla costituzione dell'oppidum Latinum ad opera di Tiberio Claudio Nerone, e non indichi invece una successiva promozione del centro a colonia civium Romanorum in età claudia o neroniana). Almeno nel caso di Aquae Sextiae e Avennio, resta comunque il dubbio se il titolo non alluda piuttosto alla successiva promozione dei due centri a coloniae civium Romanorum, indiziata dall'adozione di assetti magistratuali di marca duovirale (cf. Gascou 1997, 101-105).

132 Christol - Heijmans 1992. La titolatura di colonia Iulia è attestata per Aquae Sextiae, Apta Iulia, Carcasum, Carbantorate, Ruscino, Vienna; allude ad una originaria promozione pre-augustea anche la titolatura "ampliata" di colonia Iulia Augusta, attestata -oltre che per la stessa Aquae Sextiae- per Avennio e per Reii Apollinares. A questi casi può essere affiancato anche quello di Vasio, capoluogo della civitas Vocontiorum, i cui abitanti parrebbero fregiarsi (cf. CIL XII 1357) del titolo di Iulienses.

133 Il titolo di colonia è già documentato intorno al 40 a.C. per Cabellio (RPC I 529), Dinia (CIL XII 6037a), Glanum (CIL XII 4379), Nemausus (RPC I 519-521) e Vienna (RPC I 517; RPCSuppl I 517a).

134 Suet. Tib. 4.1: Pater Tiberi, Nero, quaestor C. Caesaris Alexandrino bello classi praepositus, plurimum ad victoriam contulit. Quare et pontifex in locum Scipionis substitutus et ad deducendas in Galliam colonias, in quis Narbo et Arelate erant, missus est. Sulla cronologia del mandato cf. MRR II, 300.

135 Suet. Tib. 13.1: Equi quoque et armorum solitas exercitationes omisit redegitque se deposito patrio habitu ad pallium et crepidas atque in tali statu biennio fere permansit, contemptior in dies et invisior, adeo ut imagines eius et statuas Nemausenses subverterint (...). Cf. Christol - Goudineau 1987. 
rante l'espletamento del suo incarico. A questo personaggio è del resto possibile attribuire con certezza quanto meno la costituzione di un oppidum Latinum: quello di Luteva, come denuncia il poleonimo Forum Neronis che Plinio associa al centro. ${ }^{136}$ Il caso potrebbe per altro non essere isolato, a giudicare dall'attestazione, negli elenchi delle civitates narbonensi compilati da Tolomeo, di un ulteriore centro con lo stesso nome situato nell'ager Meminorum, ${ }^{137}$ apparentemente da identificare con Carbantorate.

Una precoce strutturazione è postulabile anche per altri due fora transalpini, $F_{O}$ rum Iulii (poi colonia Octavanorum, di diritto romano) e Forum Voconi, entrambi già esistenti nel maggio del 43 a.C. ${ }^{138}$ ed almeno il secondo dei quali -teste Pliniocertamente di condizione latina. Al 44-43 a.C. risale infine la nascita degli oppida Latina di Cabellio e di Antipolis, che nelle prime emissioni monetali locali si fregiano del titolo di (colonia) Lepida, ${ }^{139}$ evidentemente allusivo alla loro costituzione ad opera dell'allora governatore della provincia Marco Emilio Lepido. ${ }^{140}$

A fronte di queste indicazioni cronologiche, l'estensione dello ius Latii alle comunità della provincia andrà verosimilmente inquadrata nel contesto del riassetto territoriale e amministrativo messo in atto da Cesare all'indomani della capitolazione di Massilia nell'ottobre del 49 a.C. ${ }^{141}$ Se la sua compiuta applicazione poté richiedere una serie di interventi mirati, ${ }^{142}$ protrattisi fino almeno al 43 a.C., l'unitarietà del progetto e la paternità cesariana restano a mio avviso indubbie: è quanto suggerisce l'assoluta uniformità manifestata dalla struttura istituzionale degli oppida Latina della Narbonense, che condividono -oltre alla marca coloniale- sia l'attribuzione ad una stessa tribù (la Voltinia) ${ }^{143}$ sia l'adozione di assetti magistratuali omogenei, di marca quattuorvirale. ${ }^{144}$

Nel caso della Sicilia, ${ }^{145}$ il provvedimento - che la testimonianza di Cicerone induce a ritenere varato da Cesare non molto tempo prima della morte, e al quale verosimilmente allude anche l'ambigua notizia diodorea concernente l'estensione della

136 Plin. HN. 3.37: Lutevani qui et Foroneronienses.

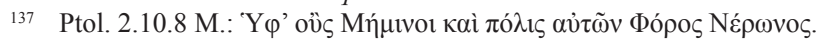

138 Cf. Cic. Fam. 10.15.3, 17.1.

$139 R P C$ I 527-528: CABE LEPI; RPC I 531-532: АNTII $\Lambda$ EПI.

140 MRR II, 326, 341-342.

141 A ciò allude, a mio avviso, una interessante notazione di Strabone relativa ad Antipolis -Str. 4.1.9: (...) $\eta^{\prime} \delta$ '

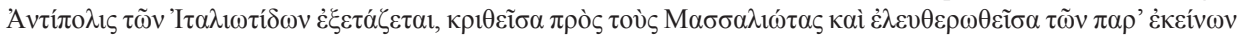
$\pi \rho \circ \tau \tau \gamma \mu \mu \alpha ́ \tau \omega v$ ("Antipolis è considerata una città italica, a seguito di un provvedimento preso contro i Massalioti che la ha resa indipendente dalla loro giurisdizione")- la cui percepita "italicità" discende forse proprio dal godimento dello ius Latii.

142 Christol 1999, 9-27.

143 Sulle tribù della Narbonense si veda da ultimo Bérard 2010.

144 Cf. ora Sisani 2018, 46-50.

145 Cic. Att. 14.12.1: Scis quam diligam Siculos et quam illam clientelam honestam iudicem. Multa illis Caesar neque me invito, etsi Latinitas erat non ferenda. Verum tamen. Ecce autem Antonius accepta grandi pecunia fixit legem a dictatore comitiis latam, qua Siculi cives Romani; cuius rei vivo illo mentio nulla. Sulla questione si veda ora Soraci 2018. Che il provvedimento cesariano abbia trovato effettiva applicazione è suggerito dall'adozione del calendario romano e dalla menzione di duoviri ( $\delta$ óo ö $v \delta \rho \varepsilon \varsigma$ ) nella serie più recente dei rendiconti finanziari epigrafici di Tauromenium (Fantasia 1999, nrr. 10-11), da datare-come implica il riferimento al mese Quinctilis (non ancora rinominato Iulius)- anteriormente al 44 a.C.: cf. Sartori 1993 [1954]. Si noti, tra 1'altro,

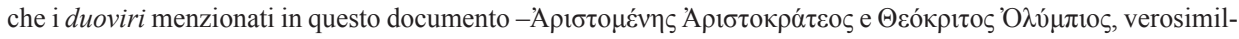
mente da identificare con gli omonimi magistrati che compongono l'ultima coppia registrata nella lista epigra-

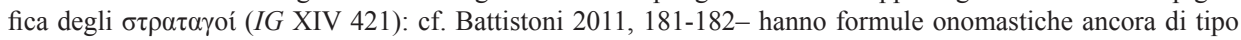
greco: un tratto pienamente coerente con la loro eventuale condizione giuridica di cives Latini. 
civitas all'intera isola ${ }^{146}$ - ebbe nei fatti vita brevissima, venendo prontamente soppiantato dalla concessione della cittadinanza romana a tutte le comunità della provincia, promossa da Antonio nell'aprile del 44 a.C. e quindi cassata, al più tardi, entro il marzo dell'anno successivo. ${ }^{147}$ Della misura cesariana resta unicamente il riflesso costituito dalla condizione latina dei centri di Centuripae, Netum e Sege$s t a,{ }^{148}$ ad essi (ri)attribuita al momento del riassetto amministrativo della provincia attuato subito dopo il 36 a.C. ${ }^{149}$ Non esistono elementi per determinare se in questa fase tali comunità abbiano statuto coloniale o municipale: il titolo di municipium è direttamente attestato per Segesta ${ }^{150}$ ma la testimonianza -come nel caso di Henna ${ }^{151}$ e di Agrigentum 152 - è forse da riferire ai concitati anni del "governo" di Sesto Pompeo (43-36 a.C.), durante i quali le comunità siceliote parrebbero avere abusivamente perpetuato l'ulteriore promozione antoniana a municipia civium Romanorum. ${ }^{153}$

Le iniziative cesariane mostrano una stretta, significativa aderenza al precedente rappresentato dalla lex Pompeia, non solo nella chiave amministrativa prescelta -quella appunto della colonizzazione fittizia- ma nella stessa strategia di applicazione: come nel caso della Cisalpina, anche i provvedimenti relativi alle comunità transalpine e siceliote si configurano come misure di portata generale, volte cioè non tanto alla promozione di singoli centri ma al globale riassetto giuridico-istituzionale di intere province. Al di fuori di queste iniziative, l'unico altro caso virtualmente certo, durante l'età repubblicana, di concessione dello ius Latii concerne la comunità iberica di Saguntum, città alleata di Roma fin dagli anni precedenti allo scoppio della seconda guerra punica, che dovette conoscere una iniziale promozione a colonia latina fittizia ad opera di Pompeo Magno.

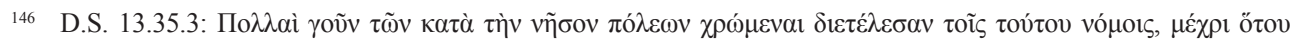

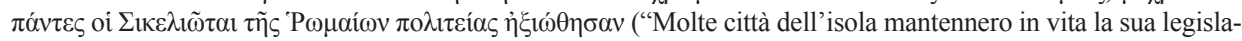

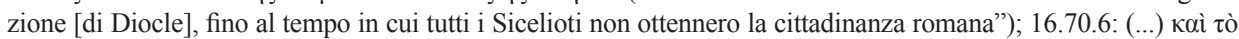

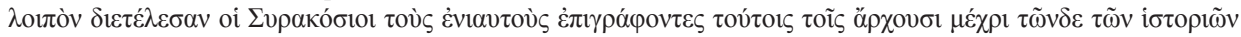

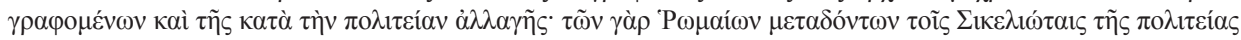

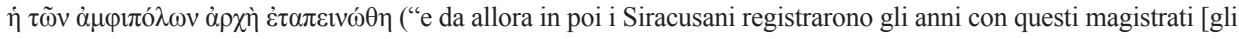
amphípoloi], fino all'epoca di composizione di queste storie e al cambiamento della forma di governo: quando infatti i Romani resero i Sicelioti partecipi della cittadinanza, la carica di amphípolos perdette prestigio"). La menzione del provvedimento in Diodoro risulterebbe coerente con la prospettiva "cesariana" dell'opera, il cui termine cronologico finale doveva porsi, nelle intenzioni dell'autore, proprio al 46-45 a.C. (D.S. 1.5.1): cf. Rubincam 1998.

147 Cic. Phil. 12.12, 13.5.

148 Qualificati come (oppida) Latinae condicionis in Plin. HN 3.91.

149 Verosimilmente nel 22-21 a.C. (cf. D.C. 54.6.1, 7.1). Sulla questione si veda da ultimo Vera 1996, 31-48, con l'ipotesi che la fonte utilizzata da Plinio nella descrizione della Sicilia sia da identificare in una "formula provinciae" redatta dopo il 36 a.C. ed aggiornata al più tardi al 14-12 a.C., quando il quadro amministrativo dell'isola doveva contemplare unicamente civitates stipendiarae, ad eccezione di cinque coloniae (Tauromenium, Catina, Syracusae, Thermae, Tyndaris), tre oppida Latinae condicionis (Centuripae, Netum, Segesta) e due oppida civium Romanorum (Messana, Lipara).

150 AE 1945, 64: C. Iulio C. f. Lon[go] / duumviro / municipium h(onoris) [c(ausa) p(osuit)]; si tratta apparentemente dello stesso magistrato che sottoscrive l'emissione monetale RPC I 649: C IVLIVS C F LONGVS II VIR EX D D, databile agli anni 44-36 a.C. (cf. Willemur 2015).

151 RPC I 661-664, a legenda MVN HENNAE.

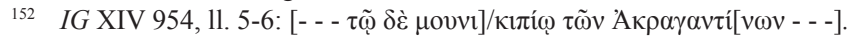

153 Nel corso dell'età imperiale documentano statuto municipale i centri di Agrigentum (AE 1966, 168; già in età augustea -tra il 2 a.C. e il 14 d.C.- il centro risulta retto da duoviri: cf. RPC I 660 e SEG XLVI 1252), Cossyra (ICos 1: 19-20 d.C.), Gaulos (CIL X 7502, 7506-7508), Halaesa (CIL X 7458: tra il 2 a.C. e il 14 d.C.; sempre ad età augustea risalgono le emissioni monetali RPC I 628-633, sottoscritte da duoviri), Haluntium (CIL X 7463-7464: tra il 12 a.C. e il 14 d.C.; IG XIV 367), Lilybaeum (CIL X 7223), Melita (CIL X 7495): in tutti i casi, è impossibile determinare se si tratti di municipia Latina o civium Romanorum. 
Negli elenchi pliniani, il centro figura tra gli oppida civium Romanorum del conventus Tarraconensis: ${ }^{154}$ notizia che dà conto dell'ormai avvenuta costituzione a $m u$ nicipium, in età triumvirale-augustea. ${ }^{155}$ L'esistenza di una precedente fase coloniaria -necessariamente latina, a fronte dei successivi sviluppi istituzionali del centro-è assicurata dalle emissioni monetali locali del tipo Roma/prora sottoscritte da coppie di magistrati che si qualificano come aediles coloniae (Saguntinorum). ${ }^{156}$ A livello cronologico, tali emissioni sono genericamente inquadrabili nei decenni centrali del I sec. a.C., secondo quanto suggerisce l'adozione di uno standard ponderale (asse di circa 17 gr) superiore a quello (asse di circa 14 gr) delle prime emissioni municipali. Sulla base di questo stesso criterio, le emissioni dichiaratamente coloniarie devono essere considerate più recenti delle prime serie locali con il tipo Roma/prora (asse di circa 20 gr): ${ }^{157}$ le serie iniziali comprendono assi e quadranti a legenda iberica ${ }^{158}$ e a legenda bilingue, ${ }^{159}$ seguite dalle emissioni sottoscritte da coppie di magistrati privi di titolatura ma con onomastica romana; ${ }^{160}$ apparentemente coeva a queste ultime è una isolata emissione con onomastica iberica ${ }^{161}$ (Fig. 4).

La precoce adozione di tipi monetali chiaramente derivati dalla zecca di Roma è senza dubbio un segnale significativo: basti riflettere sulla assoluta eccezionalità, nell'ambito delle emissioni di area iberica, del tipo della prora, adottato oltre che a Saguntum unicamente dalla zecca di Carteia, già a partire dalla fase coloniaria latina. ${ }^{162}$ Non è improbabile che l'adozione del nuovo tipo da parte della zecca saguntina risalga agli anni del bellum Sertorianum, ${ }^{163}$ durante i quali il centro appare saldamente schierato -a partire al più tardi dal 76 a.C.- sul fronte governativo: una fedeltà che valse ad alcuni esponenti della classe dirigente locale l'ottenimento della cittadinanza romana per diretta iniziativa di Cecilio Metello e di Pompeo, avallata dalla lex Gellia Cornelia del 72 a.C. ${ }^{164}$

154 Plin. $H N 3.20$.

155 Saguntum è ancora una civitas foederata nel 56 a.C. (Cic. Balb. 23); il municipium, ascritto alla tribù Galeria, risulta già costituito nel 4/3 a.C. (come si ricava da CIL II²/14, 305: Augusto / pontifici max(imo) imp(eratori) / XIIII co(n)s(uli) XII trib(unicia) / potest(ate) XV municip(es) / Saguntini). La promozione -come suggerisce la stessa ascrizione tribale- dovrà verosimilmente risalire ad età post-cesariana, dato l'orientamento pompeiano del centro durante il bellum Hispaniense (Auct. B. Hisp. 10.1; cf. Nic.Dam. Vit.Caes. 27). Al principio della fase municipale risalgono le emissioni monetali locali a legenda M SAG $(R P C$ I $200=A S$ 408-411), apparentemente da datare tra il 40 e il 20 a.C.; successive ad esse sono le emissioni sottoscritte da duoviri (RPC I 201-203=AS 416-511) e aediles ( $R P C$ I $204=A S$ 512-517), coniate durante il regno di Tiberio.

156 RPCSuppl I 199a-c (=AS 388-397); RPCSuppl I 199d (=AS 407). Cf. Ripollès - Velaza 2002; da ultimo, Amela Valverde 2011.

157 Le emissioni del tipo Roma/prora possono essere distribuite in tre fasi, databili orientativamente ante 72 a.C. (fase III), 72-30 a.C. (fase IV), età augusteo-tiberiana (fase V): cf. Ripollès 2002, 288-297.

158 AS 270-283, 333-363.

159 AS 284-316, 382.

160 AS 317-332, 364-381, 387, 398-404.

161 AS 383-386.

162 Il tipo compare inizialmente nell'emissione V (circa 110 a.C.) e perdura -in alternanza ad altri tipi, in particolare quello del delfino- fino all'emissione XVII (circa 70 a.C.).

163 L'unico elemento di cronologia assoluta è dato dal rinvenimento di alcuni esemplari delle prime emissioni saguntine del tipo Roma/prora in contesti archeologici apparentemente chiusi nel corso del bellum Sertorianum (Ripollès 2002, 288-289): la circostanza consente di datare ad epoca anteriore al 72 a.C. quanto meno gli assi ( $A S$ 270-283) e i quadranti ( $A S$ 333-363) a legenda iberica, gli assi anonimi a legenda bilingue $(A S 284-316)$ e i quadranti a legenda C A P V (AS 364-378).

164 Cic. Balb. 50-51. Sulla legge, varata ex post allo scopo di assicurare validità giuridica alle concessioni effettuate dai proconsoli durante gli anni del conflitto, si veda Periñán Gómez 2014. 
fase nrr. nominale legenda (recto) legenda (verso)

\begin{tabular}{|c|c|c|c|c|}
\hline \multirow[t]{17}{*}{ III } & $270-271$ & asse & & arse \\
\hline & $272-283$ & asse & ikoŕbeleś I balkakaltuŕ & arse \\
\hline & \multirow[t]{2}{*}{$333-362$} & quadrante & & aiubas \\
\hline & & sestante & & $\mathbf{a}$ \\
\hline & 363 & quadrante & & kai \\
\hline & \multirow[t]{2}{*}{$284-316$} & asse & SAGVNTINV & arse \\
\hline & & asse & SAGVNT & arse \\
\hline & \multirow[t]{3}{*}{$364-378$} & quadrante & & PV C A I arse \\
\hline & & quadrante & & C A PVI arse \\
\hline & & quadrante & & C AE P VA I arse \\
\hline & 317 & asse & Q VALERI I M $\underline{\underline{A E}}$ & arse \\
\hline & 318 & asse & SAGVNTINV & [M] Q C S I arse \\
\hline & $379-381$ & quadrante & & CS MQ I a \\
\hline & $319-330$ & asse & SAGVNTINV & L B M P | arse \\
\hline & $331-332$ & asse & SAGVNTINV & $\mathrm{MP} \mid$ arse \\
\hline & \multirow[t]{2}{*}{382} & quadrante & & SAGVNT \\
\hline & & sestante & SAG & VNT \\
\hline \multirow[t]{9}{*}{ IV } & $383-386$ & asse & biulakoś | balkaltuŕ & SAGV I arse \\
\hline & 387 & asse & Q POPIL | M ACIL & SAGV I arse \\
\hline & $398-401$ & quadrante & & $\underline{\mathrm{MA}} \underline{\mathrm{MB}}$ \\
\hline & $402-404$ & quadrante & & M Q \\
\hline & $405-406$ & quadrante & & M \\
\hline & 388 & asse & L AEM [-] BAE AED COL & SAGV \\
\hline & $389-390$ & asse & M AEMILI M FABI AED & SAGV \\
\hline & $391-395$ & asse & CN BAEBI GLAB L CALPVRN AED C S & SAGV \\
\hline & $396-397$ & asse & CN BAEBI L CALPVR AED COL & SAGV \\
\hline \multirow[t]{3}{*}{$\mathrm{V}$} & 407 & asse & M POP RV [-] BAEB GLOB [A]E[D COL] & SAGV \\
\hline & $408-409$ & asse & M SAG L SEMPR VETTO & L FABI POST \\
\hline & $410-411$ & asse & S M L SEMPR VETTO & L FABI POST \\
\hline
\end{tabular}

Figura 4. La zecca di Saguntum: emissioni del tipo Roma/prora.

In questo contesto andrà a mio avviso inquadrata la stessa costituzione di Saguntum a colonia latina fittizia, atta a strutturare la concessione ai suoi abitanti dello ius Latii. Relativamente alla data della promozione, è chiaro che le emissioni monetali sottoscritte da aediles coloniae forniscono unicamente un terminus ante quem, per altro non puntualmente determinabile; per contro, nulla può ricavarsi dalla testimonianza di Cicerone, che ancora nel 56 a.C. attribuisce a Saguntum la qualifica di civitas foederata, dal momento che tale definizione -come vedremo- non è affatto in contrasto con l'eventuale statuto coloniario latino del centro. In fin dei conti, risulta 
pienamente sostenibile 1'ipotesi di datare la promozione già agli anni 72-71 a.C., ${ }^{165}$ nel contesto delle misure promosse da Pompeo alla chiusura del bellum Sertorianum, che dovettero contemplare anche interventi mirati a ridefinire l'assetto di intere comunità. ${ }^{166}$

A questi stessi anni risale infatti la fondazione di Pompelo ${ }^{167} \mathrm{e}-$ al di là dei Pirenei- di Lugdunum Convenarum, ${ }^{168}$ nonché forse la stessa contributio di Osca e Calagurris. ${ }^{169} \mathrm{E}$ pur vero che nessuno di questi interventi parrebbe aver comportato alcuna forma di promozione giuridica delle comunità interessate: i Pompelonenses ancora in età augustea sono un populus stipendiarius,${ }^{170}$ mentre nel caso della civitas Convenarum l'attribuzione dello ius Latii sembrerebbe doversi datare in età cesariana, contestualmente alla strutturazione degli altri oppida Latina transalpini. ${ }^{171}$ E tuttavia, nel caso di Saguntum, la trasformazione in colonia latina potrebbe essere stata orientata non solo dalla volontà di premiare il centro per la sua fedeltà durante il bellum Sertorianum, ma anche da specifiche esigenze di amministrazione del territorio affacciato sul sinus Sucronensis.

Si è già accennato alle peculiari vicende del contermine centro di Valentia, distrutto nel 75 a.C. e la cui autonomia amministrativa parrebbe di fatto essere stata cancellata,

165 Cf., da altra prospettiva, García Fernández 2015.

166 È quanto si ricava, in termini generali, dalla testimonianza di Caes. Civ. 1.61.2-3: His paene effectis magnum in timorem Afranius Petreiusque perveniunt, ne omnino frumento pabuloque intercluderentur, quod multum Caesar equitatu valebat. Itaque constituunt ipsi locis excedere et in Celtiberiam bellum transferre. Huic consilio subfragabatur etiam illa res, quod ex duobus contrariis generibus quae superiore bello cum Sertorio steterant civitates, victae nomen atque imperium absentis <Pompei $>$ timebant, quae in amicitia manserant, magnis adfectae beneficiis eum diligebant, Caesaris autem erat in barbaris nomen obscurius. Sulle fondazioni pompeiane si vedano Amela Valverde 2000 e Olesti 2010.

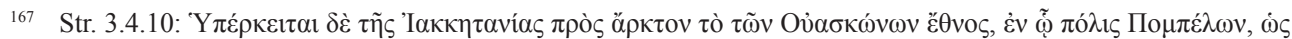

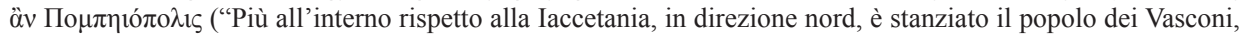
presso il quale si trova la città di Pompelo, cioè 'città di Pompeo"').

168 Hieron. adv. Vig. 4: Nimirum respondet generi suo, ut qui de latronum et Convenarum natus est semine, quos Cn. Pompeius, edomita Hispania et ad triumphum redire festinans, de Pyrenaei iugis deposuit et in unum oppidum congregavit, unde et Convenarum urbs nomen accepit; Isid. Etym. 9.2.108: Hi [i Vaccei] Pyrenaei iugis peramplam montis habitant solitudinem. Idem et Vascones (...) quos Gneus Pompeius, edomita Hispania et ad triumphum venire festinans, de Pyrenaei iugis deposuit et in unum oppidum congregavit. Unde et Convenarum urbs nomen accepit; cf. Plin. HN 4.108: in oppidum contributi Convenae. A questo intervento parrebbe alludere già Caes. Civ. 3.19.1-2: Inter bina castra Pompei atque Caesaris unum flumen tantum intererat Apsus, crebraque inter se conloquia milites habebant, neque ullum interim telum per pactiones loquentium traiciebatur. Mittit Vatinium legatum ad ripam ipsam fluminis, qui ea quae maxime ad pacem pertinere viderentur ageret, et crebro magna voce pronuntiaret, liceretne civibus ad cives legatos mittere, quod etiam fugitivis ab saltu Pyrenaeo praedonibusque licuisset, praesertim cum id agerent, ne cives cum civibus armis decertarent.

169 Caes. Civ. 1.60.1: Interim Oscenses et Calagurritani, qui erant †cum [codd., del. edd., tum Kindscher] Oscensibus contributi, mittunt ad eum legatos seseque imperata facturos pollicentur. Continuo a ritenere -con Laffi 1966, 117-119, e nonostante le perplessità ultimamente avanzate da Andreu Pintado - Jordán Lorenzo 2007, 240 - che il testo documenti una fase di fusione amministrativa di Osca e Calagurris: non vedo infatti quale altra ragione possa giustificare la notazione cesariana, evidentemente orientata dalla volontà di spiegare la motivazione giuridica per l'invio di legati che agivano in rappresentanza di entrambi i centri. Se questo è il caso, a fronte del profondo coinvolgimento dell'area nel bellum Sertorianum (Artica Rubio 2009) e a prescindere dall'identificazione della Calagurris in questione con la Nasica o la Fibularia, è più che probabile che l'intervento di contributio si inserisca nel processo di pacificazione messo in atto dal governo romano dopo la conclusione del conflitto.

170 Plin. $H N 3.24$.

171 Ne sono indizio sia l'ascrizione della comunità alla tribù Voltinia, sia l'assetto magistratuale locale di marca quattuorvirale (ILTG 76, 78): entrambi caratteri comuni alle colonie latine fittizie della Narbonense. 
fino alla deduzione della colonia triumvirale-augustea. ${ }^{172}$ Non si hanno purtroppo informazioni relative al destino inizialmente subito dagli abitanti superstiti, di cui resta incerto lo stesso status giuridico, se quello di cives Romani-nell'ipotesi che, al pari di Carteia, la colonia latina dedotta nel 138 a.C. sia stata trasformata in municipium in virtù della lex Iulia del 90 a.C.- o di Latini: nel qual caso si potrebbe pensare che sulla mancata (o eventualmente revocata) promozione abbia pesato proprio l'appoggio dato dalla città a Sertorio. ${ }^{173}$ Certo è che, in questo contesto territoriale, la scelta di istituire già nel 72/71 a.C. una nuova comunità di diritto latino a ridosso di Valentia appare pienamente logica, finendo per ricostituire in termini istituzionali, tramite il semplice spostamento a Saguntum del baricentro amministrativo dell'area, lo status quo ante.

$\mathrm{Al}$ di là delle ipotesi relative all'epoca e alle ragioni della sua costituzione, la colonia latina fittizia di Saguntum è certamente una realtà storica, della quale è opportuno rimarcare l'apparente eccezionalità nell'ambito delle province iberiche, ${ }^{174}$ dove le fonti documentarie non registrano ulteriori esempi di attribuzione dello ius Latii alle comunità locali anteriormente all'età triumvirale-augustea. La circostanza non ha impedito di postulare una più estesa applicazione della prassi, segnatamente in relazione agli oppida Latinorum veterum identificati negli elenchi pliniani da cognomina "cesariani", ${ }^{175}$ che ne denuncerebbero la creazione ad opera dello stesso Cesare. ${ }^{176}$

L'ipotesi -anche a fronte dell'ambiguità di tutte queste titolature, che potrebbero piuttosto risalire ad età triumvirale, se non augustea- è a mio avviso tutt'altro che pacifica, ed anzi si scontra con un argomento che ritengo dirimente: lo statuto certamente municipale rivestito durante l'età imperiale da almeno alcuni di questi centri, ${ }^{177}$ nessuno dei quali in ogni caso documenta veste coloniaria. A meno di non intendere questi casi come l'esito di una sopravvenuta promozione a municipia civium Romanorum, l'eventuale condizione originaria di municipia Latina spinge a datare la concessione dello ius Latii a tali comunità in età post-cesariana: ${ }^{178}$ ipotesi che per altro trova conferma nella stessa frequenza, in questo gruppo, di centri ascritti alla

172 Il centro non risulta ad esempio menzionato da Strabone, che pure illustra con dovizia di dettagli -tratti da una fonte certamente posteriore al 71 a.C., dal momento che si fa menzione dei trofei di Pompeo- il percorso della via tracciata tra i Pirenei e Gades (Str. 3.4.9): le uniche città ricordate dal geografo all'altezza del sinus Sucronensis sono Saguntum e Saetabis. Per contro, la menzione di Valentia in Pomponio Mela (2.92) deriva da una fonte che descrive la situazione della penisola iberica già degli anni 19-12 a.C. (cf. Silberman 1988, xl-xli).

173 Il caso potrebbe richiamare l'ademptio civitatis dei Volaterrani e degli Arretini, apparentemente retrocessi da Silla, a causa dell'orientamento mariano delle due comunità, nella condizione giuridica di Latini: cf. Luraschi 1979, 281-299, e da ultimo Firpo 2009, 91-103.

174 Nel caso di Carthago Nova, se è pure possibile che la deduzione coloniaria debba essere retrodatata agli anni Cinquanta del I sec. a.C. (Abascal Palazón 2002), nulla prova che essa sia stata inizialmente fondata come colonia latina e non già come colonia romana: su questa deduzione si veda da ultimo Amela Valverde 2014-2015.

175 Baetica (Plin. HN 3.7-17): Artigi Iulienses, Carisa Aurelia, Iliturgi Forum Iulium, Lacimurga Constantia Iulia, Lucurgentum Iulii Genius, Nertobriga Concordia Iulia, Osset Iulia Constantia, Segida Restituta Iulia, Seria Fama Iulia, Sexi Firmum Iulium, Ugultunia Contributa Iulia, Urgia Castrum Iulium Caesaris Salutariensis. Hispania Citerior (Plin. HN 3.18-29): Castulo Caesariorum Iuvenalium, Ceretani Iuliani, Teari Iulienses. Lusitania (Plin. HN 4.113-118): Ebora Liberalitas Iulia, Myrtilis Iulia (cf. Ptol. 2.5.4 M.).

176 Henderson 1942; González Fernández 1984.

177 Castulo (CILA 6, 91; 99; 104; IRPL 88), Ebora (IRCP 241, 373a-b), Myrtilis (IRCP 9, 96), Nertobriga (HEp 7, 1997, 71), Osset (CILA 3, 586-587), Ugultunia (CIL II 1025).

178 Cronologia verso cui orientano, in alcuni casi, le emissioni monetali locali riferibili alla fase stessa della promozione, che consentono di circoscrivere all'età triumvirale (forse già intorno al 40 a.C.) e all'età augustea, rispettivamente, l'attribuzione dello ius Latii a Sexi (RPCSuppl I 123: F i SEXs) e a Ebora (RPC I 50-51: LIBERALITATIS IVLIAE EBOR). Una promozione in età triumvirale è postulabile anche per Carisa, il cui poleonimo figura già nella forma completa di cognomen-Aurelia Cariss(a) - nel catasto di Ilici $\left(\operatorname{IRILAD}{ }^{2} 12=\right.$ ELRH C1). 
tribù Galeria, ${ }^{179}$ secondo il ricorso più atteso nel caso di promozioni risalenti ad età triumvirale-augustea. Per salvare la paternità cesariana di tali promozioni occorrerebbe per contro postulare una successiva trasformazione delle originarie colonie latine fittizie in municipia Latina: ${ }^{180}$ ma non si intendono francamente le ragioni e le finalità di una simile modifica di status, del tutto priva di paralleli ed anzi in aperto contrasto con le scelte adottate ad esempio nel caso degli oppida Latina della Narbonense, che conservano statuto coloniario anche durante l'età imperiale.

In termini più generali, la stessa attribuzione a Cesare di un esteso piano di promozione giuridica delle comunità iberiche risulta difficilmente conciliabile con la politica attuata in quest'area dal dittatore, ${ }^{181}$ in particolare dopo la conclusione del bellum Hispaniense. Nel 45 a.C., a prestar fede alla puntuale illustrazione di Cassio Dione, ${ }^{182}$ Cesare dovette procedere almeno nella Ulteriore ad una dura repressione nei confronti delle numerose comunità che avevano dato appoggio ai figli di Pompeo, tradottasi in confische territoriali, aumento dei tributi e deduzioni coloniarie a beneficio dei veterani: le uniche promozioni riguardarono quanti gli erano rimasti fedeli, i quali si videro ricompensati con l'assegnazione di terre e in alcuni casi con la concessione della cittadinanza romana. ${ }^{183}$ Tali promozioni dovettero quasi certamente riguardare singoli individui, piuttosto che intere comunità. ${ }^{184}$ Sono indicative, in questo senso, le vicende istituzionali di Ulia e di Obulco, tra le pochissime comunità cesariane della Ulteriore, ${ }^{185}$ la cui elevazione a municipia -verosimilmente di diritto latino- parrebbe realizzarsi solo nel corso dell'età augustea. ${ }^{186}$

179 Carisa, Castulo, Ebora, Iliturgi, Myrtilis, Nertobriga, Osset, Segida, Seria, Sexi, Ugultunia, Urgia: si tratta, di fatto, della totalità dei centri con cognomina "cesariani”" di cui è nota l'ascrizione tribale.

180 È questa la prospettiva da cui muovono, in chiave generale, García Fernández (2009a; 2009b) ed Espinosa Espinosa $(2014 ; 2016)$.

181 Brunt 1987, 584-588.

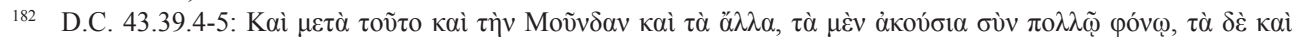

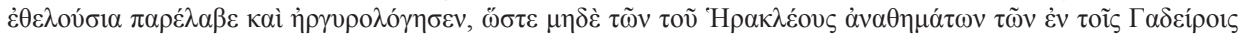

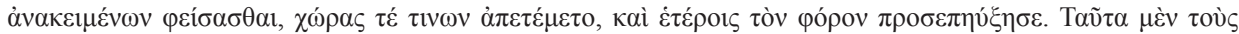

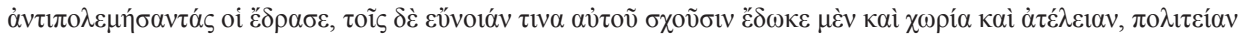

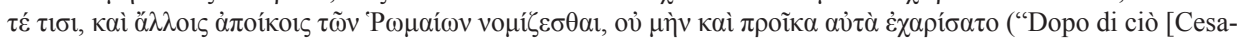
re] occupò Munda e le altre città, alcune contro la loro volontà con grande strage, altre con il loro consenso; ad esse impose il pagamento di riscatti, tanto che non risparmiò neppure gli ex-voto di Eracle che si trovavano a Gades, e ad alcune confiscò porzioni di territorio, ad altre impose aumenti di tributi. In questo modo si comportò con coloro che lo avevano combattuto; a quelli invece che lo avevano accolto favorevolmente diede terre ed esenzione dai tributi, e ad alcuni anche la cittadinanza, ad altri concesse il diritto di considerarsi coloni di Roma, ma anche questa concessione non avvenne gratuitamente"). La testimonianza dello storico è in linea con quanto implicato dal discorso tenuto da Cesare a Hispalis al termine della campagna di Munda (Auct. B. Hisp. 42).

183 Su questi interventi si veda da ultimo Amela Valverde 2016a.

184 Nel caso ad esempio di Emporiae, la testimonianza liviana -Liv. 34.9.1-3: Iam tunc Emporiae duo oppida erant muro divisa. Uno Graeci habebant, a Phocaea unde et Massilienses oriundi, alterum Hispani (...) Tertium genus Romani coloni ab divo Caesare post devictos Pompei liberos adiecti. Nunc in corpus unum confusi omnes, Hispanis prius, postremo et Graecis in civitatem Romanam adscitis- permette di istituire una chiara distinzione cronologica tra l'istallazione di coloni romani nel 45-44 a.C. e la successiva promozione delle due comunità locali, realizzatasi al più presto nel corso dell'età triumvirale e preliminare alla riunificazione amministrativa del centro, ora costituito a municipium civium Romanorum (Plin. HN 3.22; RPC I 234): su queste vicende si vedano da ultimi Pena 1992 e Amela Valverde 2015.

185 Ulia: Auct. B. Hisp. 3.1-3; D.C. 43.31.4. Obulco: Str. 3.4.9.

186 È quanto suggeriscono l'ascrizione alla tribù Galeria e l'assetto magistratuale di marca duovirale, comuni a entrambe le comunità. Nel caso di Ulia, la cui fedeltà valse al centro l'appellativo di Fidentia (Plin. HN 3.10), un terminus post quem per la promozione -già realizzatasi entro il 4 d.C. (come si ricava da $C I L \mathrm{II}^{2} / 5$, 495 , relativa ad un praefectus pro duoviro C. Caesaris)- è forse offerto dal catasto di Ilici $($ IRILAD $12=E L R H \mathrm{C} 1)$, dove il poleonimo figura, a differenza di quello di Aurelia Carissa, ancora privo di cognomen. 
Per contro, le attitudini senza dubbio più miti manifestate da Cesare alla conclusione della campagna del 49 a.C. non sembra abbiano dato luogo a significativi riassetti amministrativi in ambito locale. Il solo caso certo è -come è noto- quello di Gades ${ }^{187}$ la cui promozione si tradusse per altro nella costituzione del centro non già a oppidum Latinum ma a municipium civium Romanorum. ${ }^{188}$

Nulla dunque porta a credere che in età cesariana si sia proceduto ad una sistematica attribuzione dello ius Latii alle comunità iberiche: un processo il quale -tolto il precedente pompeiano di Saguntum - dovette di fatto prendere avvio al più presto nel corso dell'età triumvirale. La paternità augustea dei cinquantuno oppida iberici che Plinio dichiara Latio antiquitus donata ${ }^{189}$ contribuirebbe per altro a giustificare il giudizio espresso al principio dell'età tiberiana da Strabone in relazione ai Turdetani:

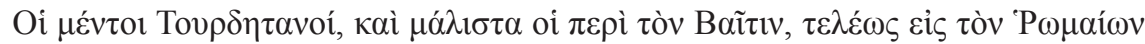

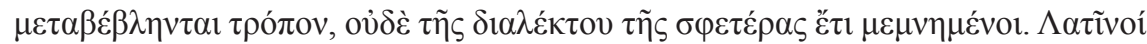

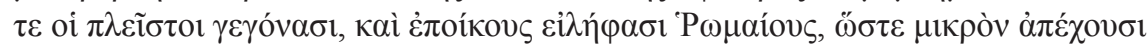

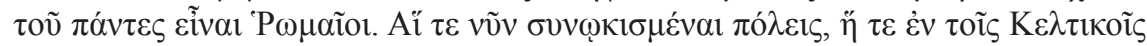

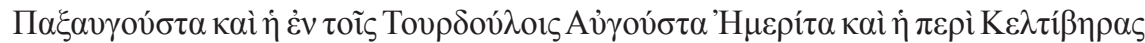

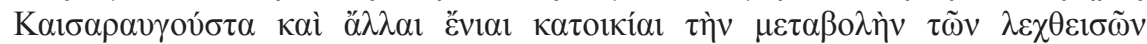

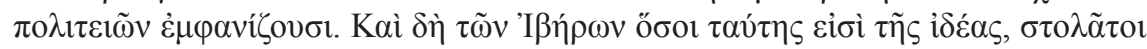

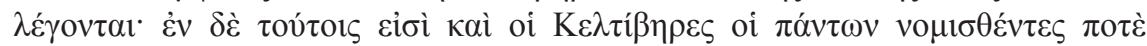
$\theta \eta \rho 1 \omega \delta \varepsilon ́ \sigma \tau \alpha \tau \mathrm{ol} .{ }^{190}$

Il geografo registra puntualmente la grande diffusione dello ius Latii tra le comunità della Betica, dove infatti gli elenchi pliniani attestano l'esistenza di ben ventotto oppida Latina, dodici dei quali identificati da cognomina "cesariani". La loro even-

187 Liv. Per. 110.2; D.C. 41.24.1.

188 In questo stesso contesto è forse da collocare anche la nascita dei municipia civium Romanorum di Italica e di Carmo: comunità entrambe fedeli a Cesare nel 49 a.C. (Caes. BC 2.19.4 e 20.6; per Carmo cf., in relazione ai fatti del 48 a.C., Auct. B. Alex. 57.2-3 e 64.1), almeno la prima delle quali parrebbe aver mantenuto lo stesso atteggiamento anche nel 45 a.C. (cf. Auct. B. Hisp. 25.4). Nel caso di Italica-a prescindere dalle suggestioni offerte dalla menzione, già nel 48 a.C., di municipes Italicenses (Auct. B. Alex. 52.4)- la paternità cesariana della promozione è in particolare denunciata dalla ascrizione del centro alla tribù Sergia; per quanto riguarda Carmo, la cronologia pre-augustea del municipium è suggerita dall'assetto magistratuale, di marca quattuorvirale. Sui due casi -e su quelli, problematici, di Asido e di Ceret-torno in Sisani 2018, 50-60.

189 Plin. HN 3.7 (Baetica): (oppida) Latio antiquitus donata XXIIX; 3.18 (Hispania Citerior): (oppida) Latinorum veterum XVIII; 3.77 (insulae): (oppida) Latina Guium et Tucis; 4.117 (Lusitania): (oppida) Latii antiqui III. Per quanto riguarda il numero degli oppida Latina della Baetica, i codici presentano diverse lezioni: XXU.X (cod. A), XXIIX (codd. DFR $\left.{ }^{1} E a d\right), X X I I$ (cod. $\left.\mathrm{R}^{2}\right), X X I X$ (cod. 1), emendate dal Detlefsen in XXVII. Sarei piuttosto dell'avviso di accogliere la lezione $X X I I X(=X X V I I I)$ presente nella maggior parte dei codici, alla quale possono essere agevolmente ricondotte tutte le altre rese. Nel calcolo finale, presuppongo come è chiaro che i due oppida Latina delle Baleari non siano conteggiati da Plinio tra i diciotto dichiarati per l'Hispania Citerior, come pare doversi ricavare da Plin. HN 3.18: Nunc universa provincia dividitur in conventus VII (...) Accedunt insulae, quarum mentione seposita. Civitates provincia ipsa praeter contributas aliis CCXCIII continet; cf. 3.25: Carthaginem conveniunt populi LXV exceptis insularum incolis. Sul tema mi riservo di tornare in un prossimo contributo.

190 Str. 3.2.15: "I Turdetani, in particolare quelli stanziati lungo il Baetis, hanno completamente modellato i propri costumi su quelli dei Romani, tanto da non ricordare più la propria lingua. Per la maggior parte sono diventati Latini, e hanno accolto coloni romani, cosicché per poco non sono diventati tutti Romani. Le città di recente costituzione -Pax Augusta tra i Celti, Augusta Emerita tra i Turduli, Caesaraugusta presso i Celtiberi, e altre colonie ancora- mostrano chiaramente il cambiamento dei costumi politici adottati. E quelli tra gli Iberi che hanno scelto tale stile di vita, li chiamano stolati: tra questi ci sono anche i Celtiberi, un tempo considerati i più selvaggi di tutti”. Su questo passo si veda la dettagliata analisi di Canto 2001. 
tuale attribuzione a Cesare appare tuttavia in contrasto con la prospettiva cronologica di Strabone, che attraverso il collegamento con le deduzioni coloniarie -Pax (Iulia) Augusta, Augusta Emerita, Caesaraugusta- dell'ultimo quarto del I sec. a.C. parrebbe implicitamente proiettare tale rivoluzione amministrativa proprio in età augustea. L'ampio ricorso da parte di Augusto alla chiave latina nella promozione giuridica delle comunità locali è del resto esplicitamente attestato, in termini più generali, da Suetonio:

Urbium quasdam, foederatas sed ad exitium licentia praecipites, libertate privavit, alias aut aere alieno laborantis levavit aut terrae motu subversas denuo condidit aut merita erga populum Romanum adlegantes Latinitate vel civitate donavit. ${ }^{191}$

Non si vede dove altro, se non appunto nelle province iberiche, Augusto possa aver esercitato questo ricorso su scala tale da giustificarne la pur generica menzione da parte del biografo. Tolto il caso delle comunità narbonensi, già promosse in età cesariana, ${ }^{192}$ l'unico altro settore per il quale Plinio registra una significativa diffusione dello ius Latii è quello dei distretti alpini, ${ }^{193}$ dove tuttavia la promozione risale quasi certamente ad età post-augustea. ${ }^{194}$ Relativamente agli oppida Latina delle

191 Suet. Aug. 47.

192 Nella Narbonense l'unico oppidum Latinum strutturato ex novo nel corso dell'età augustea parrebbe essere, a giudicare dal poleonimo, quello di Augusta Tricastinorum: ma l'urbanizzazione del caput gentis non deve necessariamente coincidere, in termini cronologici, con l'attribuzione dello ius Latii ai Tricastini, da datare in età cesariana (si veda in merito, a partire dai dati contenuti nel catasto B di Orange, Christol 2006). Allo stesso modo, nel caso di Lucus Augusti, l'intervento augusteo dovette comportare unicamente la creazione di un nuovo centro di aggregazione - a connotazione eminentemente sacrale- nell'ambito della civitas Vocontiorum, il cui polo propriamente amministrativo è da identificare in Vasio (cf. Mela 2.75 e Ptol. 2.10.8 M.). Resta incerto a quando risalga la promozione della civitas Auscorum, certamente posteriore al 56 a.C. (cf. Caes. Gal. 3.27) ma già realizzatasi entro l'età augusteo-tiberiana (Str. 4.2.2): la capitale del distretto si fregia, a partire almeno da una certa epoca, del titolo di Augusta (Ptol. 2.7.11 M.), ignorato tuttavia sia da Pomponio Mela (3.20: Eliumberrum) sia dagli itineraria (itin. Ant. 462.6: Climberrum; tab. Peut. 2.30: Eliberre; itin. Hier. 550.8: civitas Auscius). Negli altri casi Augusto si limiterà a confermare lo status quo ante, in particolare per quanto riguarda la natura coloniaria degli oppida precedentemente istituiti: a ciò allude la nuova titolatura -colonia (Iulia) Augusta- assunta in questo contesto da alcune comunità (Alba, Aquae Sextiae, Avennio, Nemausus, Reii Apollinares).

193 Plin. HN 3.135: Sunt praeterea Latio donati incolae, ut Octodurenses et finitimi Ceutrones, Cottianae civitates et Turi Liguribus orti, Bagienni Ligures et qui Montani vocantur Capillatorumque plura genera ad confinium Ligustici maris; cf. 3.47: Alpes populique Inalpini multis nominibus, sed maxime Capillati oppido Vediantiorum civitatis Cemenelo. Plinio riunisce in un unico blocco le comunità latine delle Alpes Graiae et Poeninae (Octodurenses, Ceutrones), Cottiae (Cottianae civitates) e Maritimae (Turi, Bagienni Ligures, Bagienni Montani, Capillati). Sul popolamento di questi distretti cf. Str. 4.6.6.

194 Laffi 2001 [1976]; Weber 1991; Kremer 2006, 181-185. Almeno le comunità delle Alpes Maritimae ottennero lo ius Latii solo nel 63 d.C. (Tac. Ann. 15.32: Eodem anno Caesar nationes Alpium maritimarum in ius Latii transtulit): unicamente nel caso di Cemenelum -la sola comunità del distretto a risultare ascritta alla tribù Claudia- si può prospettare una più precoce promozione, sotto Claudio (cf. Morabito 2010, 102-104). Sempre a Nerone si deve forse la generalizzata promozione delle comunità delle Alpes Cottiae, come suggerisce la loro ascrizione alla tribù Quirina: la misura poté essere varata contestualmente alla redactio in formam provinciae del distretto nel 66 d.C. Nel caso delle Alpes Graiae et Poeninae, la promozione potrebbe invece risalire a Claudio, a giudicare dai poleonimi assunti dai capoluoghi degli Octodurenses e dei Ceutrones: Forum Claudii (Augusti) Vallensium Octodurus e Forum Claudii Ceutronum Axima. Resta incerto a quando risalga la promozione dei Camunni e dei Trumplini (Plin. HN 3.133-134), in ogni caso successiva al loro assoggettamento nel 16 a.C.: la misura va forse attribuita ad età neroniana o ad età flavia (cf. Gregori 2012, 111-119). Per quanto riguarda infine gli oppida (Latina?) del Norico (Plin. HN 3.146), cinque (Virunum, Celeia, Teurnia, Aguntum, Iuvaum) si datano al regno di Claudio, uno (Solva) a quello dei Flavi. 
province africane, quelli della Mauretania -Arsennaria e Tipasa, forse Icosium $^{195}$ risalgono con certezza o probabilità ad età claudia o vespasianea; solo per Uzalis, ${ }^{196}$ nella Proconsolare, è prospettabile una promozione precoce, eventualmente di età triumvirale o augustea. Nel caso infine della Sicilia, lo ius Latii nuovamente riconosciuto a Centuripae, Netum e Segesta ${ }^{197}$ dopo il 36 a.C. si configura, di fatto, nei termini di semplice riconferma di una condizione giuridica già sancita da Cesare.

A fronte di questo quadro, mi sembra ragionevole concludere che nelle province iberiche la diffusa attribuzione dello ius Latii alle comunità locali, che sotto Vespasiano acquisirà carattere globale, è sì un fenomeno precoce rispetto ad altre aree ma parrebbe prendere avvio solo nel corso dei decenni finali del I sec. a.C. Il bisogno avvertito da Plinio di registrare, in relazione a queste sole province, l'antiquitas degli oppida Latina ivi presenti non discende da presunte peculiarità storico-istituzionali della Latinitas goduta da questi centri: ${ }^{198}$ esso tradisce piuttosto la volontà dell'autore -già procuratore imperiale nella Tarraconense tra il 72 e il 74 d.C., ${ }^{199}$ che ben conosceva la rivoluzione giuridica prodotta nell'universa Hispania dall'editto promulgato da Vespasiano nei primissimi anni del suo regno ${ }^{200}$ - di rimarcare il carattere di vero e proprio precedente rappresentato dalla politica promossa in questi stessi territori già da Augusto, e nel contempo di segnalare ai suoi lettori il mancato aggiornamento delle fonti ufficiali (i “digesti provinciali” augustei) da lui utilizzate. ${ }^{201}$

\section{Latinitas senza conubium: i municipia Latina e la lex Minicia}

La politica augustea segna non solo la rinnovata diffusione su larga scala dello ius Latii, ma anche una vera e propria riforma dell'istituto, sperimentata proprio in relazione alla promozione giuridica delle comunità iberiche. Fino a Cesare, il nuovo Latium aveva sempre assunto -così in area cisalpina, transalpina e iberica (Saguntum): il caso siceliota resta, come si è detto, sub iudice-connotati coloniari, in piena

195 Plin. HN 5.19: Arsennaria Latinorum; 5.20: Caesarea (...) a divo Claudio coloniae iure donata, eiusdem iussu deductis veteranis Oppidum Novum et Latio dato Tipasa, itemque a Vespasiano imperatore eodem munere donatum Icosium. Nel caso di Icosium, la notizia pliniana -piuttosto che documentare l'attribuzione dello ius Latii- è forse da leggere in parallelo alla precedente menzione dello ius coloniae concesso da Claudio a Caesarea, e dunque da intedere come un riferimento alla promozione del centro a colonia civium Romanorum (cf. CIL VIII 20853). Su tutti questi casi si veda Gascou 1982, 156-161.

196 Plin. HN 5.29: oppidum Latinum unum Uzalitanum. Cf. Gascou 1982, 142.

197 Plin. $H N 3.91$.

198 Come proposto da García Fernández (2009a; 2009b) e da Espinosa Espinosa (2014; 2016), per i quali i centri identificati negli elenchi pliniani come oppida Latinorum veterum coinciderebbero tutti con originarie colonie latine pre-augustee: e tuttavia, a seguire questa prospettiva, si giungerebbe alla paradossale conclusione che nelle province iberiche -tolto eventualmente il caso di Guium e Tucis, le uniche comunità classificate da Plinio (HN 3.77) semplicemente come oppida Latina- Augusto non avrebbe effettuato alcuna nuova concessione dello ius Latii, limitandosi a convertire in municipia Latina le colonie latine di più antica promozione.

199 Syme 1979 [1968].

200 Cf. Plin. HN 3.30: Universae Hispaniae Vespasianus imperator Augustus iactatum procellis rei publicae Latium tribuit.

201 Sulla natura di questi documenti si veda Nicolet 1989, 207-225. Nell'illustrazione pliniana delle province iberiche, gli interventi volti ad aggiornare i dati istituzionali tratti dalle fonti augustee sono di fatto rarissimi: per quanto riguarda gli elenchi ragionati di comunità cf. Plin. HN 3.14: Contributa Iulia Ugultuniae, cum qua et Curiga nunc est; 3.18: Nunc universa provincia [1'Hispania Citerior] dividitur in conventus VII; 4.110: Amanum portus, ubi nunc Flaviobrica colonia; per quanto riguarda i commentarii di Agrippa cf. Plin. HN 3.17: Baeticae longitudo nunc a Castulonis oppidi fine (...). 
aderenza ai principi introdotti dalla lex Pompeia, elaborata in un contesto storico in cui il diritto latino era evidentemente ancora percepito come una condizione inscindibile dalla pratica della colonizzazione, reale o fittizia che fosse. Con Augusto, gli oppida Latio donata di nuova costituzione assumono invece veste municipale: ${ }^{202}$ una struttura istituzionale, quella del municipium Latinum, ${ }^{203}$ che conosce la sua prima applicazione appunto nelle province iberiche e alla quale parrebbero adeguarsi tutte le attribuzioni dello ius Latii susseguitesi nel corso dell'età imperiale. ${ }^{204}$

Non è facile - a fronte dell' assoluto silenzio delle fonti-formulare ipotesi concrete sulle ragioni di questa riforma, che in ogni caso non possono ridursi a questione meramente nominalistica: l'alternativa tra forma coloniaria e forma municipale parrebbe piuttosto avere carattere sostanziale, in primo luogo sul piano del diritto pubblico, per quanto attiene in particolare alla base giuridica del rapporto che legava Roma alle comunità locali.

La formula elaborata dalla lex Pompeia, si è detto, è chiaramente ispirata ai principi della colonizzazione latina tradizionale, che all'epoca rappresentava l'unico possibile modello di riferimento per un provvedimento il quale, nella sostanza, mirava ad estendere alle civitates peregrinae della Cisalpina l'insieme dei diritti goduti fino al 90 a.C. dall'intero nomen Latinum. Quest'ultimo, come è noto, raggruppava comunità formalmente sovrane: i socii nominis Latini, legati a Roma da trattati di alleanza la cui struttura perpetuava negli aspetti fondanti le clausole del vecchio foedus Cassianum. ${ }^{205}$ Alcune testimonianze portano a credere che anche le colonie latine fittizie istituite tra 1'89 a.C. e l'età cesariana fossero, tecnicamente, civitates foederatae.

È quanto può ricavarsi, in primo luogo, dal dettato del fragmentum Atestinum, ${ }^{206}$ che trasmette due clausole di una legge del 48 a.C., varata allo scopo di ridefinire le competenze dei tribunali locali della Cisalpina all'indomani della concessione -sancita, nello stesso anno, dalla lex Roscia- della cittadinanza romana alle colonie latine fittizie della provincia, contestualmente promosse a municipia civium Romanorum. ${ }^{207}$

202 García Fernández 2001, 73-124.

203 Locuzione direttamente attestata dalla lex Irnitana (cap. 30), ma già implicitamente presente nella tabula Siarensis (RS 37), fr. b, col. I, 11. 7-8: neve quid eo die rei seriae publice agere [liceret mag(istratibus) p(opuli) R(omani) iisque qui i(ure) d(icundo) p(raerunt) in] municipio aut colonia, c(ivium) R(omanorum) aut Latinorum.

204 Kremer 2006, 180-188. Hanno assetto municipale gli oppida Latina costituiti a partire dall'età giulio-claudia nelle province alpine e africane, e lo stesso ricorso struttura la generalizzata concessione dello ius Latii all'universa Hispania sotto Vespasiano. Assai più complesso è il quadro offerto dalle province galliche, germaniche e danubiane, su cui gravano i dubbi relativi ai tempi e ai modi dell'eventuale estensione dello ius Latii alle comunità locali, in se stessa postulabile solo in via di ipotesi. Se nel caso delle province germaniche (Raepsaet Charlier 1999) e danubiane (Cîrjan 2010; Varga 2011) la compresenza di coloniae (con certezza o probabilità tutte di diritto romano) e municipia (eventualmente di diritto latino) non contrasta con l'assunto iniziale, nel caso delle tre Gallie (Dondin Payre 1999) -dove l'unica colonia civium Romanorum certa è quella di $L u$ gudunum - si pone il problema relativo alla natura giuridica di quelle civitates apparentemente peregrinae per le quali la documentazione epigrafica attesta titolatura coloniaria, a fronte in particolare dell'assenza in queste province di comunità privilegiate a statuto dichiaratamente municipale. Andrà tenuta seriamente in conto l'ipotesi che in tutti questi casi lo statuto coloniario sia da intendere non già come la chiave istituzionale adottata in funzione dell'attribuzione stessa dello ius Latii, ma come il segno della concessione di benefici aggiuntivi (cf. Kremer 2006, 162-164).

205 Sánchez 2016.

206 CIL I I 600 (=RS 16).

207 Sulla cronologia e il contenuto di questo provvedimento rimando a Sisani 2016a, 47-52. 
Nella clausola derogatoria ${ }^{208}$ volta a confermare in via transitoria le competenze giurisdizionali dei magistrati locali già eletti prima dell'approvazione della lex Roscia, le massime cariche di governo delle comunità cisalpine ${ }^{209}$ sono richiamate cumulativamente tramite la locuzione IIvir isve qui ibi lege foedere plebive scito senatusve consulto institutove iure dicundo praefuit: dove l'asindeto lege foedere -intendi: lege foederis ${ }^{210}$ - allude con tutta evidenza ad assetti istituzionali fondati su foedera $\mathrm{i}$ quali, a fronte del contesto storico in cui si inserisce la normativa, non possono che essere quelli che avevano accompagnato la costituzione ex lege Pompeia delle colonie latine fittizie della provincia. ${ }^{211}$ La suggestione offerta dal fragmentum Atestinum è sostenuta e confermata dalla qualifica di populus foederatus che Cicerone, nel 56 a.C., assegna a Ravenna ${ }^{212}$ comunità cisalpina senza dubbio insignita dello ius Latii fin dall'89 a.C.: una qualifica estesa, nello stesso contesto, anche a Saguntum, ${ }^{213}$ la cui trasformazione in colonia latina -come si è visto- ha buone probabilità di risalire già al 72-71 a.C.

Possiamo dunque concludere che nell' 89 a.C. la trasformazione in colonie latine fittizie delle civitates peregrinae della Cisalpina si sia accompagnata alla ratifica di veri e propri foedera con le singole comunità: o meglio, coerentemente con le dinamiche più attese, che queste ultime abbiano nel loro insieme aderito ad una "formula-tipo" volta da un lato a sancire i principi dell'autonomia locale, dall'altro a specificare -sul modello del foedus Cassianum - i contenuti giuridici dello ius Latii; a definire nel concreto i nuovi assetti amministrativi e territoriali avranno invece provveduto, centro per centro, i constitutores operanti in virtù della stessa lex Pompeia, che dovette propriamente configurarsi (teste Asconio) come una lex coloniaria. Solo in questa forma la riorganizzazione istituzionale delle comunità locali di una intera provincia poteva essere espletata con la dovuta celerità secondo criteri di razionalità ed equità. È anzi probabile che la formula elaborata per la Cisalpina abbia costituito il modello anche per le successive applicazioni dell'istituto, che fino all'età cesariana dimostrano piena aderenza al precedente introdotto dalla lex Pompeia.

208 Fragmentum Atestinum, col. I, 11. 10-[22]: Quoius rei in qu<o>que municipio colonia praefectura quoiusque IIvir(i) eiusve, qui ibei lege foedere pl(ebi)ve sc(ito) s(enatus)ve c(onsulto) institutove iure dicundo praefuit, ante legem seive illud pl(ebi) sc(itum) est quod L. Roscius a(nte) d(iem) VEid(us) Mart(ias) populum plebemve rogavit, quod privatim ambig<er>etur, iuris dic[ti]o iudicis arbitri recuperatorum datio addictiov[e fuit] quantaeque rei pequniaeve fuit, eius rei pequni[aeve] quo magis privato Romae revocatio sit quo[ve mi]nus quei ibei i(ure) d(icundo) p(raefuit) d(e) e(a) r(e) ius dicat iudice [m addicat det, ita] utei ante legem sive illud pl(ebi) sc(itum) est [quod L. Roscius a(nte) d(iem)] V Eidus Mart(ias) populum plebe[mve rogavit ei quei ibei i(ure) d(icundo) p(raefuit) iuris dictione]m iu[dicis arbitri recuperatorum dationem addictionemve esse oportuit, ex h(ac) l(ege) n(ihilum) r(ogatur)].

209 Municipia coloniae praefecturae (cf. col. I, 1. 5): secondo la specifica forma istituzionale -nel caso delle colonie latine fittizie, quella di municipia - assunta (o mantenuta) dalle comunità locali all'atto dell'estensione della $c i$ vitas Romana all'intera provincia. Sull'assetto magistratuale delle comunità cisalpine si veda ora Sisani 2018, 60-70.

210 Cf. Luraschi 1983, 312-324. La locuzione è direttamente attestata da Liv. 23.10.6 e da Verg. Aen. 11.321-322.

211 Non può infatti trattarsi dei vetusti foedera stretti anteriormente alla guerra sociale (sui quali cf. Luraschi 1979, 23-101), che è impensabile contenessero clausole volte a regolare l'assetto interno delle comunità alleate, alcuni dei quali tra l'altro -come afferma Cicerone (Balb. 32) in relazione ai Cenomani e agli Insubri- escludevano espressamente ogni forma di concessione della cittadinanza romana: un ricorso invece strutturale nel caso delle colonie latine fittizie, che dimostra come tali trattati, a partire dall'89 a.C., fossero ormai agli effetti giuridici lettera morta.

212 Cic. Balb. 50.

213 Cic. Balb. 23. 
Tra le clausole di questa formula dovevano senza dubbio figurare quelle relative agli iura costitutivi del nuovo Latium: in primo luogo le norme regolanti lo ius adipiscendae civitatis per magistratum, che andava a sommarsi-come dichiara esplicitamente Asconio- all'insieme dei diritti già goduti dalle colonie latine di tipo tradizionale. Ad intendere alla lettera la testimonianza del commentatore di Cicerone, ${ }^{214}$ dovremmo concludere che alle colonie fittizie istituite nell' 89 a.C. fossero state riconosciute tutte quelle prerogative -lo ius commercii, lo ius conubii, lo ius migrandi e lo ius suffragii- che avevano mantenuto piena operatività lungo l'intero corso della storia del nomen Latinum. ${ }^{215}$ Nelle fonti, va detto chiaramente, conferme esplicite della vigenza di questi iura per le colonie cisalpine non ve ne sono: non mancano tuttavia indizi significativi, almeno per quanto attiene da un lato allo ius entero o commercii, ${ }^{216}$ dall'altro allo ius migrandi e allo ius suffragii. ${ }^{217}$ La questione si pone in termini più articolati nel caso dello ius conubii: ed è questione cruciale, perché proprio in relazione ad essa è possibile intendere, a mio avviso, un aspetto centrale della Latinitas municipale di età imperiale.

Che le colonie latine fittizie, al pari di quelle tradizionali, godessero dello ius conubii è suggerito con forza dalla documentazione epigrafica delle comunità narbonensi che avevano ottenuto lo ius Latii in età cesariana, dalla quale emerge chiaramente come i figli di unioni "miste" -nati cioè da padre romano e madre latina o da padre latino e madre romana- seguissero la condizione giuridica paterna. ${ }^{218}$ La circostanza è in apparente contrasto con le previsioni della lex Minicia, che presuppongono l'esistenza di comunità di diritto latino ormai prive di conubium:

Quod autem diximus, ${ }^{219}$ inter c(iuem) $\boldsymbol{R}$ (omanam) peregrinumque nisi conu $<$ bium sit eum qui $>\mid$ nascitur peregrinum esse, lege Minicia cau $<$ tum $>\mid$ est, ut si is quidem $<$ deterioris $>$ parentis condicionem $\mathbf{s}<$ equatur $>$; | eadem lege enim ex diuerso cauet $<$ ur ut $>$, si peregrin $<$ am cum $>\mid$ qua ei conubium non sit uxorem dux<erit

214 Cf. Luraschi 1979, 218-220.

215 Luraschi 1979, 221-299.

216 Si vedano in merito le riflessioni sviluppate da Luraschi 1979, 333-336, in relazione al mutamento di regime giuridico che dovette interessare l'ager peregrinus della Cisalpina nell' 89 a.C. Una testimonianza diretta di tale mutamento è ora offerta dal catasto B di Verona (Cavalieri Manasse - Cresci Marrone 2015 e 2017), da datare senza dubbio nei decenni iniziali del I sec. a.C.: documento che va propriamente inteso come il prodotto di una ricognizione censuale (cf. Maganzani 2015), promossa dal governo centrale allo scopo di ridefinire -sul piano giuridico, più che gromatico-1'assetto dell'ager Veronensis a seguito della trasformazione del centro in colonia latina fittizia. Nel caso degli oppida Latina di età imperiale, la conferma decisiva della vigenza dello ius commercii si avrebbe attribuendo carattere di attualità a Tit. Ulp. 19.4: Mancipatio locum habet inter cives Romanos et Latinos coloniarios Latinosque Iunianos eosque peregrinos, quibus commercium datum est, dove l'allusione ai Latini coloniarii può eventualmente mascherare -come in Gai. Inst. 1.29: Statim enim ex lege Aelia Sentia minores triginta annorum manumissi et Latini facti si uxores duxerint vel cives Romanas vel Latinas coloniarias vel eiusdem condicionis cuius et ipsi essent (...)- un riferimento alle comunità beneficiarie dello ius Latii (cf. Luraschi 1979, 246-247).

217 È quanto emerge da alcuni episodi degli anni Sessanta del I sec. a.C., legati alla causa Transpadanorum: cf. Luraschi 1979, 342-352.

218 Chastagnol 1998. Non esistono prove che questo regime abbia subito modifiche in età adrianea: cf. in merito Gascou 1999.

219 Cf. Gai. Inst. 1.75-77: Ex iis quae diximus apparet, sive civis Romanus peregrinam sive peregrinus civem Romanam uxorem duxerit, eum qui nascitur peregrinum esse (...) Loquimur autem de his scilicet, <inter> quos conubium non sit; nam alioquin si civis Romanus peregrinam cum qua ei conubium est uxorem duxerit, sicut supra quoque diximus, iustum matrimonium contrahitur et tunc ex his qui nascitur civis Romanus est et in potestate patris erit. Item si civis Romana peregrino cum quo ei conubium est nupserit, peregrinum sane procreat et is iustus patris filius est, tamquam si ex peregrina eum procreasset. 
c(iuis) $R$ (omanus)>, peregri|nus ex eo coitu nascatur. Sed hoc maxime casu neces|saria lex Minicia: nam remota ea lege diuersam | condicionem sequi deb<eret, quia> ex eis inter quos non | est conubium qui nascitur iure gentium matris con|dicioni accedit. Qua parte autem iubet lex ex c(iue) R(omano) et pe|regrina peregrinum nasci, superuacua uidetur: | nam et remota ea lege hoc utique iure gentium |futurum erat. Adeo autem hoc ita est, ut ex $* * *|* * *| * * *$ $<$ non> | solum exterae nationes et gentes, sed etiam qui La|tini nominantur: sed ad alios Latinos pertinet, qui $\mid$ proprios populos propriasque ciuitates habebant | et erant peregrinorum numero. ${ }^{220}$

Conubio interveniente liberi semper patrem sequuntur; non interveniente conubio matris condicioni accedunt, excepto eo qui ex peregrino et cive Romana peregrinus nascitur, quoniam lex Minicia [edd., Mensia cod.] ex alterutro peregrino natum deterioris parentis condicionem sequi iubet. ${ }^{221}$

La testimonianza di Gaio -nonostante le lacune del testo- è nel complesso piuttosto chiara, grazie anche alla convergente seppure assai più sintetica illustrazione degli estratti (pseudo-)ulpianei. ${ }^{222}$ La lex Minicia andava a modificare, in tema di status liberorum, la norma secondo la quale i figli nati in assenza di conubium seguivano iure gentium la condizione giuridica della madre, sancendo il criterio assoluto della deterioris parentis condicio. La legge concerneva nello specifico le unioni contratte non interveniente conubio tra cives Romani e peregrini, ivi compresi qui Latini nominantur. La chiosa di Gaio -sed ad alios Latinos pertinet-è chiaramente funzionale ad evitare che i Latini soggetti alle previsioni della lex Minicia venissero confusi con un'altra categoria di Latini: i Latini Iuniani, sui quali si appuntavano i maggiori interessi del giurista. Gli alii Latini -stante il contesto cronologico della testimonianza, in cui essi figurano come una categoria giuridicamente vitale- dovranno allora identificarsi proprio con i membri delle comunità beneficiarie dello ius Latii: comunità che la lex Minicia evidentemente trattava a tutti gli effetti alla stregua di civitates peregrinae, ponendole sullo stesso piano delle exterae nationes et gentes. 223

Prima di interrogarsi sulle ragioni delle modifiche introdotte rispetto alle norme contemplate dallo ius gentium, è cruciale cercare di determinare la cronologia della legge. ${ }^{224}$ Essa è ancora vigente ai tempi di Gaio, che ne parla in termini di attualità;

220 Gai. Inst. 1.78-79. Riproduco in forma semi-diplomatica la lezione del palinsesto veronese basandomi sulle edizioni Krueger - Studemund 1923 e David - Nelson 1954-1968: a fronte delle oggettive difficoltà di lettura presentate in questo punto dal codice (si veda l'apografo di Studemund 1874, con i supplementi di Krueger Studemund 1923, xvii-xxxix, e la riproduzione fotografica di Briguglio 2012), ho ritenuto opportuno distinguere le stringhe di testo chiaramente leggibili (in neretto) da quelle di restituzione meno sicura; le ipotesi di integrazione delle lacune figurano tra parentesi uncinate.

221 Tit. Ulp. 5.8 .

222 Per una rivalutazione in senso classico di quest'opera, la cui paternità è stata recentemente ricondotta se non allo stesso Ulpiano alla sua cerchia di allievi, si veda Mattioli 2012.

223 Questa, in estrema sintesi, l'analisi di Luraschi 1979, 238-257, che accolgo in pieno. Mi sembra anzi decisivo, a sostegno di tale lettura, il parallelo tra Gai. Inst. 1.79: (...) sed ad alios Latinos pertinet, qui proprios populos propriasque civitates habebant et erant peregrinorum numero, e 1.95: Quod ius [il Latium] quibusdam peregrinis civitatibus datum est vel a populo Romano vel a senatu vel a Cesare (cf. Luraschi 1979, 250-251).

224 Su questo problema si veda in particolare Luraschi 1976 (cf. Luraschi 1979, 254), e da ultima Mancini 1997, $31-42$. 
le sue previsioni parrebbero inoltre presupposte da un senatus consultum adrianeo, ${ }^{225}$ volto in apparenza a meglio definire lo status liberorum nelle unioni contratte in assenza di conubium, che sanciva la condizione di iustus patris filius di colui che fosse nato da padre peregrinus e madre civis Romana (Fig. 5).

In termini cronologici, l'alternativa che si pone è in particolare quella tra l'età repubblicana -giocoforza post guerra sociale, se il contesto giuridico è effettivamente quello del nuovo Latium - e l'età imperiale: nel qual caso la lex Minicia, trattandosi di lex rogata, dovrà risalire ad età augustea o tiberiana. ${ }^{226} \mathrm{~A}$ fronte di quanto si è detto in relazione alla vigenza dello ius conubii per gli oppida Latina della Narbonense, credo che una datazione della legge in età post-cesariana debba considerarsi ipotesi preferenziale: un terminus post quem che costituisce in se stesso un ottimo indizio per circoscrivere la cronologia della lex Minicia, il cui rogator andrà verosimilmente identificato - piuttosto che con il console dell's8 d.C. L. Minicius Rufuscon un ignoto consul suffectus di età tiberiana. ${ }^{27}$

Giusta questa attribuzione cronologica, la lex Minicia sarebbe quindi successiva alle attribuzioni dello ius Latii effettuate in età triumvirale-augustea, e dunque alla stessa nascita della nuova categoria dei municipia Latina. Proprio quest'ultima riforma costituisce del resto la premessa a mio avviso necessaria per intendere i contenuti della legge, elaborata in funzione di una Latinitas ormai esclusa -a differenza delle colonie latine fittizie istituite tra 1'89 a.C. e l'età cesariana- dal godimento dello ius conubii. ${ }^{228}$

La mancanza di questa prerogativa, almeno nel caso dei municipia Latina di età flavia, è confermata dal tenore dell'ultimo caput della lex Irnitana (la cosiddetta epistula Domitiani), ${ }^{229}$ dove 1'allusione ai quaedam conubia contemplati dalla lex Latii lascia chiaramente intendere che, in se stesso, lo ius conubii non era più un

225 Gai. Inst. 1.77: Hoc tamen tempore <ex> senatus consulto, quod auctore divo Hadriano factum est, etiamsi non fuerit conubium inter civem Romanam et peregrinum, qui nascitur, iustus patris filius est; cf. 1.92: Peregrina quoque si vulgo conceperit, deinde civis Romana fiat et tunc pariat, civem Romanum parit; si vero ex peregrino secundum leges moresque peregrinorum conceperit, ita videtur ex senatus consulto, quod auctore divo Hadriano factum est, civem Romanum parere, si et patri eius civitas Romana donetur. L'intervento di Adriano in materia sarà da collegare all'interesse manifestato dall'imperatore nei riguardi dello ius Latii (Hist.Aug. Hadr. 21.7: Latium multis civitatibus dedit), verosimilmente da lui stesso riformato con l'introduzione del Latium maius (cf. Luraschi 1979, 321).

226 Le ultime leggi note per le quali la procedura comiziale venne certamente seguita -le leges (Iuniae) Petroniae de liberalibus causis, de servis e de adulterii iudicio (19 d.C.), la lex Valeria Aurelia de honoribus Germanici (20 d.C.), la lex (Asinia Antistia) de flaminica Diali (23 d.C.), la lex Visellia de libertinis (24 d.C.), la lex Iunia Vellaea testamentaria (28 d.C.)- risalgono ad età tiberiana; l'eventuale ricorso a questo iter fino ancora al principato di Nerva, quand'anche ammesso, parrebbe contemplare unicamente leggi rogate dagli stessi imperatori. Cf. Rotondi 1912, 108-113, e da ultimo Ferrary 2012.

227 Così Mancini 1997, 39. Restano valide a riguardo le osservazioni di Roos 1918, 208-209, pur se formulate sulla base di una errata lettura della datazione consolare riportata dalla cd. tabella emptionis di Tolsum (FIRA III $^{2} 137$ = AE 2010, 1053): C. Fuufio (!) Cn. Min/icio co(n)s(ulibus), ora da correggere in C. Fufeo (!) Gemin/io (!) $\operatorname{co}(n) s($ ule) (29 d.C.). Vi è semmai qualche possibilità di riferire la lex Minicia al consolato di L. Minicius Severus e L. Plotius Marcellus: coppia consolare -attestata da ILS 5161k: III Non(as) Oct(obres) L. Minic(io) L. Plotio, e da TabHerc, nr. 11, 298-299: [L. Mi]nicio Severo [L. Plo]tio Marcello co(n)s(ulibus)- da collocare in un anno non precisabile ma certamente anteriore, come assicura il documento ercolanense, al 62/63 d.C.

228 Cf. Luraschi 1979, 256-257.

229 Lex Irnitana, tab. X, col. c, 11. 33-38: Conubia comprehensa quaedam lege Lati scio et postea aliqua, sic $u\{i\} t$ sollicitudo vestra indicat, parum considerate coisse; quibus in praeteritum veniam do, in futurum exigo memineritis legis, cum iam omnes indulgentiae partes consummatae sint. Si tratterà di quelle stesse unioni "latine" richiamate dalla normativa (capp. 21 e 40) come legitimae o iustae nuptiae: cf. Cherry 1990, 245-246. 


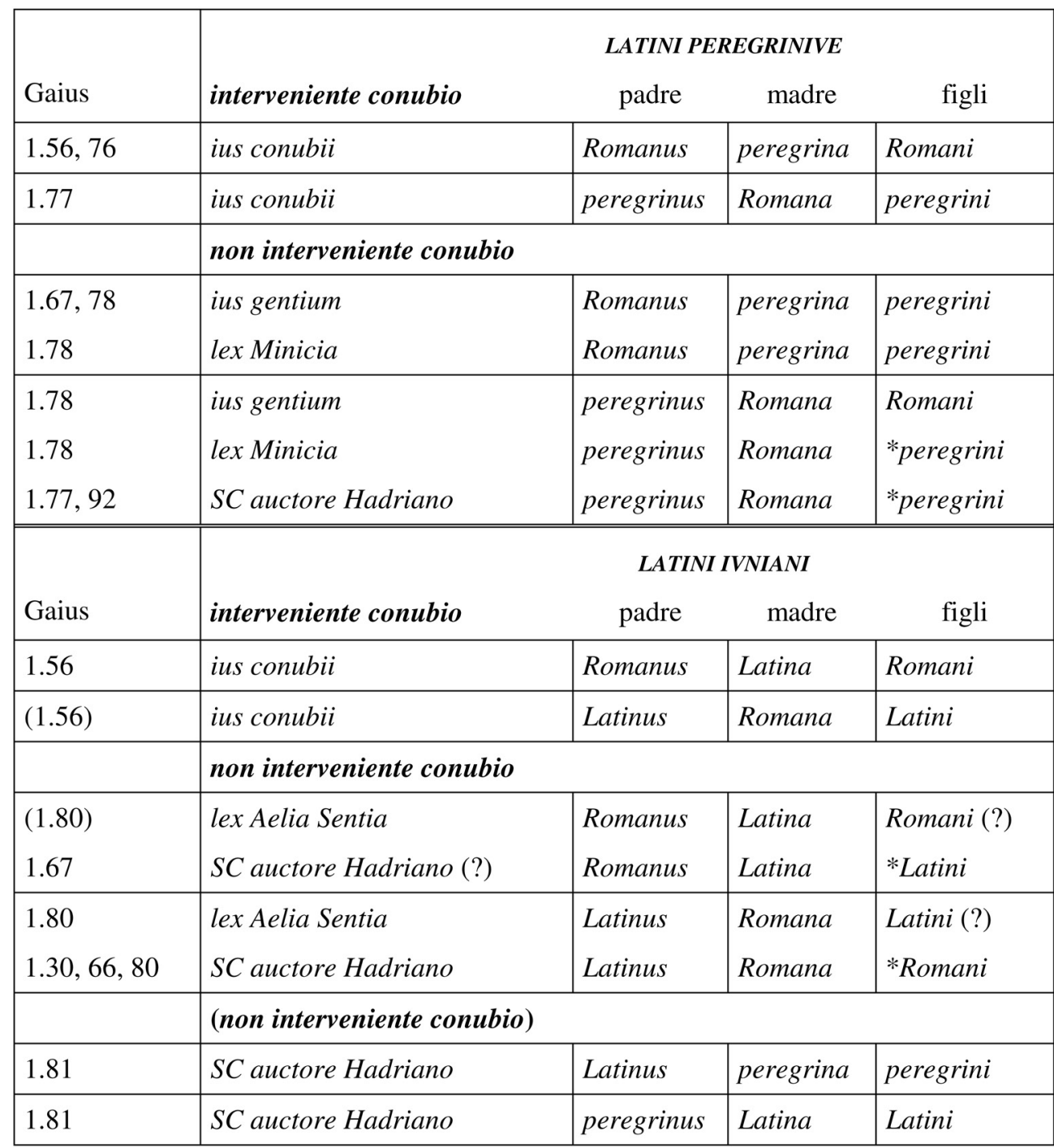

Figura 5. La normativa sullo status liberorum relativa ai Latini nelle Institutiones di Gaio.

elemento costitutivo del nuovo Latium. ${ }^{230} \mathrm{Si}$ spiegano, in questo senso, le nuove previsioni collegate allo ius adipiscendae civitatis per magistratum, in virtù delle quali il riconoscimento della civitas Romana era esteso non solo ai figli e ai nipoti -come già in età repubblicana- ma anche ai genitori (o forse meglio agli ascendenti maschi) e al coniuge dell'ex magistrato: ${ }^{231}$ previsione quest'ultima resa opportuna

Mancini 1997, 39-42; López Barja de Quiroga 2002-2003, 69-70. Altra prospettiva in Dardaine 2003, 99-106.

231 Lex Irnitana, cap. 21 (su cui si veda in particolare Dardaine 2003): R(ubrica). Quae ad modum civitatem Romanam in eo municipio consequantur. Qui ex senatoribus decurionibus conscriptisve municipii Flavi Irnitani magistratus, uti h(ac) l(ege) conprehensum est, creati sunt erunt, ii, cum eo honore abierint, cum parentibus 
proprio dall'assenza di conubium. Per contro, la liberalità della normativa flavia in tema di naturalizzazioni -tutta apparente: si pensi alle limitazioni concernenti il numero dei magistrati coinvolti- non rischiava di produrre una incontrollata (e in quanto tale indesiderata) amplificazione del fenomeno, quale poteva essere innescata dall'eventuale attribuzione iure gentium della civitas Romana alla prole concepita dalle figlie e dalle nipoti dell'ex magistrato, ove queste avessero contratto matrimonio con un civis Latinus o un peregrinus: esito precluso appunto dalle previsioni della lex Minicia, evidentemente elaborata proprio a questo scopo.

La circostanza spinge a postulare l'attuazione, tra l'età cesariana e l'età flavia, di una radicale riforma dell'istituto, che non può che risalire ad età triumvirale-augustea, in connessione diretta con l'introduzione del nuovo assetto di marca municipale che caratterizza la Latinitas di età imperiale: credo, in altri termini, che l'invenzione del municipium Latinum sia da intendere come un autentico escamotage, funzionale a veicolare le modifiche apportate da Augusto ai contenuti giuridici dello ius Latii. Se nel caso delle colonie latine fittizie tali contenuti erano stati fissati una volta per tutte dalle clausole del foedus-modello elaborato nell' 89 a.C., quest'ultimo risultava come è chiaro inapplicabile a comunità municipali, lasciando al legislatore piena libertà per una ricontrattazione dei diritti riconosciuti ai centri oggetto di nuova promozione.

Successivamente a questa riforma, la Latinitas provinciale comprenderà dunque due diverse categorie di comunità -le colonie latine fittizie, ormai concentrate nella sola Narbonense, e i municipi di diritto latino-e due diversi regimi giuridici, distinti sulla base dell'attribuzione o meno dello ius conubii. In questo contesto, la lex Minicia recepisce e sviluppa una premessa evidentemente già contenuta nella riforma augustea, che attraverso la cassazione dello ius conubii dai diritti costitutivi dello ius Latii aveva di fatto sancito la piena equiparazione tra municipes Latini e peregrini.

Al momento della sua elaborazione nell' 89 a.C., lo ius Latii si caratterizzava per la natura meramente transitoria di questa forma "guidata" di promozione, come conferma la rapida attribuzione della civitas Romana alle colonie latine fittizie della Cisalpina, attuata ad appena quarant'anni di distanza dalla promulgazione della lex Pompeia. Si intende appieno, in quest'ottica, il dissenso espresso da Cicerone nei confronti dell'operato del console del 51 a.C. Claudio Marcello, che aveva ordinato la fustigazione di un latino di Novum Comum reo di un non meglio determinato crimine. ${ }^{232}$ La riprovazione dell'Arpinate - tutta basata su un'unica considerazione: "erat tamen Transpadanus"- è indicativa di un atteggiamento evidentemente diffuso, che riconosceva ai cives Latini una dignità pari, de facto se non de iure, a quella dei cives Romani. Le estensioni dello ius Latii attuate nel corso dell'età cesariana muovono ancora da queste stesse premesse, come dimostra nel caso della Sicilia la quasi immediata promozione a municipia civium Romanorum, ad opera di Antonio,

coniugibusque ac liberis, qui legitimis nuptis quaesiti in potestate parentium [f]uer $<i>n t$, item nepotibus ac neptibus filio natis, qui quaeve in potestate parentium fuer $<i>n t$, cives Romani sunto, dum ne plures cives Romani sint quam quod ex $h(a c) l(e g e)$ magis [t]ratus creare oportet. Le più antiche testimonianze di questo regime "allargato" sono offerte dagli editti ottavianei de privilegiis veteranorum (FIRA $\mathrm{I}^{2} 56=\mathrm{I}^{3} 6.1$ ) e de Seleuco navarcha $\left(\right.$ FIRA I $\mathrm{I}^{2} 55=\mathrm{I}^{3}$ 6.2): cf. Luraschi 1979, 325-328.

232 Cic. Att. 5.11.2: Marcellus foede de Comensi. Etsi ille magistratum non gesserit, erat tamen Transpadanus; ita mihi videtur non minus stomachi nostro quam Caesari fecisse. Sed hoc ipse viderit. Sull'episodio (cf. Plu. Caes. 29 e App. BC 2.98) si veda Luraschi 1979, 457-486. 
degli oppida Latina istituiti da Cesare: ${ }^{233}$ promozione la cui effimera durata non ne sminuisce il valore concettuale.

A partire dall'età triumvirale-augustea, e in forma più marcata dopo l'approvazione della lex Minicia, civitas Latina e civitas Romana vengono invece incanalate su binari di fatto paralleli. Il passaggio dall'una all'altra condizione giuridica è ancora consentito, ma solo attraverso il canale ufficiale aperto dallo ius adipiscendae civitatis per magistratum: il canale "ufficioso" -quello delle unioni matrimoniali, che in determinate condizioni consentiva alla prole l'accesso automatico alla cittadinanza- era stato prima disinnescato dalla riforma augustea, che attraverso il mancato riconoscimento dello ius conubii aveva reso poco appetibili i matrimoni misti, ${ }^{234}$ poi definitivamente chiuso dalla lex Minicia, che in relazione ad essi aveva sancito il principio assoluto della deterioris parentis condicio nella determinazione dello status liberorum.

\section{Bibliografia}

Abascal Palazón, J. M. (2002): "La fecha de promoción colonial de Carthago Noua y sus repercusiones edilicias", Mastia 1, 21-44.

Amela Valverde, L.

(2000): "Las ciudades fundadas por Pompeyo Magno en Occidente: Pompaelo, Lugdunum Convenarum y Gerunda", Polis 12, 7-41.

(2011): "Sagunto, colonia", Arse 45, 153-161.

(2012): "Sobre la dificultad de leer una inscripción: la leyenda monetal L. AP. DEC.", Hispania Antiqua 36, 67-85.

(2014): "Sobre amonedaciones en tiempos de guerra. El caso de Carteia", Acta Numismatica 44, 93-108.

(2014-2015): "Reflexiones sobre el origen de la colonia romana de Carthago Nova", Arse 48-49, 317-329.

(2015): "Sobre un pasaje de Livio (Liv. 34, 9, 3): la instalación de colonos cesarianos en Emporiae y el papel de Domicio Calvino", Tiempo y Sociedad 19, 58-74.

(2016a): "Las colonias 'cesarianas' del mediodía peninsular. Una síntesis", Hispania Antiqua $40,85-117$.

(2016b): "Las primeras emisiones de Emporiae", Hécate 3, 96-110.

Andreu Pintado, J. (ed.), (2009): Los Vascones de las fuentes antiguas. En torno a una etnia de la antigüedad peninsular (=Universitat de Barcelona. Col-lecció Instrumenta 32), Barcelona.

Andreu Pintado, J. - Jordán Lorenzo, Á. (2007): "Nuevas reflexiones en torno a las fuentes literarias sobre los Vascones en la antigüedad", Lucentum 26, 233-252 (http://dx.doi. org/10.14198/LVCENTVM2007.26.10).

Artica Rubio, E. (2009): "Algunos apuntes sobre los Vascones en la guerra sertoriana”, [in] Andreu Pintado (ed.), 2009, 169-190.

Badian, E. (1970-1971): "Roman politics and the Italians (133-91 B.C.)", Dialoghi di Archeologia 4-5, 373-409.

233 Cic. Att. 14.12.1.

234 Una testimonianza diretta in questo senso è offerta da Sen. Ben. 4.35.1: Promisi tibi in matrimonium filiam; postea peregrinus adparuisti; non est mihi cum externo conubium; eadem res me defendit, quae vetat. Cf. Cherry $1990,263$. 
Bandelli, G.

(2002): "La colonizzazione romana della penisola iberica da Scipione Africano a Bruto Callaico", [in] Hispania terris omnibus felicior. Premesse ed esiti di un processo di integrazione, Pisa, 105-142.

(2009): "Parma durante la repubblica. Dalla fondazione della colonia a Cesare", [in] D. Vera (ed.), Storia di Parma II, Parma, 181-217.

Barbati, S. (2013): “Ancora sulle cosiddette 'colonie latine fittizie' transpadane (Ascon. in Pis. 3 Clark)", Quaderni Lupiensi di Storia e Diritto 3, 59-106.

Barreda Pascual, A. (2007): "Las magistraturas monetales de las primeras acuñaciones de fundaciones latinas en Hispania", [in] M. Mayer - G. Baratta - A. Guzmán (eds.), Provinciae Imperii Romani inscriptionibus descriptae. XII Congressus Internationalis Epigraphiae Graecae et Latinae (Barcelona, 3-8 Septembris 2002), Barcelona, vol. I, 113-122.

Bats, M. (2007): "Droit latin, adtributio et contributio. Strabon, Pline, Nîmes et les Volques Arécomiques", MEFRA 119, 51-62 (https://doi.org/10.3406/mefr.2007.10325).

Battistoni, F. (2011): "Time(s) for Tauromenion: the pilaster with the list of the stratagoi (IG XIV 421) - The Antikythera mechanism", ZPE 179, 171-188.

Bérard, F. (2010): "Remarques sur les tribus dans les cités de Gaule Narbonnaise", [in] M. Silvestrini (ed.), Le tribù romane, Bari, 21-27.

Bradeen, D. W. (1958-1959): "Roman citizenship per magistratum”, ClJ 54, 221-228.

Briguglio, Ph. (2012): Gai codex rescriptus in Bibliotheca Capitulari Ecclesiae Cathedralis Veronensis, Firenze.

Broughton, T. R. S. (1951-1986): The magistrates of the Roman Republic, New York (=MRR). Brunt, P. A. (1987): Italian manpower (225 B.C. - A.D. 14), Oxford².

Burnett, A. - Amandry, M. - Ripollès, P. P.

(1998): Roman Provincial Coinage I. From the death of Caesar to the death of Vitellius (44 BC - AD 69), London² (=RPC I).

(2015): Roman Provincial Coinage. Consolidated supplement I-III (1992-2015), London (=RPCSuppl).

Caballos Rufino, A. (1987-1988): “M. Trahius, C.f., magistrado de la Italica tardorrepublicana", Habis 18-19, 299-317.

Cadiou, F.

(2008a): Hibera in terra miles. Les armées romaines et la conquête de l'Hispanie sous la République (218-45 av. J.-C.), (=Bibliothèque de la Casa de Velázquez 38), Madrid. (2008b): "Entre épigraphie et archéologie: remarques sur certaines difficultés du dossier de la Valentia hispanique à l'époque républicaine", Cahiers du Centre Gustave Glotz 19, 35-52 (https://doi.org/10.3406/ccgg.2008.1667).

Camodeca, G. (2017): Tabulae Herculanenses. Edizione e commento I (=Vetera 20), Roma $(=$ TabHerc $)$.

Canto, A. M.

(2001): "Sinoicismo y stolati en Emerita, Caesaraugusta y Pax: una relectura de Estrabón III, 2, 15", Gerión 19, 425-476 (http://dx.doi.org/10.5209/GERI.15171).

(2010): "I Traii betici. Novità sulla famiglia e le origini di Traiano", [in] J. Alvar - J. M. Blázquez (eds.), Traiano (=«L'Erma» di Bretschneider. Biblioteca Spagnola di Studi Classici 5), Roma, 27-64.

Cavalieri Manasse, G. - Cresci Marrone, G.

(2015): "Un nuovo frammento di forma dal Capitolium di Verona", [in] Cresci Marrone (ed.), 2015, 21-54. 
(2017): "Due frammenti di formae dal Capitolium di Verona", [in] S. Segenni - M. Bellomo (edd.), Epigrafia e politica. Il contributo della documentazione epigrafica allo studio delle dinamiche politiche nel mondo romano, Milano, 65-94.

Cels-Saint-Hilaire, J. (1985): "Les libertini: des mots et des choses", DialHistAnc 11, 330-379 (http://dx.doi.org/10.3406/dha.1985.1667).

Chastagnol, A. (1998): "La condition des enfants issus de mariages inégaux entre citoyens romains et pérégrins dans les cités provinciales de droit latin", [in] G. Paci (ed.), Epigrafia romana in area adriatica, Pisa-Roma, 249-262.

Chaves Tristán, F. (1979): Las monedas hispano-romanas de Carteia, Barcelona.

Cherry, D. (1990): “The Minician law: marriage and the Roman citizenship", Phoenix 44, 244-266 (http://dx.doi.org/10.2307/1088935).

Christol, M.

(1999): "La municipalisation de la Gaule Narbonnaise", [in] Dondin Payre - RaepsaetCharlier (éd.), 1999, 1-27.

(2006): "Interventions agraires et territoire colonial: remarques sur le cadastre B d'Orange", [in] A. Gonzáles - J.-Y. Guillaumin (éd.), Autour des Libri coloniarum. Colonisation et colonies dans le monde romain, Besançon, 83-92.

Christol, M. - Goudineau, C. (1987): "Nîmes et les Volques Arècomiques au I ${ }^{\text {er }}$ siècle avant J.-C.”, Gallia 45, 87-103 (https://doi.org/10.3406/galia.1987.2881).

Christol, M. - Heijmans, M. (1992): "Les colonies latines de Narbonnaise: un nouveau document d'Arles mentionnant la Colonia Iulia Augusta Avennio", Gallia 49, 37-44 (https:// doi.org/10.3406/galia.1992.2927).

Cichorius, C. (1922): Römische Studien, Leipzig-Berlin.

Cîrjan, R. (2010): “Droit romain et droit latin dans les cités danubiennes de l'empire romain ( ${ }^{\mathrm{er}}$-III' ${ }^{\mathrm{e}}$ siècles): remarques méthodologiques", [in] M. V. Angelescu - I. Achim - A. Bâltâc - V. Rusu Bolindeț - V. Bottez (éd.), Antiquitas Istro-Pontica. Mélanges d'archéologie et d'histoire offerts à Alexandru Suceveanu, Cluj-Napoca, 121-130.

Corell, J. (2012): Inscripcions romanes del País Valencià VI. Ilici, Lucentum, Allon, Dianium $i$ els seus territoris, Valencia $\left(=I R I L A D^{2}\right)$.

Crawford, M. H. (ed.), (1996): Roman Statutes I (=BICS Supplement 64), London (=RS).

Cresci Marrone, G. (ed.), (2015): Trans Padum ... usque ad Alpes. Roma tra il Po e le Alpi: dalla romanizzazione alla romanità (=Studi e Ricerche sulla Gallia Cisalpina 26), Roma.

Curchin, L. A. (2015): The local magistrates of Roman Spain. A supplement, Waterloo $\left(=L M R S^{2}\right)$.

Dardaine, S. (2003): “Citoyenneté, parenté, conubium dans les réglements des municipes flaviens de Bétique", [in] S. Armani - A. U. Stylow - B. Hurlet Martineau (eds.), Epigrafía y sociedad en Hispania durante el Alto Imperio: estructuras y relaciones sociales (=Acta Antiqua Complutensia IV), Alcalá de Henares-Madrid, 93-106.

David, M. - Nelson, H. L. W. (1954-1968): Gai institutionum commentarii IV, Leiden.

De Hoz García Bellido, M. P. - Díaz Ariño, B. - Ribera Lacomba, A. (2013): “Grafitos sobre cerámica procedentes de los niveles romanorrepublicanos de Valentia (Valencia, España)", Palaeohispanica 13, 407-429.

Díaz Ariño, B. (2008): Epigrafía latina republicana de Hispania, Barcelona (=ELRH).

Diego Santos, F. (1986): Inscripciones romanas de la provincia de León, León (=IRPL).

Dondin Payre, M. (1999): "Magistratures et administration municipale dans les Trois Gaules", [in] Dondin Payre - Raepsaet-Charlier (éd.), 1999, 126-230.

Dondin Payre, M. - Raepsaet-Charlier, M.-Th. (éd.), (1999): Cités, municipes, colonies. Les processus de municipalisation en Gaule et en Germanie sous le Haut Empire romain (=Histoire ancienne et médiévale 53), Paris. 
Encarnação, J. d' (1984): Inscrições romanas do Conventus Pacensis, Coimbra (=IRCP).

Espinosa Espinosa, D.

(2014): Plinio y los “oppida de antiguo Lacio”. El proceso de difusión del Latium en Hispania Citerior (=BAR International Series 2686), Oxford.

(2016): "Reflexiones sobre la probable promoción de Cesse/Tarraco a colonia latina", Klio 98, 570-604 (https://doi.org/10.1515/klio-2016-0043).

Esteban Ortega, J. (2014): Corpus de inscripciones latinas de Cáceres III. Capera, Cáceres (=CILCC III).

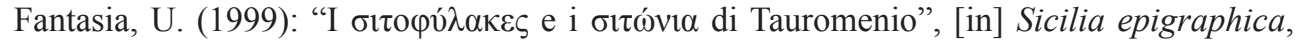
Pisa, 251-279.

Faoro, D. (2015): “Gentes e civitates adtributae. Fenomeni contributivi della romanità cisalpina”, [in] Simblos. Scritti di storia antica VI, Bologna, 155-199.

Ferrary, J. L.

(1979): "Recherches sur la législation de Saturninus et de Glaucia II. La loi de iudiciis repetundarum de C. Servilius Glaucia”, MEFRA 91, 85-134 (https://doi.org/10.3406/ mefr.1979.1186).

(2012): "La législation augustéenne et les dernières lois comitiales", [in] J. L. Ferrary (ed.), Leges publicae. La legge nell'esperienza giuridica romana, Pavia, 569-592.

Firpo, G. (2009): “Colonia Arretium: da Silla a Cesare”, Rendiconti dell'Istituto Lombardo $143,87-118$.

Gabba, E.

(1973 [1954]): "Le origini della guerra sociale e la vita politica romana dopo 1'89 a.C.", [in] Esercito e società nella tarda Repubblica romana, Firenze, 193-345.

(1973 [1970]): “Aspetti della lotta di Sesto Pompeo in Spagna”, [in] Esercito e società nella tarda Repubblica romana, Firenze, 473-520.

García Bellido, M P P. - Blázquez, C. (2001): Diccionario de cecas y pueblos hispánicos (=CSIC. Textos Universitarios 35-36), Madrid (=DCPH).

García Fernández, E.

(2001): El municipio latino. Origen y desarrollo constitucional (=Gerión Anejos. Anejo V), Madrid.

(2009a): "Reflexiones sobre la latinización de Hispania en época republicana", [in] J. Andreu Pintado - J. Cabrero Piquero - I. Rodà de Llanza (eds.), Hispaniae. Las provincias hispanas en el mundo romano (=Institut Català d'Arqueologia Clàssica. Documenta 11), Tarragona, 377-390.

(2009b): "Gracurris y los oppida de antiguo Lacio", [in] Andreu Pintado (ed.), 2009, 215-230.

(2011): "Movilidad, onomástica e integración en Hispania en época republicana: algunas observaciones metodológicas", [in] J. M. Iglesias Gil - A. Ruiz Gutiérrez (eds.), Viajes y cambios de residencia en el mundo romano, Santander, 47-66.

(2012): "Sobre la condición latina y su onomástica: los ediles de Andelo", ETF Serie II, Historia Antigua 25, 423-436 (https://doi.org/10.5944/etfii.25.2012.10300).

(2014): "Estrabón (III 2, 1) y la fundación de Córdoba. Una nueva propuesta de interpretación", [in] M. Chiabà (ed.), Hoc quoque laboris praemium. Scritti in onore di Gino Bandelli, Trieste, 173-187.

(2015): "Clientela y difusión onomástica en Hispania: algunas observaciones sobre la documentación de Sagunto", [in] A. Beltrán - I. Sastre - M. Valdés (eds.), Los espacios de la esclavitud y la dependencia desde la antigüedad, Besançon, 589-605. 
Gascou, J.

(1982): "La politique municipale de Rome en Afrique du Nord. De la mort d'Auguste au début du III siècle", [in] Aufstieg und Niedergang der römischen Welt II/10.2, BerlinNew York, 136-229.

(1991): "Duumvirat, quattuorvirat et statut dans les cités de Gaule Narbonnaise", [in] Epigrafia. Actes du colloque en mémoire de Attilio Degrassi (=Collection de l'École française de Rome 143), Rome, 547-563.

(1997): "Magistratures et sacerdoces municipaux dans les cités de Gaule Narbonnaise", [in] M. Christol - O. Masson (éd.), Actes du Xe congrès international d'épigraphie grecque et latine (=Publications de la Sorbonne. Série Histoire Ancienne et Médievale 42), Paris, 75-140.

(1999): "Hadrien et le droit latin", ZPE 127, 294-300.

(2002): "Une inscription de Martigues et le statut de Maritima Avaticorum", RANarb 35, 195-198 (https://doi.org/10.3406/ran.2002.1103).

González Fernández, J.

(1982): Inscripciones romanas de la provincia de Cádiz, Cádiz (=IRPCa).

(1984): “Italica, municipium iuris Latini”, MelCasaVelazquez 20, 17-43.

(1991a): Corpus de inscripciones latinas de Andalucía II. Sevilla I: La Vega (Hispalis), Sevilla (=CILA 2).

(1991b): Corpus de inscripciones latinas de Andalucía II. Sevilla II: La Vega (Italica), Sevilla (=CILA 3).

González Román, C. - Mangas Manjarrés, J. (1991): Corpus de Inscripciones Latinas de Andalucía III. Jaén I, Sevilla (=CILA 6).

Gregori, G. L. (2012): "I Flavi e le popolazioni alpine adtributae a Brixia", [in] F. Morandini - P. Panazza (edd.), Divus Vespasianus, Brescia, 111-131.

Henderson, M. I. (1942): "Julius Caesar and Latium in Spain", JRS 32, 1-13 (http://dx.doi. $\operatorname{org} / 10.2307 / 296455)$.

Hernández Fernández, J. S. (1994): "Tito Livio XLIII,3 y los nomina de los magistrados monetales de Carteia", Faventia 16, 83-109.

Humbert, M. (1976): “Libertas id est civitas: autour d'un conflit négatif de citoyennetés $\mathrm{II}^{\mathrm{e}} \mathrm{s}$. avant J.-C.”, MEFRA 88, 221-242 ( https://doi.org/10.3406/mefr.1976.1056).

Klotz, A. (1927): C. Iuli Caesaris Commentarii III, Leipzig.

Kremer, D. (2006): Ius Latinum. Le concept de droit latin sous la République et l'Empire, Paris.

Krueger, P. - Studemund, G. (1923): Gai Institutiones, Berlin7.

Laffi, U.

(1966): Adtributio e contributio. Problemi del sistema politico-amministrativo dello stato romano, Pisa.

(2001 [1976]): “Sull'organizzazione amministrativa dell'area alpina nell'età giulio-claudia", [in] Studi di storia romana e di diritto (=Storia e Letteratura. Raccolta di Studi e Testi 206), Roma, 325-359.

(2001 [1988]): "La colonizzazione romana tra la guerra latina e l'età dei Gracchi: aspetti istituzionali", [in] Studi di storia romana e di diritto (=Storia e Letteratura. Raccolta di Studi e Testi 206), Roma, 85-111.

López Barja de Quiroga, P. (2002-2003): "Relaciones entre el ius Latii y el ius personarum (ley Flavia, caps. 21-23 y 97)", Memorias de Historia Antigua 23-24, 59-75.

Luraschi, G.

(1976): "Sulla data e sui destinatari della lex Minicia de liberis", SDHI 42, 431-443. 
(1978): "Sulle leges de civitate (Iulia, Calpurnia, Plautia Papiria)", SDHI 44, 321-370.

(1979): Foedus, ius Latii, civitas. Aspetti costituzionali della romanizzazione in Transpadana (=Pubblicazioni della Università di Pavia. Studi nelle Scienze Giuidiche e Sociali n.s. 29), Padova.

(1983): "Sulle magistrature nelle colonie latine fittizie (a proposito di Frag. Atest. linn. 10-12)", SDHI 49, 261-329.

(1986): "Nuove riflessioni sugli aspetti giuridici della romanizzazione in Transpadana", [in] La Lombardia tra protostoria e romanità, Como, 43-65.

(2007): "Per l'identificazione della colonia invocata da Catullo nel carme 17", [in] Fides humanitas ius. Studii in onore di Luigi Labruna, Napoli, 3047-3064.

Maganzani, L. (2015): "Il nuovo catasto di Verona. Profili giuridici", [in] Cresci Marrone (ed.), 2015, 93-117.

Mancini, G.

(1990): “Ius Latii e ius adipiscendae civitatis Romanae per magistratum nella lex Irnitana", Index 18, 367-388.

(1997): Cives Romani municipes Latini I, Milano.

Mattioli, F. (2012): "Un tentativo di messa a punto riguardo alla più recente dottrina sui Tituli ex corpore Ulpiani. Ipotesi e prospettive di ricerca”, [in] G. Purpura (ed.), Revisione ed integrazione dei Fontes Iuris Romani Anteiustiniani (FIRA). Studi preparatori II, Torino, 85-117.

Meister, K. (1976): “Die Bundesgenossengesetzgebung des Gaius Gracchus”, Chiron 6, 113 125.

Morabito, S. (2010): "Entre Narbonnaise et Italie: le territoire de la province des Alpes Maritimae pendant l'Antiquité romaine ( $\mathrm{I}^{\mathrm{er}}$ s. av. J.-C. - V' s. apr. J.-C.)”, Gallia 67/2, 99-124.

Nicolet, C. (1989): L'inventario del mondo. Geografia e politica alle origini dell'impero romano, Roma-Bari.

Olesti, O. (2010): "Los veteranos de Cneo Pompeyo y Quinto Cecilio Metelo Pio en la Hispania Citerior", [in] C. Fornis Vaquero - J. Gallego - P. López Barja de Quiroga (eds.), Dialéctica histórica y compromiso social. Homenaje a Domingo Plácido, Zaragoza, 1007-1028.

Padilla Monge, A. (2011): “Algunas cuestiones en torno a la elite de Carteia", Gerión 29, 239-263 (http://dx.doi.org/10.5209/rev_GERI.2011.v29.n1.39056).

Pena, $\mathrm{M}^{\mathrm{a}} \mathrm{J}$.

(1986): "Los magistrados monetales de Valentia", Saguntum 20, 151-164 (http://dx.doi. org/10.7203/SAGVNTVM..3717).

(1989): “Consideraciones sobre el estatuto jurídico de Valentia", Saguntum 22, 303-317 (http://dx.doi.org/10.7203/SAGVNTVM..3703).

(1992): "Emporiae", Dialoghi di Archeologia 10, 65-77.

(2004): "La tribu Velina en Mallorca y los nombres de Palma y Pollentia", Faventia 26/2, 69-90.

Periñán Gómez, B. (2014): “Apuntes sobre la lex Gellia Cornelia de civitate danda”, [in] P. I. Carvajal - M. Miglietta (eds.), Estudios jurídicos en homenaje al Profesor Alejandro Guzmán Brito III, Alessandria, 547-577.

Pina Polo, F. (2009): "Deportation of indigenous population as a strategy for Roman dominion in Hispania", [in] Á. Morillo - N. Hanel - E. Martín (eds.), Limes XX. XX Congreso Internacional de Estudios sobre la Frontera Romana (=Anejos de Gladius 13), Madrid, vol. I, 281-288. 
Purpura, G. (2012): Revisione ed integrazione dei Fontes Iuris Romani Anteiustiniani (FIRA). Studi preparatori, Torino $\left(=\right.$ FIR $\left.A^{3}\right)$.

Raepsaet Charlier, M.-Th. (1999): "Les institutions municipales dans les Germanies sous le Haut Empire: bilan et questions", [in] Dondin Payre - Raepsaet-Charlier (éd.), 1999, 271352.

Ribera Lacomba, A. - Jiménez Salvador, J. L. (2012): “Valentia, ciudad romana: su evidencia arqueológica", [in] J. Beltrán Fortes - O. Rodríguez Gutiérrez (eds.), Hispaniae urbes. Investigaciones arqueológicas en ciudades históricas (=Universidad de Sevilla. Serie Historia y Geografía 203), Sevilla, 77-120.

Riccobono, S. (1940-1943): Fontes Iuris Romani Antejustiniani, Firenze (=FIRA2).

Ripollès, P. P.

(1988): La ceca de Valentia (=Estudis Numismàtis Valencians 2), Valencia.

(2002): “La ordenación y la cronología de las emisiones", [in] Ripollès - Llorens (eds.), 2002, 273-301.

Ripollès, P. P. - Llorens, M. M. (eds.), (2002): Arse-Saguntum. Historia monetaria de la ciudad y su territorio, Sagunto $(=A S)$.

Ripollès, P. P. - Velaza, J. (2002): "Saguntum, colonia Latina", ZPE 141, 285-291.

Roos, A. G. (1918): "Quo tempore exarata sit tabella emptionis in Frisia nuper reperta", Mnemosyne 46, 201-215.

Rotondi, G. (1912): Leges publicae populi Romani, Milano.

Rubincam, C. (1998): "How many books did Diodorus Siculus originally intend to write?", Classical Quarterly 48, 229-233 (http://dx.doi.org/10.1093/cq/48.1.229).

Rutter, N. K. (2001): Historia Numorum. Italy, London (=HNI).

Sánchez, P. (2016): “Latini, id est foederati. Le statut juridique des colonies latines sous la République", Athenaeum 104, 50-82.

Sánchez Moreno, E. (2017): “Las guerras celtibérico-lusitanas (114-93 a.C.) y su dimensión geopolítica", [in] J. Principal Ponce - T. Ñaco del Hoyo - M. Durán Caixal - I. Mestres Santacreu (eds.), Roma en la península ibérica presertoriana. Escenarios de implantación militar provincial (=Universitat de Barcelona. Col·lecció Instrumenta 56), Barcelona, 59-77.

Saquete, J. C. - Guerra Millán, S. (2015): “Una inscripción constructiva procedente de $M e$ tellinum (provincia Lusitania)", ZPE 196, 303-306.

Sartori, F. (1993 [1954]): “Appunti di storia siceliota: la costituzione di Tauromenio", [in] Dall'Italía all'Italia I (=Saggi e Materiali Universitari 27), Padova, 323-347.

Schäfer, Th. - Alföldy, G. (2015): Inschriften, [in] Th. Schäfer - K. Schmidt - M. Osanna (Hrsg.), Cossyra I. Die Ergebnisse der Grabungen auf der Akropolis von Santa Teresa/ Pantelleria (=Tübinger Archäologische Forschungen 10), Rahden, 777-804 (=ICos).

Silberman, A. (1988): Pomponius Mela. Corographie, Paris.

Sisani, S.

(2011): “In pagis forisque et conciliabulis. Le strutture amministrative dei distretti rurali in Italia tra la media repubblica e l'età municipale", MemLinc IX/27, 541-780.

(2015): L'ager publicus in età graccana (133-111 a.C.). Una rilettura testuale, storica e giuridica della lex agraria epigrafica, Roma.

(2016a): "Le istituzioni municipali: legislazione e prassi tra il I secolo a.C. e l'età flavia", [in] L. Capogrossi Colognesi - E. Lo Cascio - E. Tassi Scandone (edd.), L'Italia dei Flavi (=Acta Flaviana 3), Roma, 9-55.

(2016b): "Il significato del termine Italia nella tabula Heracleensis e la data di costituzione a provincia della Gallia Cisalpina", Historikà 6, 83-98. 
(2017): “Tergeste e le 'colonie' cesariane della Gallia Togata (in margine a b.g. 8.24.3)", [in] A. Giovannini (ed.), Trieste e l'Istria, Trieste, 105-152.

(2018): "Le magistrature locali delle comunità municipali di ambito provinciale: uno studio sulla diffusione del quattuorvirato e del duovirato tra l'età tardo-repubblicana e l'età imperiale", Gerión 36/1, 41-77 (http://dx.doi.org/10.5209/GERI.60293).

Soraci, C. (2018): "Diritto latino, cittadinanza romana e municipalizzazione: trasformazioni graduali e progressive in Sicilia tra Cesare e Augusto", DialHistAnc 44/1, 37-58.

Stannard, C. - Faria, A. M. de (2009): "M·OCT IIIIVIR at Paestum, not P·MION IIIIVIR at Carteia: the intellectual history of a misattribution", SchwNumRu 88, 81-100.

Studemund, G. (1874): Gaii Institutionum commentarii quattuor, Leipzig.

Syme, R. (1979 [1968]): "Pliny the procurator", [in] Roman papers II, Oxford, 742-773.

Tarpin, M. (2018): “Urbem condere / coloniam deducere: la procédure de 'fondation' coloniale”, [in] M. Tarpin (ed.), Settlement systems: structures hierarchies and territories. New approaches, Besançon (in corso di stampa).

Varga, R. (2011): “Cives Romani Latinive cives?”, [in] I. Piso - V. Rusu Bolindeț - R. Varga - S. Mustaţă - E. Beu Dachin - L. Ruscu (edd.), Scripta classica. Radu Ardevan sexagenarii dedicata, Cluj-Napoca, 377-383.

Vera, D. (1996): “Augusto, Plinio il Vecchio e la Sicilia in età imperiale. A proposito di recenti scoperte epigrafiche e archeologiche ad Agrigento", Kokalos 42, 31-58.

Villaronga, L. (1994): Corpus nummum Hispaniae ante Augusti aetatem, Madrid (=CNH).

Weber, E. (1991): "Le città transalpine. Lo stato della ricerca", [in] Epigrafia. Actes du colloque en mémoire de Attilio Degrassi (=Collection de l'École française de Rome 143), Rome, 539-545.

Willemur, P. (2015): "De quelques émissions coloniales romaines en Sicilie: retour à Tyndaris", [in] P. G. van Alfen - G. Bransbourg - M. Amandry (eds.), Fides. Contributions to numismatics in honor of Richard B. Witschonke, New York, 435-453.

Wiseman, T. P. (1971): New men in the Roman senate (139 B.C. - 14 A.D.), London-New York.

Wuilleumier, P. (1963): Inscriptions latines des Trois Gaules, Paris (=ILTG). 